\title{
NIST Calibration Service for Capacitance Standards at Low Frequencies
}

NIST

Special

Publication

250-47

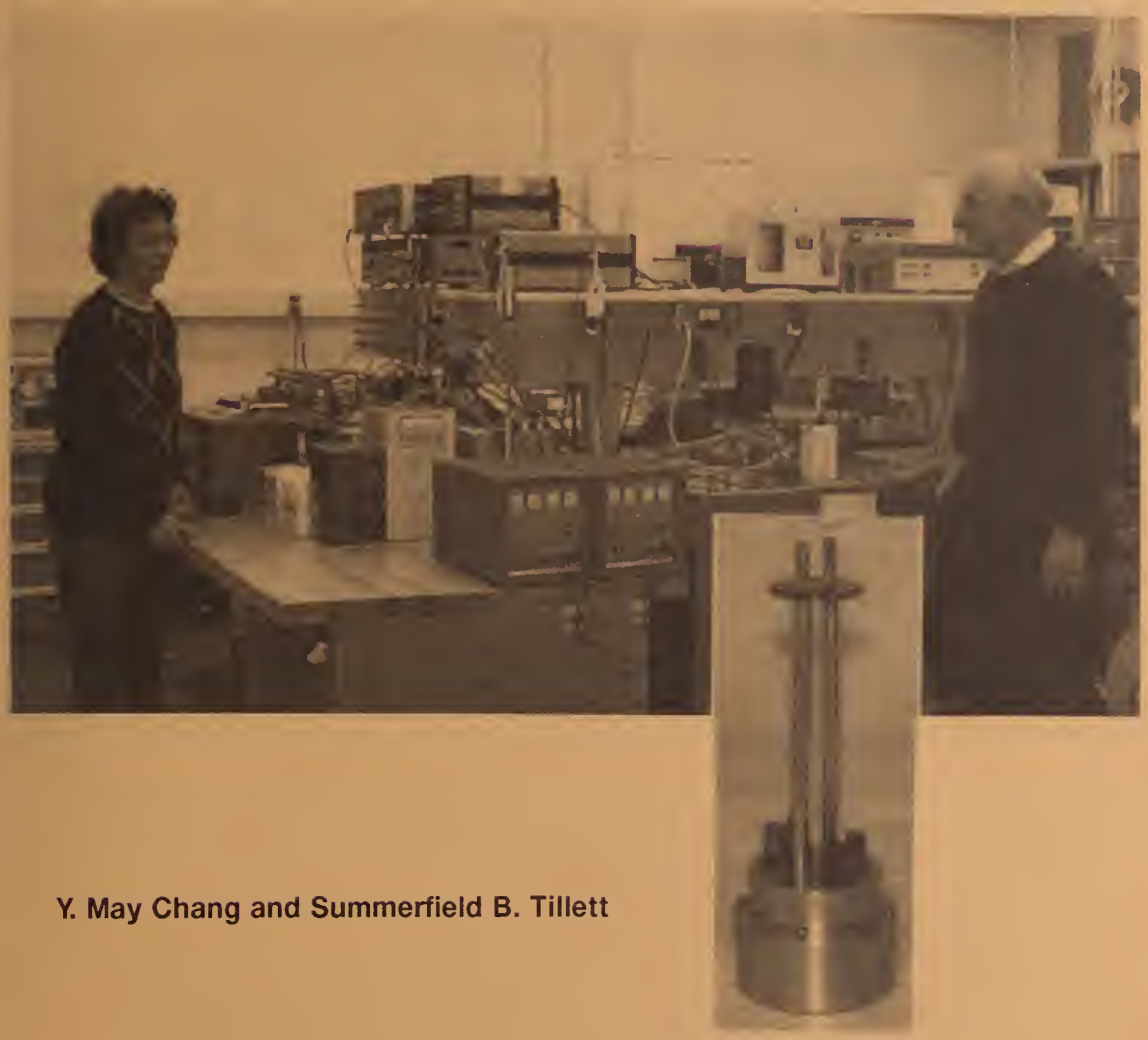

U.S. Department of Commerce Technology Administration

National Institute of Standards and Technology

100

157

$.250-47$ 
he National Institute of Standards and Technology was established in 1988 by Congress to "assist industry in the development of technology ... needed to improve product quality, to modernize manufacturing processes, to ensure product reliability ... and to facilitate rapid commercialization ... of products based on new scientific discoveries."

NIST, originally founded as the National Bureau of Standards in 1901, works to strengthen U.S. industry's competitiveness; advance science and engineering; and improve public health, safety, and the environment. One of the agency's basic functions is to develop, maintain, and retain custody of the national standards of measurement, and provide the means and methods for comparing standards used in science, engineering, manufacturing, commerce, industry, and education with the standards adopted or recognized by the Federal Government.

As an agency of the U.S. Commerce Department's Technology Administration, NIST conducts basic and applied research in the physical sciences and engineering, and develops measurement techniques, test methods, standards, and related services. The Institute does generic and precompetitive work on new and advanced technologies. NIST's research facilities are located at Gaithersburg, MD 20899, and at Boulder, CO 80303. Major technical operating units and their principal activities are listed below. For more information contact the Publications and Program Inquiries Desk, 301-975-3058.

Office of the Director

- National Quality Program

- International and Academic Affairs

\section{Technology Services}

- Standards Services

- Technology Partnerships

- Measurement Services

- Technology Innovation

- Information Services

\section{Advanced Technology Program}

- Economic Assessment

- Information Technology and Applications

- Chemical and Biomedical Technology

- Materials and Manufacturing Technology

- Electronics and Photonics Technology

\section{Manufacturing Extension Partnership Program}

- Regional Programs

- National Programs

- Program Development

Electronics and Electrical Engineering Laboratory

- Microelectronics

- Law Enforcement Standards

- Electricity

- Semiconductor Electronics

- Electromagnetic Fields'

- Electromagnetic Technology ${ }^{1}$

- Optoelectronics ${ }^{1}$

\section{Chemical Science and Technology} Laboratory

- Biotechnology

- Physical and Chemical Properties ${ }^{2}$

- Analytical Chemistry

- Process Measurements

- Surface and Microanalysis Science
Physics Laboratory

- Electron and Optical Physics

- Atomic Physics

- Optical Technology

- Ionizing Radiation

- Time and Frequency ${ }^{1}$

- Quantum Physics'

\section{Materials Science and Engineering} Laboratory

- Intelligent Processing of Materials

- Ceramics

- Materials Reliability'

- Polymers

- Metallurgy

- NIST Center for Neutron Research

\section{Manufacturing Engineering} Laboratory

- Precision Engineering

- Automated Production Technology

- Intelligent Systems

- Fabrication Technology

- Manufacturing Systems Integration

\section{Building and Fire Research} Laboratory

- Structures

- Building Materials

- Building Environment

- Fire Safety Engineering

- Fire Science

\section{Information Technology Laboratory}

- Mathematical and Computational Sciences ${ }^{2}$

- Advanced Network Technologies

- Computer Security

- Information Access and User Interfaces

- High Performance Systems and Services

- Distributed Computing and Information Services

- Software Diagnostics and Conformance Testing

\footnotetext{
'At Boulder, CO 80303 .

${ }^{2}$ Some elements at Boulder, $\mathrm{CO}$.
} 


\section{NIST MEASUREMENT SERVICES: NIST Calibration Service for Capacitance Standards at Low Frequencies}

Y. May Chang and Summerfield B. Tillett

\section{Electricity Division}

Electronics and Electrical Engineering Laboratory

National Institute of Standards and Technology

Gaithersburg, MD 20899-0001

April 1998

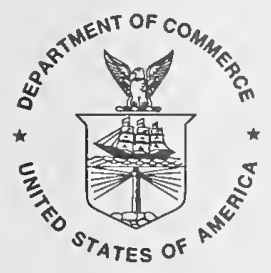

U.S. Department of Commerce

William M. Daley, Secretary

Technology Administration

Gary R. Bachula, Acting Under Secretary for Technology

National Institute of Standards and Technology

Raymond G. Kammer, Director 
National Institute of Standards and Technology Special Publication 250-47 Natl. Inst. Stand. Technol. Spec. Publ. 250-47, 79 pages (Apr. 1998)

CODEN: NSPUE2 


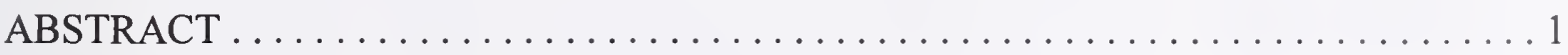

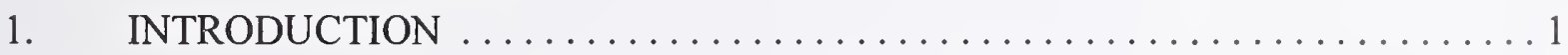

2. DESCRIPTION OF SERVICE .......................... 2

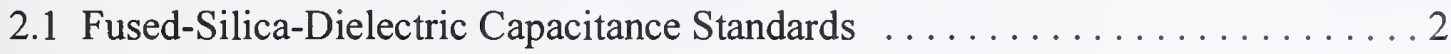

2.2 Nitrogen-Dielectric Capacitance Standards . . . . . . . . . . . . . . 3

2.3 Three-Terminal Air-Dielectric Capacitance Standards . .............. 4

2.4 Two-Terminal Capacitance Standards with HF Coaxial Connectors . . . . . . . 4

2.5 Two- and Three-Terminal Mica-Dielectric Capacitance Standards with

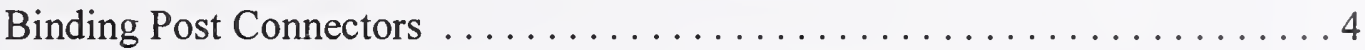

2.6 Capacitance Measurement Assurance Program (C-MAP) . . . . . . . . . . 5

3. DESCRIPTION OF MEASUREMENT SYSTEMS $\ldots \ldots \ldots \ldots \ldots \ldots \ldots$

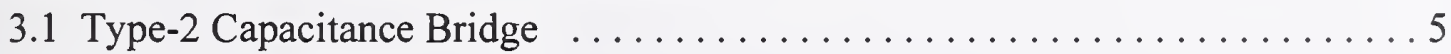

3.2 Type-12 Capacitance Bridge $\ldots \ldots \ldots \ldots \ldots \ldots \ldots \ldots \ldots \ldots \ldots \ldots \ldots \ldots \ldots \ldots . \ldots \ldots$

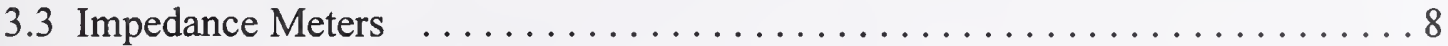

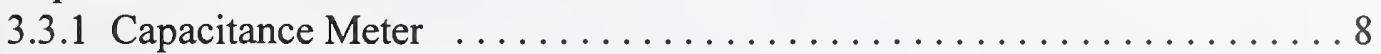

3.3.2 Digital Impedance Meter $\ldots \ldots \ldots \ldots \ldots \ldots \ldots \ldots \ldots$

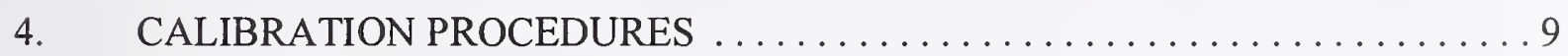

4.1 Type-2 Capacitance Measurement System . . . . . . . . . . . . . . . 9

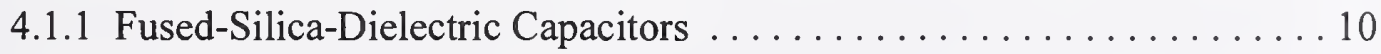

4.1.2 Nitrogen-Dielectric Capacitors . . . . . . . . . . . . . . . 10

4.1.3 Air-Dielectric Capacitors ........................... 11

4.1.4 Two-Terminal Capacitors with HF Coaxial Connectors $\ldots \ldots \ldots \ldots 11$

4.2 Type-12 Capacitance Measurement System . . . . . . . . . . . . . . 12

4.2.1 Two-Terminal Measurements . . . . . . . . . . . . . . . 12

4.2.2 Three-Terminal Measurements . . . . . . . . . . . . . . . 13

5. QUALITY CONTROL IN THE IMPEDANCE CALIBRATION

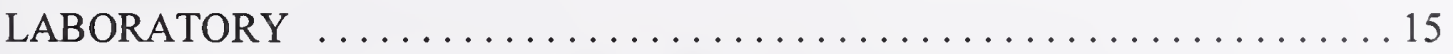

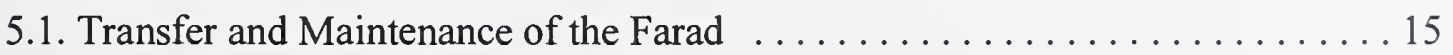

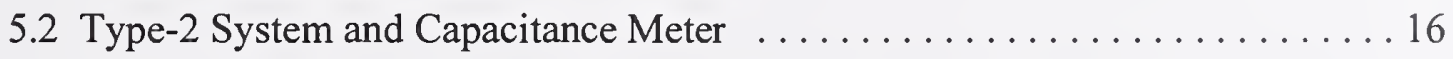

5.3 Type-12 System, Capacitance Meter, and Digital Impedance Meter . . . . . 16 


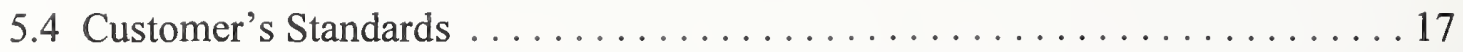

6. REPORTED VALUE AND MEASUREMENT UNCERTAINTY . . . . . . . 17

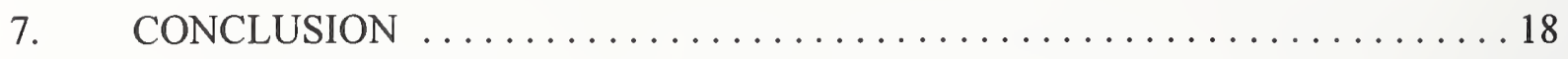

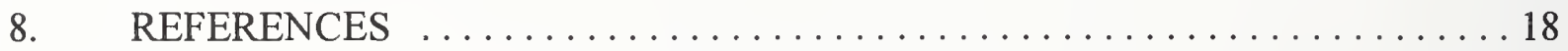

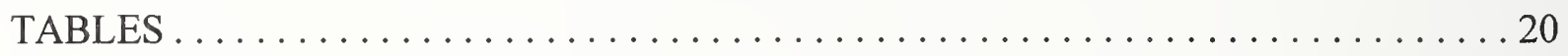

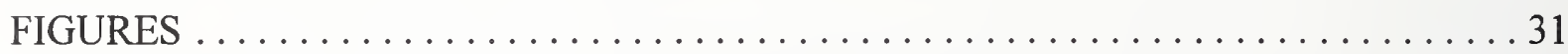

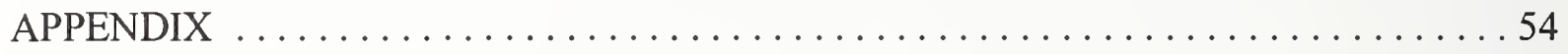

A1. General Information on Fused-Silica-Dielectric Standard Capacitors . . . . . . . 55

A2. Typical REPORT OF CALIBRATION for Fused-Silica-Dielectric

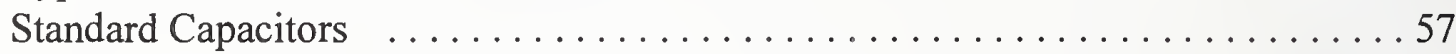

A3. General Information on Nitrogen-Dielectric Standard Capacitors . . . . . . . . . 59

A4. Typical REPORT OF CALIBRATION for Nitrogen-Dielectric

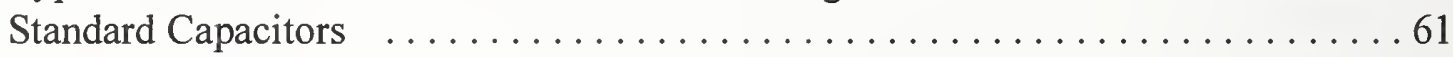

A5. Description of Tests used to Determine the Effect of Small Mechanical Stress on High Stability, Nitrogen-Dielectric Standard capacitors . . . . . . . . . . . 63

A6. Typical REPORT OF CALIBRATION for Test Results of the Effect of Small Mechanical Stress on Nitrogen-Dielectric Standard Capacitors . . . . . . . 65

A7. General Information on Three-Terminal Standard Capacitors . . . . . . . . . . 67

A8. Typical REPORT OF CALIBRATION for Three-Terminal

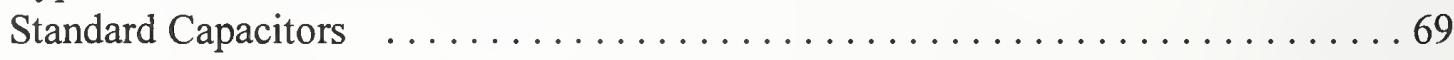

A9. General Information on Two-Terminal Standard Capacitors with

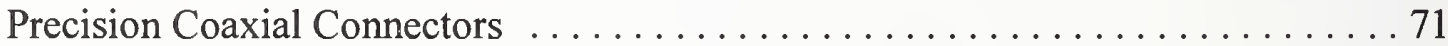

A10. Typical REPORT OF CALIBRATION for Two-Terminal Standard Capacitors with Precision Coaxial Connectors $\ldots \ldots \ldots \ldots \ldots . . . .73$

A11. General Information on Mica-Dielectric Standard Capacitors with Binding Post Connectors . . . . . . . . . . . . . . . . . . . 75

A12. Typical REPORT OF CALIBRATION for Mica-Dielectric Standard Capacitors

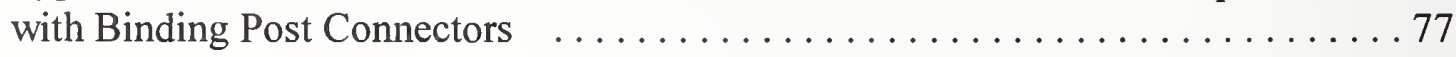


Table 1. Summary of Standard Capacitors Acceptable for Calibrations . . . . . . . . 20

Table 2. Summary of Reference and Check Standards of the Type-2 Bridge . . . . . . . 21

Table 3. NIST Calibration Design for Fused-Silica-Dielectric Standard Capacitors . . . 22

Table 4a. NIST Calibration Design for 10 pF Nitrogen-Dielectric Standard Capacitors . . 23

Table 4b. NIST Calibration Design for 100 pF Nitrogen-Dielectric Check Standards . . . 23

Table 4c. NIST Calibration Design for 1000 pF Nitrogen-Dielectric Check Standards . . 23

Table 4d. NIST Calibration Design for One $100 \mathrm{pF}$ (or $1000 \mathrm{pF}$ )

Nitrogen-Dielectric Standard Capacitors .................... 24

Table 4e. NIST Calibration Design for Two $100 \mathrm{pF}$ (or $1000 \mathrm{pF}$ )

Nitrogen-Dielectric Standard Capacitors .................... 24

Table 4f. NIST Calibration Design for Three $100 \mathrm{pF}$ (or $1000 \mathrm{pF}$ )

Nitrogen-Dielectric Standard Capacitors ..................... 24

Table 5. NIST Large Uncertainty Calibration Design for Nitrogenand Air-Dielectric Standard Capacitors . ..................... 25

Table 6. Summary of Check Standards of the Type-12 Bridge .............. 26

Table 7. Calibration Uncertainties of Fused-Silica- and Nitrogen-Dielectric Standard Capacitors ............................. 27

Table 8. Calibration Uncertainties of Air-Dielectric and Two-Terminal HF Coaxial Connector Standard Capacitors $\ldots \ldots \ldots \ldots \ldots \ldots \ldots \ldots$

Table 9. Calibration Uncertainties of Capacitance Values of Two- and Three-Terminal Mica- Dielectric Standard Capacitors . . . . . . . . . . . 29

Table 10. Calibration Uncertainties of Conductance Values of Two- and Three-Terminal Mica- Dielectric Standard Capacitors ............... 30 


\section{List of Figures}

Figure 1a. Schematic Diagram of the NIST Type-2 Capacitance Bridge . . . . . . . 31

Figure 1b. Simplified Circuit Diagram of the NIST Type-2 Capacitance Bridge . . . . . 32

Figure 2a. Schematic Diagram of the NIST Type-12 Capacitance Bridge . . . . . . . 33

Figure 2b. Simplified Circuit Diagram of the NIST Type-12 Capacitance Bridge (Generally Showing only the Capacitance Components) ........... 34

Figure 3. The NIST Type-12 Capacitance Bridge with Conductance Components . . . 35

Figure 4. Block Diagram of Measurement Process and Standards being Used in the Impedance Calibration Laboratory $\ldots \ldots \ldots \ldots \ldots \ldots \ldots \ldots \ldots$

Figure 5. NIST Reference Adapter for Two-Terminal HF Coaxial Connector

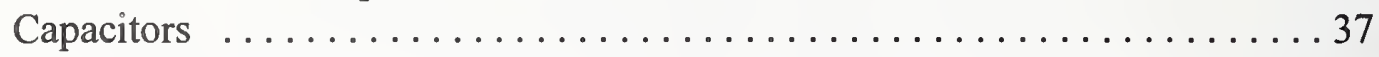

Figure 6. Connection of Reference Adapter and HF Coaxial Connector Capacitors . . . 38

Figure 7. Fixture (P2) Used with the Type-12 Bridge for Two-Terminal

Capacitance Measurements ............................. 39

Figure 8. Components of the Type-12 Bridge for Two-Terminal

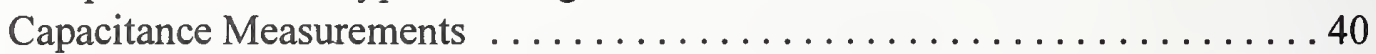

Figure 9. Fixture (P3) Used with the Type-12 Bridge for Three-Terminal Capacitance Measurements ......................... 41

Figure 10. Components of the Type-12 Bridge for Three-Terminal Capacitance Measurements ........................ 42

Figure 11. Average Values of Four Reference Standards (10 pF Oil-Bath Type) at Reference Temperature Values . .....................43

Figure 12. Block Diagram of the Farad Transfer and Calibration Process Using the Type-2 Bridge ................................ 44

Figure 13. NIST Reference Standard $\# 102(10 \mathrm{pF}$ Air-Bath Type $) \ldots \ldots \ldots \ldots \ldots . \ldots 45$

Figure 14. NIST Reference Standard $\# 131(100 \mathrm{pF}$ Air-Bath Type) $\ldots \ldots \ldots \ldots \ldots 46$

Figure 15. NIST Check Standard \#1865 (1000 pF Nitrogen-Dielectric Capacitor) . . . . . 47

Figure 16. Data of NIST Check Standard \#1865 Measured by Using the Type-2 Bridge and C-Meter $\ldots \ldots \ldots \ldots \ldots \ldots \ldots \ldots \ldots \ldots \ldots$

Figure 17a. Measurement Differences of $1000 \mathrm{pF}$ Customer's Capacitors between using the C-Meter and the Type-2 Bridge .................. 49

Figure 17b. Measurement Differences of $100 \mathrm{pF}$ Customer's Capacitors between using the C-Meter and the Type-2 Bridge $\ldots \ldots \ldots \ldots \ldots \ldots \ldots \ldots \ldots \ldots \ldots \ldots \ldots \ldots$

Figure 17c. Measurement Differences of $10 \mathrm{pF}$ Customer's Capacitors between

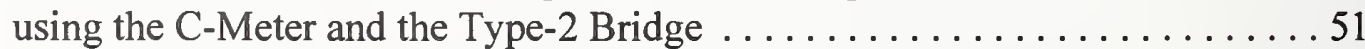

Figure 18. Three-Terminal Measurements of NIST Check Standard \#27620

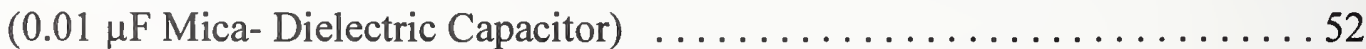

Figure 19. Data of NIST Check Standard \#27620 Measured by Using the Type-12 Bridge, C-Meter, and DIM $\ldots \ldots \ldots \ldots \ldots \ldots \ldots \ldots \ldots \ldots \ldots \ldots \ldots \ldots$ 
NIST Calibration Service for Capacitance Standards at Low Frequencies

Y. May Chang and Summerfield B. Tillett

ABSTRACT - This document describes the capacitance calibration service provided by NIST, including measurement procedures and systems used to calibrate capacitance standards of nominal values in the range of $0.001 \mathrm{pF}$ to $1 \mu \mathrm{F}$, at frequencies up to $10 \mathrm{kHz}$. Discussed are the process to transfer the unit of capacitance from the NIST capacitance primary laboratory, which maintains the U.S. representation of the farad, realized by the calculable capacitor, and the quality controls of reference standards and check standards in the calibration laboratory. Also included are summaries of calibration uncertainties of capacitors of various dielectric materials, such as fused-silica, nitrogen, air, and mica.

\section{INTRODUCTION}

Most standards laboratories use one or a group of capacitance standards as a reference to maintain the unit of capacitance and to compare to unknown capacitors. NIST provides a calibration service for capacitance standards of various dielectric materials, including fused-silica, nitrogen, air, and mica, and of nominal values in the range between $0.001 \mathrm{pF}$ and $1 \mu \mathrm{F}$, at frequencies of $(66,100,400$, 1000 , and 10000$) \mathrm{Hz}$, as shown in Table 1. The primary reference of the NIST Impedance Calibration Laboratory (ICL) is a group of NIST-made $10 \mathrm{pF}$ oil-bath type, fused-silica-dielectric capacitors, whose values are traceable to the NIST calculable capacitor, which is used as the U.S. realization of the farad [1]. ICL staff also maintain a pair of commercial air-bath type, fused-silicadielectric capacitors used as secondary reference standards having one $10 \mathrm{pF}$ and one $100 \mathrm{pF}$ capacitor in each temperature-controlled air bath, and a group of check standards of nominal values of $(1,10,100,1000$, and 10000$) \mathrm{pF}$. The secondary references are calibrated against the primary reference periodically by using a transformer ratio capacitance measuring system [2], known as the "Type-2" bridge, at 1:1 and 1:10 ratios. The Type-2 bridge is also utilized to measure the NIST check standards and customer's standards with coaxial connectors.

There is another system in the ICL, a resistance-ratio-type capacitance measuring system, known as the "Type-12" bridge. It is mainly used to measure mica-dielectric capacitors with binding post connectors. The references of the Type- 12 bridge are internal dial ${ }^{1}$ capacitors, which have corrections that are traceable to the reference used with the Type- 2 bridge. Commercial impedance meters also have been utilized to support capacitance calibrations in the ICL after being characterized in terms of NIST standards.

${ }^{1}$ The term dial as used in this document refers to the settings or values of adjustable components used to balance bridges. 


\section{DESCRIPTION OF SERVICE}

NIST offers a calibration service for capacitance standards in a wide range of capacitance values and geometrical configurations in the audio-frequency range. Three-terminal fused-silica-, nitrogen-, and air-dielectric standard capacitors with GR $874^{2}$ coaxial connectors and with nominal values of (1, $10,100,1000$, and 10000$) \mathrm{pF}$ can be calibrated at frequencies of $100 \mathrm{~Hz}, 400 \mathrm{~Hz}$, and $1 \mathrm{kHz}$. Twoand three-terminal mica-dielectric capacitors with exposed binding-post connectors, in the range from $0.001 \mathrm{pF}$ to $1 \mu \mathrm{F}$, can be calibrated at frequencies up to $10 \mathrm{kHz}$. Two-terminal air- and micadielectric capacitors with high-frequency (HF) GR900 coaxial connectors, including the GR900 terminations, are calibrated only at $1 \mathrm{kHz}$. Table 1 contains a summary of the commonly known capacitance standards that are accepted for calibration with the stated configurations at the specified frequencies. Requests for capacitance types other than those described in Table 1 are handled under the category of "Special Test", which requires prearrangement with NIST personnel. Additionally, NIST provides a MAP transfer service, known as the Capacitance Measurement Assurance Program (C-MAP) for capacitance standards at the $100 \mathrm{pF}$ and $1000 \mathrm{pF}$ levels and at a frequency of $1 \mathrm{kHz}$ [3]. In the ICL, all capacitors except fused-silica-dielectric capacitors, are measured at an ambient temperature of $23^{\circ} \mathrm{C} \pm 1{ }^{\circ} \mathrm{C}$ and relative humidity levels of less than 50 percent.

It is the customer's responsibility to ensure that the capacitance standard received by NIST is in good working condition, i.e. having tight connectors and good solder joints. The capacitor will be returned to the customer without calibration if it is found to be defective, or its connector has been modified, unless prior arrangements are made.

When a Report of Calibration is issued to the customer, general information on each type of standard capacitor is also enclosed. Examples of the report and the information of various types of capacitors submitted for calibration are included in the Appendix.

Detailed information on calibration services at NIST is described in the NIST Special Publication 250 (SP250) [4]. The cost of services is listed in the Fee Schedule which is the Appendix of SP250 and is updated periodically.

\subsection{Fused-Silica-Dielectric Capacitance Standards}

Due to the magnitude of their temperature coefficient, approximately $10 \mathrm{ppm} /{ }^{\circ} \mathrm{C}$, fused-silicadielectric standard capacitors are designed for use in temperature controlled ovens, either air baths or oil baths. Unless the air-bath type capacitors are submitted in temperature-controlled ovens with temperature sensors having a resolution of $0.001{ }^{\circ} \mathrm{C}$, the ICL staff will provide, where possible, temperature measurements using standard platinum resistance thermometers taken at the time of the measured capacitance value.

${ }^{2}$ Commercial connectors or standards are identified in this technical note only to specify that these are being used to perform measurements. It is not to be taken as a recommendation or endorsement by NIST, nor does it imply that these are necessarily the best available connectors and standards for the purpose. 
Model GR 1408 is a typical commercial air-bath type, fused-silica-dielectric capacitance standard with nominal values of $10 \mathrm{pF}$ and $100 \mathrm{pF}$, that is accepted for calibrations at frequencies of $100 \mathrm{~Hz}$, $400 \mathrm{~Hz}$, and $1 \mathrm{kHz}$. Since the exact temperature coefficients of individual capacitors are unknown, no correction for temperature is made, however, both the capacitance values of GR1408 capacitors and the air-bath temperature at the time of measurement are reported. Model AH11A (with nominal values of $1 \mathrm{pF}, 10 \mathrm{pF}$, and $100 \mathrm{pF}$ ) is another type of commercial air-bath, fused-silica capacitor that is accepted for calibrations at the above three frequencies. However, this model of capacitor is completely sealed within a temperature-controlled oven, without any possibility to measure the oven's internal temperature. Since the actual temperature of the capacitor cannot be measured, it is not reported. Both the capacitance value of the AH11A capacitor and the temperature display reading taken at the time of measurement are reported. AH11A capacitors with nominal values other than $(1,10$, and 100$) \mathrm{pF}$ are acceptable for calibration as "Special Test".

All oil-bath type, fused-silica capacitors are also acceptable for calibration as "Special Test". These are measured in the oil bath in the ICL at a temperature of $25^{\circ} \mathrm{C} \pm 0.01^{\circ} \mathrm{C}$.

\subsection{Nitrogen-Dielectric Capacitance Standards}

Nitrogen-dielectric capacitors are the most common standard capacitors at the $10 \mathrm{pF}, 100 \mathrm{pF}$, and $1000 \mathrm{pF}$ levels. Models GR1404 and ESI SC1000, commercially-made capacitors with parallelplates, are the typical capacitors that are accepted for calibrations at frequencies of $100 \mathrm{~Hz}, 400 \mathrm{~Hz}$, and $1 \mathrm{kHz}$.

There are two different types of measurements performed on these capacitors according to the desired uncertainty level of the calibration. The "large-uncertainty" calibration is performed at laboratory conditions with an uncertainty of $25 \mathrm{ppm}^{3}$. The "small-uncertainty" calibration process monitors the capacitor for a longer period of time under a physically stable condition with an uncertainty as low as 4 ppm [6].

Also, a supplementary test should be considered for new standards whose properties with regard to transportation and mechanical shocks are not known. This series of physical tests determines the relative effect on the capacitance resulting from various impacts and changes in orientation [7]. These tests which simulate the conditions during shipping of the capacitor, normally are performed prior to the small- uncertainty measurement to estimate the variation of the capacitance values during shipment. The maximum variations in capacitance values for each type of physical test are reported. Requests for calibrations at the small-uncertainty level without performing the physical tests are also accepted. NIST issues separate calibration reports for each of the above measurements.

${ }^{3}$ The term uncertainty as used in this document refers to the relative standard uncertainty when the unit is expressed in ppm [5]. 


\subsection{Three-Terminal Air-Dielectric Capacitance Standards}

A typical example of a three-terminal air-dielectric capacitance standard is the model GR1403 with nominal values that range from $0.001 \mathrm{pF}$ to $1000 \mathrm{pF}$. Another example, the model GR1615-P1, has a nominal value of $10000 \mathrm{pF}$. GR1403 capacitors are accepted for calibration and tested at a laboratory temperature of $23{ }^{\circ} \mathrm{C} \pm 1{ }^{\circ} \mathrm{C}$, and at frequencies of $100 \mathrm{~Hz}, 400 \mathrm{~Hz}$, and $1 \mathrm{kHz}$, while GR1615-P1 capacitors are calibrated only at $1 \mathrm{kHz}$. The total uncertainty of calibration ranges between $100 \mathrm{ppm}$ and $2000 \mathrm{ppm}$, according to the nominal value of the capacitor and the nominal measurement frequency. The calibration uncertainties are described in detail in [6], and summarized later in this document (section 4.1.3).

\subsection{Two-Terminal Capacitance Standards with HF Coaxial Connectors}

This category of two-terminal capacitance standards is mainly used for the calibration of highfrequency bridges and other impedance measuring instruments. These normally have GR900 coaxial connectors, which have a known reference plane to separate the bridge and the standard capacitor to improve the performance of the standards up to radio frequency range. Models GR1405 (with capacitance values from $1 \mathrm{pF}$ to $20 \mathrm{pF}$ ), GR1406 (with capacitance values from $50 \mathrm{pF}$ to $1000 \mathrm{pF}$ ), and GR1407 (with capacitance values from $0.001 \mu \mathrm{F}$ to $0.1 \mu \mathrm{F}$ ) are all accepted for calibration at a frequency of $1 \mathrm{kHz}$.

In addition, ICL staff provide calibration services for capacitors with standard terminations such as the open-circuit-termination models GR900-WO and GR900-WO4, at a frequency of $1 \mathrm{kHz}$.

The total uncertainties of calibration for the above standards range from $75 \mathrm{ppm}$ to $1000 \mathrm{ppm}$, and are described in detail in [6], and summarized in a later part of this document (section 4.1.4).

\subsection{Two- and Three-Terminal Mica-Dielectric Capacitance Standards with Binding Post Connectors}

The most common examples of this type of capacitance standard are the models GR1409 and GR509, which can be measured at frequencies of $66 \mathrm{~Hz}, 100 \mathrm{~Hz}, 400 \mathrm{~Hz}, 1 \mathrm{kHz}$, and $10 \mathrm{kHz}$, in twoor three-terminal configurations, according to the appropriate terminal connections. Capacitance and conductance values are given in the Report of Calibration for this type of capacitor and represent the equivalent parallel capacitance and conductance values of the capacitor.

When the capacitor is shipped to NIST, it is important that the customer specifies whether the capacitor is to be measured in two- or three-terminal configuration.

Measurements of other models of mica-dielectric capacitors with different types of connectors, or at frequencies higher than $10 \mathrm{kHz}$, would be considered for calibration as "Special Test" by prearrangement. 


\subsection{Capacitance Measurement Assurance Program (C-MAP)}

This is a recently re-established measurement service implemented using a commercial meter (based on fused-silica reference capacitors) as a transport standard to measure capacitance standards with nominal values of $100 \mathrm{pF}$ and $1000 \mathrm{pF}$, at a frequency of $1 \mathrm{kHz}$. Besides determining the values of customer's capacitance standards, the C-MAP is used to evaluate the customer's capacitance measurement system. The C-MAP has the advantage that the customer's standards remain in their laboratory to reduce the down-time due to the absence of the standards, and to avoid any changes of values due to transportation. The Type-A uncertainties of the C-MAP are usually lower than those of the regular calibration because the changes of values in the customer's capacitors due to shipping and hysteresis effects from variation of environmental conditions do not enter into the experiment. The NIST C-MAP service is described in detail by Chang [3].

\section{DESCRIPTION OF MEASUREMENT SYSTEMS}

The NIST capacitance calibration facility consists of two major measurement systems. One is the Type- 2 bridge, which is mainly used to calibrate high-quality standards (such as nitrogen-, air-, and fused-silica-dielectric capacitors) with shielded terminals, and of nominal values up to $10000 \mathrm{pF}$ at frequencies of $100 \mathrm{~Hz}, 400 \mathrm{~Hz}$, and $1 \mathrm{kHz}$. The other is the Type-12 bridge, which is a resistanceratio capacitance measuring system for calibration of mica-dielectric capacitors with exposed terminals, and having nominal values from $0.001 \mu \mathrm{F}$ to $1 \mu \mathrm{F}$, at frequencies of $(66,100,400,1000$, and 10000$) \mathrm{Hz}$. Recently, two commercial impedance meters that have been carefully characterized using NIST standards are also used to support capacitance calibrations.

\subsection{Type-2 Capacitance Bridge}

The NIST Type- 2 bridge is a transformer-ratio capacitance bridge using both external capacitors and internal capacitors to perform measurements of unknown capacitors. Figure 1a is the schematic diagram of the Type- 2 bridge. Construction of the bridge components and bridge operation procedures were described in detail by Cutkosky [2]. As illustrated in Fig. 1a, the internal capacitors are a set of eight fixed-cylindrical air capacitors with values ranging from $10^{-5} \mathrm{pF}$ to $100 \mathrm{pF}$ to provide a total capacitance up to $111 \mathrm{pF}$. These capacitors are connected to the voltage taps of the transformer via linear switches to form the equivalent of a decade capacitance of each capacitor by using dial (or switch) settings. During calibrations, an unknown capacitor is compared to a reference capacitance standard whose value is well defined, and the dial settings of the internal capacitors are adjusted to obtain a balance of the bridge. The reference capacitor and the unknown capacitor are connected to the bridge terminals at ratios of 1:1, 10:1, or 1:10, according to their nominal values. One of the internal capacitors (of nominal value of $1 \mathrm{pF}$ ) is constructed as a temperaturecompensated capacitor, as described in detail in [8]. Other internal capacitors can be calibrated against the $1 \mathrm{pF}$ unit immediately after it is compared to a reference capacitance standard. The capacitance value of the unknown is determined from the dial readings and corrections of the internal 
capacitors, and the value of the reference standard.

In addition, the Type- 2 bridge has a conductance balance circuit, also described in [8], to measure the conductance component of the unknown capacitor. As shown in Fig. 1a, the conductance balance is controlled by a set of four dials and a multiplier switch to provide a total conductance from $10^{-8} \mu \mathrm{S}$ to $1 \mu \mathrm{S}$. There is another switch which reverses the sign of the conductance component to allow the measured components to have greater or less conductance than the internal capacitors. Figure $1 \mathrm{~b}$ is a simplified circuit diagram showing the Type-2 bridge, where $\mathrm{C}_{\mathrm{s}}$ is the reference capacitor, $C_{x}$ is the unknown capacitor to be calibrated, $C_{d}$ is the sum of internal dial capacitors, $G_{a}$ is the conductance of the internal capacitors, $G_{r}$ is the settings of the conductance dials, and $M$ is the multiplier switch for the conductance readings. The conductance balance control provides an in-phase balance to compensate for the difference in the loss components of the reference, internal, and unknown capacitors in order to obtain a precise comparison of the unknown capacitor and the reference capacitor. The uncertainty of the conductance dial readings, which depends on the ac characteristics of a fixed metal film resistor, is very large, about $1 \%$, but the conductance measurement of unknown capacitors using the Type- 2 bridge is not reported for NIST calibrations.

\subsection{Type-12 Capacitance Bridge}

The NIST Type- 12 bridge is a resistance-ratio capacitance measurement system using internal standards as the reference and is used to calibrate customer's mica capacitors. This type of bridge was originally designed by Bell Laboratories in 1942 [9] to provide precision measurements of capacitance up to $1.11 \mu \mathrm{F}$ and conductance up to $1000 \mu \mathrm{S}$. Later on, an improved unity-ratio admittance bridge, known as the Type-12 capacitance bridge was developed, also by Bell Laboratories, with a capacitance divider to measure low capacitance values and multi-range, directreading conductance standards. Figure $2 \mathrm{a}$ is the schematic of the Type-12 bridge. Specifications of bridge components and internal standards, and operation procedures of the Type- 12 bridge were described in detail by Wimhelm [10]. As illustrated in Fig. 2a, the internal standards consist of two mica capacitance standards (represented schematically as one standard, $\mathrm{C}_{\mathrm{M}}$ ), three air differential capacitance standards (represented as $\mathrm{C}_{\mathrm{A}}$ ), and two differential conductance (resistance) standards (represented as $\mathrm{G}_{\mathrm{S}}$ ). Each standard is adjustable with ten steps to be interpreted as dial readings. The dials of $\mathrm{C}_{\mathrm{M}}$ cover from $(0.1$ to 1$) \mu \mathrm{F}$ and from $(0.01$ to 0.1$) \mu \mathrm{F}$. The dials of $\mathrm{C}_{\mathrm{A}}$ cover from $(0.001$ to 0.01$) \mu \mathrm{F},(0.0001$ to 0.001$) \mu \mathrm{F}$, and $(0.00001$ to 0.0001$) \mu \mathrm{F}$, plus a continuously adjustable capacitor providing a capacitance range of $(11 \pm 0.5) \mathrm{pF}$. A mica capacitor of $0.005 \mu \mathrm{F}$ (not shown in Fig. 2a) is used as a transfer standard and is measured using the Type- 2 bridge, and then used to calibrate the $0.01 \mu \mathrm{F}$ steps of $\mathrm{C}_{\mathrm{M}}$ (the lowest step of mica dials) and of $\mathrm{C}_{\mathrm{A}}$ (the highest step of air dials) of the Type- 12 bridge. All other steps of mica and air dials are calibrated from the $0.01 \mu \mathrm{F}$ steps to be used as reference, in terms of dial corrections. The dials of $\mathrm{G}_{\mathrm{s}}$, from (10 to 100$) \mu \mathrm{S}$ and from (100 to 1000$) \mu \mathrm{S}$, plus a continuously adjustable dial with range of (-1 to 11$) \mu \mathrm{S}$, are calibrated by resistance standards. During calibration measurements, both capacitance and conductance dials are used simultaneously to obtain a balance, and both capacitance and conductance values of the customer's capacitor are reported.

Figure $2 \mathrm{~b}$ is a simplified diagram of the Type- 12 bridge showing only the components which need to be considered for capacitance measurements. $\mathrm{C}_{\mathrm{X}}$ is the unknown capacitor to be measured, which 
is connected to arm $A D$ and/or arm $C D$, according to the measurement configurations. $\mathrm{R}_{1}$ and $\mathrm{R}_{2}$ are resistors with a ratio of $1: 1, C_{\mathrm{m}}$ is the value of $\mathrm{C}_{\mathrm{M}}$, and $C_{\mathrm{a}}$ and $C_{\mathrm{c}}$ are the effective capacitance from the differential air capacitors, $\mathrm{C}_{\mathrm{A}}$, on arms $\mathrm{AD}$ and $\mathrm{CD}$, respectively, such that:

$$
\left.C_{\mathrm{a}}+C_{\mathrm{c}}=C \text { ( a constant }\right) \text {. }
$$

In addition, each dial of $\mathrm{C}_{\mathrm{A}}$ is arranged so that the dial reading indicates the difference of the effective capacitance between arms $\mathrm{AD}$ and $\mathrm{CD}$, plus the constant capacitance $C$, such that:

$$
C_{\mathrm{r}}=\left(C_{\mathrm{a}}-C_{\mathrm{c}}\right)+C,
$$

where $C_{\mathrm{r}}$ is the value of $\mathrm{C}_{\mathrm{A}}$ corresponding to the dial reading, $r$.

By substituting Eq. (1) into Eq. (2), it becomes:

$$
C_{\mathrm{r}}=2 C_{\mathrm{a}} .
$$

Let $\mathrm{C}_{\mathrm{A}}, \mathrm{C}_{\mathrm{A} 2}$, and $\mathrm{C}_{\mathrm{A} 3}$ represent the three dials of $\mathrm{C}_{\mathrm{A}}$ for $0.001 \mu \mathrm{F} / \mathrm{step}, 0.0001 \mu \mathrm{F} / \mathrm{step}$, and 0.00001 $\mu \mathrm{F} / \mathrm{step}$, respectively. Using $\mathrm{C}_{\mathrm{A} 3}$ as an example, the total capacitance of this dial is equal to $50 \mathrm{pF}$ $(=C)$, and contains a set of four capacitors of $5 \mathrm{pF}, 10 \mathrm{pF}, 15 \mathrm{pF}$, and $20 \mathrm{pF}$. When the dial readings of $\mathrm{C}_{\mathrm{A} 3}, r_{3}$, are increased from 0 to 1,1 to 2 , and 9 to 10 , these capacitors are switched back

and forth individually between arms $C D$ and $A D$ to achieve the relationship in Eq. (1). The capacitance values corresponding to the dial readings are obtained in accordance with Eq. (3) and to the following procedure to switch these capacitors:

At dial reading $r_{3}=0$, all four capacitors are on arm $\mathrm{CD}$, then

$$
C_{\mathrm{c} 3}=50 \mathrm{pF} \text { and } C_{\mathrm{a} 3}=0 \text {; therefore, } C_{\mathrm{r} 3}=0 \text {. }
$$

At dial reading $r_{3}=1$, the $5 \mathrm{pF}$ capacitor is on arm $\mathrm{AD}$, the other three are on arm $\mathrm{CD}$, then $C_{\mathrm{c} 3}=45 \mathrm{pF}$ and $C_{\mathrm{a} 3}=5 \mathrm{pF}$; therefore, $C_{\mathrm{r} 3}=10 \mathrm{pF}$.

At dial reading $r_{3}=2$, the $10 \mathrm{pF}$ capacitor is on arm $\mathrm{AD}$, the other three are on arm $\mathrm{CD}$, then $C_{\mathrm{c} 3}=40 \mathrm{pF}$ and $C_{\mathrm{a} 3}=10 \mathrm{pF}$; therefore, $C_{\mathrm{r} 3}=20 \mathrm{pF}$.

At dial reading $r_{3}=10$, all four capacitors are on arm $\mathrm{AD}$, and then

$C_{\mathrm{c} 3}=0$ and $C_{\mathrm{a} 3}=50 \mathrm{pF}$; therefore, $C_{\mathrm{r} 3}=100 \mathrm{pF}$.

The final value of $C_{\mathrm{r}}$ is the sum of the values of all three air dial capacitors, $C_{\mathrm{r} 1}, C_{\mathrm{r} 2}$, and $C_{\mathrm{r} 3}$.

Similar to the internal air capacitors, the conductance standard of the Type-12 bridge is a differential- 
type standard, independently connected to arms $\mathrm{AD}$ and $\mathrm{CD}$ such that the sum of conductance of both arms is a constant. Figure 3 is a simplified diagram of Type- 12 bridge that includes the conductance components in each arm, and a divider resistor, $R_{K}$, (see Fig. 2a), which serves as a range shifter, $K_{\mathrm{g}}$, so that the reading of the conductance standard is divided by $1,10,100,1000$, or 10 000. $\mathrm{G}_{\mathrm{x}}$ is the conductance component of the unknown capacitor, $\mathrm{C}_{\mathrm{x}}$. Specifications and operating procedures of conductance standard of the Type- 12 bridge were described in detail by Wimheim [10]. As shown in Fig. 2b, $\left(G_{\mathrm{a}} / K_{\mathrm{g}}\right)$ and $\left(G_{\mathrm{c}} / K_{\mathrm{g}}\right)$ are effective conductances on arm $\mathrm{AD}$ and arm $\mathrm{CD}$, respectively, and the quantity $\left(G_{\mathrm{a}}+G_{\mathrm{c}}\right)$ is equal to a constant. Both the decades and the variable dials of the conductance standard provide readings to cover the required range and keep the sum of $G_{\mathrm{a}}$ and $G_{\mathrm{c}}$ a constant.

The Type-12 system is used mainly to measure two- and three-terminal mica capacitors with binding-post connectors from $0.001 \mu \mathrm{F}$ to $1 \mu \mathrm{F}$. Accordingly, two special fixtures have been constructed to be used for two- and three-terminal measurements, designated as P2 and P3, respectively. These fixtures have binding post connectors, such that the capacitors can be plugged into the bridge via either P2 or P3 directly without using cables, in order to eliminate lead impedance. Detailed descriptions of P2 and P3 are given later in this document (sections 4.2.1 and 4.2.2).

\subsection{Impedance Meters}

The advantage of using impedance meters is that measurements can be performed and results can be transferred automatically to a computer. This reduces both the measuring time and possibilities for human errors when hand-written data are being transferred. Presently, there are two types of commercial impedance meters being used to support the NIST capacitance calibration service.

\subsubsection{Capacitance Meter}

This type of Capacitance Meter employed in the ICL (hereafter referred to as the C-Meter) measures capacitors with respect to internal temperature-controlled, fused-silica-dielectric capacitors. It has a resolution up to one part in $10^{8}$, but operates only at a frequency of $1 \mathrm{kHz}$. It was evaluated by carrying out two separate pilot programs [11], and is now used as the transfer standard in the NIST C-MAP service, and to support the calibration of standard capacitors at a frequency of $1 \mathrm{kHz}$.

The C-Meter is utilized to perform measurements, at a frequency of $1 \mathrm{kHz}$, on nitrogen-dielectric capacitors in the large uncertainty tests ( $25 \mathrm{ppm}$ ); on air-dielectric capacitors; during the physical tests on the nitrogen-dielectric capacitance standards to observe the changes in capacitance values; and on two-terminal capacitance standards with HF coaxial connectors, including the standard terminations.

The C-Meter is characterized by using it to monitor the NIST check standards of mica-dielectric capacitors at $1 \mathrm{kHz}$. It is used to calibrate customer's mica-dielectric capacitors at $1 \mathrm{kHz}$ by using the "substitution method" [12], as discussed in the following section (3.3.2). 


\subsubsection{Digital Impedance Meter}

This type of Digital Impedance Meter employed in the ICL (hereafter referred to as DIM) uses standard ac resistors as internal references and measures standard capacitors, inductors, and ac resistors, over a frequency range from $12 \mathrm{~Hz}$ to $1 \mathrm{MHz}$. The DIM does not have the precision achievable with the C-Meter, but operates at multiple frequencies. It is also characterized by using it to monitor the NIST mica-dielectric check standard capacitors at various frequencies. The DIM is used to calibrate customer's mica-dielectric capacitors at $1 \mathrm{kHz}$, and will be used at other frequencies after the database of check standards is established at other frequencies.

The process of characterization of a meter is to use the meter to monitor the NIST check standards for a period of three years or more, and to compare the data with those obtained from the NIST Type12 bridge. During the calibration of customer's standards, both the customer's standard and the NIST check standard of the identical nominal value are measured using the meter. A predicted value of the NIST check standard is obtained by using the linear regression analysis performed on its database of the Type- 12 measurements. The measured value of the customer's standard is adjusted by using the difference of the predicted value and the measured value of the NIST check standard. Detailed description of such process is given in [12], as the "substitution method".

The DIM is also utilized to perform "Special Test" measurements, especially in responding to requests for capacitance measurements at frequencies not specified in SP250.

\section{CALIBRATION PROCEDURES}

\subsection{Type-2 Capacitance Measurement System}

As mentioned previously, the Type- 2 system, with its internal capacitors, is used to compare customer's standards with shielded terminals to external NIST reference standards. Due to the unknown temperature coefficients of the internal bridge capacitors, it is necessary to calibrate them immediately prior to performing the measurements in order to obtain the uncertainty required. The procedure used to calibrate the internal dial capacitors of the Type- 2 bridge and the equations used to calculate the dial corrections are discussed in detail by Chang [6]. The Type-2 bridge is also employed to transfer the unit of capacitance from the Primary Standards Laboratory (PSL) to achieve traceability of the unit of the farad.

The process of using the Type- 2 bridge to measure customer's standards is based on use of redundant measurement designs in calibration, as described by Cameron [13]. The procedure is to perform a sequence of measurements in accordance with the calibration design to redundantly intercompare a number of reference standards and unknowns. The solution to the design provides true values for each of the unknowns based on the known value of the reference standard, and the design also provides an estimate of the Type-A measurement uncertainty. Table 2 is a list of NIST reference standards and the check standards of the Type- 2 system. 
The calibration design used in the ICL is similar to the experimental designs for groups of 3,4 , and 5 standards, described by Eicke and Cameron [14]. For example, the design for a group of 3 standards is to perform intercomparison of these standards six times by connecting them to the positive (+) and negative (-) output terminals of the Type-2 bridge (see Fig. 1b), thus performing a left-right balance in order to eliminate certain systematic errors. Table 3 illustrates the experimental design for three different groups (A, B, and C) of 3 standards, which are used in the ICL as the three measurement sets for the calibration of fused-silica standard capacitors of nominals of $1 \mathrm{pF}, 10 \mathrm{pF}$, and $100 \mathrm{pF}$, respectively. In Table 3, each row represents one measurement, and the symbols of +1 , $-1,+0.1$, and -0.1 under each capacitor refer to the connections of one end of the capacitor to the respective output terminals of the Type- 2 bridge, to obtain ratios of 1:1 and 10:1, as shown in Fig. 1b. In each group, there are six measurements to be performed by using the primary reference to compare and determine the values of the secondary reference and one customer's standard, or two customer's standards if it is requested. Figure 4 is a block diagram to illustrate the measurement process and the standards being used in the ICL to transfer the capacitance value from the primary reference (in the oil bath) to the customer's standards of various nominal values and dielectrics.

\subsubsection{Fused-Silica-Dielectric Capacitors}

Customer's fused-silica capacitors, as well as ICL secondary reference standards (nominal values of $10 \mathrm{pF}$ and $100 \mathrm{pF}$ ), are calibrated, at ratios of $1: 1$ and $10: 1$, respectively, directly against the ICL primary reference, maintained in the oil bath. The procedure also requires recording the values of the resistive temperature sensors of oil-bath type capacitors and the temperatures of air-bath type capacitors. The value used for the primary reference is corrected from the predicted value at reference temperature (in terms of resistance value), using the known temperature coefficient and the resistive sensor value at the time of measurement. Calibration results of air-bath capacitors are not temperature corrected and, hence, reflect both capacitance and temperature variations.

Since the temperature coefficients of customer's air-bath type, fused-silica capacitors are unknown, it is necessary to perform multiple measurements over a two- to three-week period to compare the variations in capacitance to measurements of similar capacitors to determine if the capacitor is behaving normally. Both the average capacitance value and the average temperature are reported.

The calibration design for fused-silica capacitors in the ICL is that used for groups of 3 standards (see Table 3), which requires three standards to perform one set of measurements. Therefore, the secondary reference is used if only one unknown fused-silica capacitor is being calibrated.

\subsubsection{Nitrogen-Dielectric Capacitors}

Measurement process and standards used for the calibration of nitrogen-dielectric capacitors are illustrated in Fig. 4, Tables 4a to 4f, and discussed in the following.

Customer's nitrogen-dielectric capacitors of nominal value of $10 \mathrm{pF}$ are calibrated directly with the secondary reference \#102 and the NIST check standard \#871 at 1:1 ratio, as shown in Table 4a. 
For capacitors having nominal values of $100 \mathrm{pF}$ and $1000 \mathrm{pF}$, a two-step process is performed. First, the secondary reference \#131 is used to measure the NIST check standards \#493 and \#517 (or \#1717 and $\# 1865$ ) of nominal values of $100 \mathrm{pF}$ (or $1000 \mathrm{pF}$ ) at a ratio of $1: 1$ (or 10:1), as shown in Tables $4 \mathrm{~b}$ and $4 \mathrm{c}$. Then, the check standards are used as working standards to calibrate simultaneously one, two, or three customer's standards of the identical nominal values at a ratio of $1: 1$, as shown in Tables 4d, 4e, and 4f, respectively. Likewise, capacitors of nominal values of $1 \mathrm{pF}$ and $10000 \mathrm{pF}$ can be calibrated by using the $10 \mathrm{pF}$ working standard at $1: 10$ ratio and the $1000 \mathrm{pF}$ working standard at 10:1 ratio, respectively. Since 1994, the C-Meter has been used to perform additional measurements of customer's nitrogen dielectric capacitors at $1 \mathrm{kHz}$ for a period of several days to observe their stabilities. The average value of the Type- 2 bridge and all of the C-Meter measurements is reported.

In the case of large uncertainty $(>25 \mathrm{ppm})$ calibrations, a simpler measurement procedure is used. After the check standards have been measured, the unknown is compared to a check standard of the same nominal value twice by interchanging their positions in the bridge at the 1:1 ratio, as shown in Table 5. Since 1993, the C-Meter has also been included as part of the large uncertainty calibration at $1 \mathrm{kHz}$ by monitoring the capacitance standards for a period of 30 minutes at fiveminute intervals. The average value of these measurements is the reported value and the standard deviation is used to determine the variability of the capacitor.

The C-Meter is also utilized to perform measurements of capacitors subjected to physical tests, if requested. Such tests are performed at $1 \mathrm{kHz}$ and only the changes of capacitance values during the tests are reported.

\subsubsection{Air-Dielectric Capacitors}

Since the total calibration uncertainties of this type of capacitor are between $100 \mathrm{ppm}$ and $2000 \mathrm{ppm}$, the measurement procedure given in Table 5 is used for those capacitors of nominal values equal to and greater than $0.1 \mathrm{pF}$, either at a 1:1 ratio or a 1:10 ratio. For air-dielectric capacitors of lower values $(0.01 \mathrm{pF}$ and $0.001 \mathrm{pF})$, these are calibrated directly against the internal capacitors of the Type- 2 bridge by connecting them to the +1 and -1 output taps of the transformer and the detector. The C-Meter is also utilized to measure all air-dielectric capacitors at $1 \mathrm{kHz}$, in the same manner as in the large uncertainty calibration above.

\subsubsection{Two-Terminal Capacitors with HF Coaxial Connectors}

Since NIST only provides calibration services on this type of capacitor at a frequency of $1 \mathrm{kHz}$, the C-Meter is used to perform measurements on all capacitors with HF coaxial connectors, including the terminations.

In order to perform three-terminal measurements on the two-terminal HF coaxial capacitors, a precision adapter was constructed by mounting a GR900 connector to a fixture such that the capacitance value can be defined and measured. Figure 5 illustrates the construction of the NIST 
reference adapter used for HF coaxial capacitor measurements. The capacitance of the reference adapter was determined by using another adapter with an inner terminal connected to ground. Measurements were performed by mating the adjustable adapter, which also has a GR900 connector, with the reference adapter in five positions of $0^{\circ}, 90^{\circ}, 180^{\circ}, 270^{\circ}$, and back to $0^{\circ}$. The average value of these five measurements is then used as the capacitance value of the reference adapter. Therefore, calibrations of HF two-terminal coaxial standard capacitors are also performed using five measurements by connecting the unknown to the reference adapter, as shown in Fig. 6, in the above five positions. The average value of these measurements is then the capacitance value of the sum of the unknown capacitor and the reference adapter. The capacitance of the unknown can be determined by subtracting the known capacitance value of the reference adapter from the measured value.

\subsection{Type-12 Capacitance Measurement System}

The Type- 12 capacitance bridge is mainly used to measure mica capacitors with banana plugs and binding post connectors in two- or three-terminal configurations from $0.001 \mu \mathrm{F}$ up to $1 \mu \mathrm{F}$. The basic equations of balance for each configuration at various nominal values given below are discussed in detail by Chang [6]. Depending on the terminal connections, measurement procedures are slightly different as described in the following sections.

\subsubsection{Two-Terminal Measurements}

The two-terminal configuration of mica capacitors is achieved by connecting the low terminal binding post to the ground terminal of the capacitor and removing its ground terminal-plug. Therefore, there are only two terminal-plugs, HIGH and LOW, of the capacitor connected to the bridge, via the HIGH and LOW double insulated binding posts of a metal plate - fixture P2 (see Fig. 7). The HIGH terminal of $\mathrm{P} 2$ is connected to the bridge corner " $\mathrm{D}$ " and the LOW terminal is connected to the bridge corner " $\mathrm{C}$ ", via the metal plate and a copper bushing, which is used to mount the plate to the bridge, as shown in Fig. 7. For rigidity, a piece of rectangular Teflon is mounted on top of the plate to support the capacitor being measured, and four Bakelite standoffs are mounted underneath the plate to support the plate on the bridge, also shown in Fig. 7. The procedure for the two-terminal measurements is to balance the bridge twice, once with the unknown capacitor, $C_{x}$ connected to the arm $\mathrm{CD}$ of the Type- 12 bridge and once with $\mathrm{C}_{\mathrm{X}}$ disconnected entirely, as shown in Fig. 8. The two-terminal capacitor can plug into the bridge directly, via the special fixture P2, without using any cables.

Theoretically, the difference of the balance readings represents the capacitance value of the unknown, given by:

$$
C_{\mathrm{x}}=\left(C_{\mathrm{m}}{ }^{\prime}-C_{\mathrm{m} 0}\right)+\left(C_{\mathrm{r}}{ }^{\prime}-C_{\mathrm{r} 0}\right),
$$

where $C_{\mathrm{m}}$ ' is the reading of mica dials when $\mathrm{C}_{\mathrm{x}}$ is connected to the bridge,

$C_{\mathrm{m} 0}$ is the reading of mica dials when $\mathrm{C}_{\mathrm{X}}$ is disconnected from the bridge, 
$C_{\mathrm{r}}{ }^{\prime}$ is the reading of air dials when $\mathrm{C}_{\mathrm{X}}$ is connected to the bridge, and

$C_{\mathrm{r} 0}$ is the reading of air dials when $\mathrm{C}_{\mathrm{X}}$ is disconnected from the bridge.

The relationship of air dials reading, $C_{\mathrm{r}}$ and values of the differential air capacitors $\mathrm{C}_{\mathrm{A}}$ was given in Section 3.2, and, according to Eq. (3), $C_{\mathrm{r}}=2 C_{\mathrm{a}}$.

During measurements when $\mathrm{C}_{\mathrm{X}}$ is not connected to the bridge, the mica dials are always set to zero, i.e. $C_{\mathrm{m} 0}=0$. Then Eq. (4) becomes:

$$
C_{\mathrm{x}}=C_{\mathrm{m}}{ }^{\prime}+\left(C_{\mathrm{r}}{ }^{\prime}-C_{\mathrm{r} 0}\right) .
$$

For measurements of two-terminal capacitors of nominal values up to $0.005 \mu \mathrm{F}$, only air dials are needed to balance the bridge without using the mica dials, i.e. $C_{\mathrm{m}}{ }^{\prime}=0$; then Eq. (5) becomes:

$$
C_{\mathrm{X}}=\left(C_{\mathrm{r}}{ }^{\prime}-C_{\mathrm{r} 0}\right) \text {. }
$$

Therefore, Eq. (5) is used to calculate the value of two-terminal capacitors with nominal values larger than $0.005 \mu \mathrm{F}$.

\subsubsection{Three-Terminal Measurements}

The three-terminal configuration for mica dielectric capacitors is to connect the $\mathrm{HIGH}, \mathrm{LOW}$, and GROUND terminal-plugs separately to the Type-12 bridge, via the HIGH, LOW, and GROUND binding posts of a brass plate - fixture $\mathrm{P} 3$ (see Fig. 9). The HIGH terminal of $\mathrm{P} 3$ is connected to the bridge corner "D", the LOW terminal is connected to a switch ( $\mathrm{S}_{\mathrm{AC}}$ in Fig. 2a), which can be selected to connect the LOW terminal to either bridge corner " $\mathrm{C}$ " or "A", and the GROUND is connected to the plate. For support, a piece of rectangular brass is constructed underneath the plate. The plate also has internal leads to make the proper connections between the capacitor binding posts and the terminals to be plugged onto the bridge, while a brass bushing is used to mount the fixture to the bridge, also shown in Fig. 9. The procedure for three-terminal measurements is to balance the bridge twice, first by connecting the unknown $\mathrm{C}_{X}$ to the arm $\mathrm{CD}$ and then to the arm $\mathrm{AD}$, as shown in Fig. 10. Since this can be accomplished by changing the positions of the bridge switch, $\mathrm{S}_{\mathrm{AC}}$, the capacitor being calibrated remains connected to $\mathrm{P} 3$ during the measurements.

In order to obtain a balance for unknown capacitors of nominal values higher then $0.005 \mu \mathrm{F}$, additional capacitance on the arm $\mathrm{CD}$ is required. This is achieved by connecting a capacitance decade box, $\mathrm{C}_{\mathrm{b}}$, to the arm, $\mathrm{CD}$, also shown in Fig. 10. Therefore, $\mathrm{C}_{\mathrm{b}}$ is always connected to the bridge in performing three-terminal measurements, and it is set to zero when lower valued capacitors are being measured. For capacitors with nominal values up to $0.5 \mu \mathrm{F}, \mathrm{C}_{\mathrm{b}}$ is set to a fixed value during both balances, using it as a dummy capacitor.

For capacitors of nominal values up to $0.005 \mu \mathrm{F}$, only air dials are needed to balance the bridge, as in the two-terminal case. With both the mica dials and the decade box set to zero, the value of the unknown, $C_{\mathrm{X}}$, can be expressed as: 


$$
C_{\mathrm{X}}=(1 / 2)\left(C_{\mathrm{r} 2}-C_{\mathrm{r} 1}\right),
$$

where $C_{\mathrm{r} 2}$ is the reading of air dials when $\mathrm{C}_{\mathrm{X}}$ is connected to the arm $\mathrm{CD}$ of the bridge, and

$C_{\mathrm{r} 1}$ is the reading of air dials when $\mathrm{C}_{\mathrm{x}}$ is connected to the arm $\mathrm{AD}$ of the bridge.

For capacitors of nominal values from higher than $0.005 \mu \mathrm{F}$ to $0.5 \mu \mathrm{F}$, a certain setting of the decade box, $\mathrm{C}_{\mathrm{b}}$, is needed for each nominal value, but should remain as a constant during both balances. Also, the mica dials are needed to obtain balance when the unknown is connected to the arm CD. The value of the unknown, $C_{\mathrm{X}}$, can be expressed as:

$$
C_{\mathrm{x}}=(1 / 2) C_{\mathrm{m}}+(1 / 4)\left(C_{\mathrm{r} 2}-C_{\mathrm{r} 1}\right)
$$

where $C_{\mathrm{m}}$ is the reading of mica dials when $\mathrm{C}_{\mathrm{x}}$ is connected to the arm $\mathrm{CD}$ of the bridge.

For capacitors of nominal value of higher than $0.5 \mu \mathrm{F}$, a different measurement procedure is used. Due to the limitation of internal mica capacitors of the Type-12 bridge, four balances, instead of two, are needed and the decade box $\mathrm{C}_{\mathrm{b}}$ is set to either zero or the nominal value of the unknown. Using $C_{\mathrm{X}}=1 \mu \mathrm{F}$ as an example, the four steps of connections and settings are :

1) Connect $\mathrm{C}_{\mathrm{x}}$ to arm $\mathrm{AD}$, set mica dials to zero, and $C_{\mathrm{b}}$ to $1 \mu \mathrm{F}$. Use air dials to obtain balance, and record the reading as $C_{\mathrm{ra}}$.

2) Disconnect $\mathrm{C}_{\mathrm{X}}$, and leave $C_{\mathrm{b}}$ at $1 \mu \mathrm{F}$. Use both air and mica dials to obtain balance, and record the readings as $C_{\mathrm{rb}}$ and $C_{\mathrm{mb}}$, respectively.

3) Connect $\mathrm{C}_{\mathrm{x}}$ to arm $\mathrm{CD}$, and set $C_{\mathrm{b}}$ to zero. Use both air and mica dials to obtain balance, and record the readings as $C_{\mathrm{rc}}$ and $C_{\mathrm{mc}}$, respectively.

4) Disconnect $\mathrm{C}_{\mathrm{X}}$, set both mica dials and $C_{\mathrm{b}}$ to zero. Use air dials to obtain balance, and record the reading as $C_{\mathrm{rd}}$.

After the above four measurements and data recordings are completed, the value of the unknown, $C_{\mathrm{X}}$, can be calculated from:

$$
C_{\mathrm{x}}=(1 / 2)\left(C_{\mathrm{mb}}+C_{\mathrm{mc}}\right)+(1 / 2)\left[\left(C_{\mathrm{rb}}-C_{\mathrm{ra}}\right)+\left(C_{\mathrm{rc}}-C_{\mathrm{rd}}\right)\right] .
$$

Since there are no perfect capacitors, there must be some power loss, which appears as the equivalent parallel conductance of the capacitor. Therefore, the procedure of obtaining a balance condition of the Type-12 bridge is to balance both the quadrature and the in-phase components of the bridge by adjusting both the capacitance and conductance dials, as shown in Fig. 3. Eqs. (5) to (9) are used to calculate unknown capacitances, $C_{X}$, of various nominal values and terminal configurations after each balance is obtained and capacitance dial readings are recorded. As shown in Fig. 3, Eqs. (5) to (9) can also be utilized to calculate the conductance value of the unknown capacitor by substituting the $C_{\mathrm{X}}$ and capacitance dial readings with $G_{\mathrm{X}}$ and conductance dial readings, respectively. 


\section{QUALITY CONTROL IN THE IMPEDANCE CALIBRATION LABORATORY}

In order to achieve high quality in the measurement results, it is important to establish procedures to assure that the measuring systems and reference and check standards are in a state of statistical control. In the ICL, the unit of capacitance is transferred from the PSL, and maintained via primary reference standards to perform calibrations of customer's standards. Quality control procedures have been established in many parts of the calibration process, including maintaining the farad, developing control charts of reference and check standards, observing the variations in measurements, and examining the calibration data history of the customer's standard.

\subsection{Transfer and Maintenance of the Farad}

The primary reference of the ICL is a group of four NIST-made, $10 \mathrm{pF}$ oil-bath type, fused-silicadielectric capacitors, which are maintained in an oil bath at a temperature of $25^{\circ} \mathrm{C}$ and are traceable to the calculable capacitor via another NIST-made, $10 \mathrm{pF}$ air-bath type, fused-silica capacitor used as the transfer standard. Each of the reference standards, including the transfer standard, has a known temperature coefficient at its reference temperature, which is measured in terms of a resistive temperature sensor. Therefore, besides the capacitance value, it is necessary to measure the resistance of the copper wire wrapped around the individual capacitor, to determine the temperature of the capacitor during measurements. Thus, a temperature correction that corresponds to the measured deviation from the reference temperature (or reference resistance value) can be applied to the reference capacitance value when performing calibrations.

The above procedure for maintaining the farad has been developed and used in the ICL since 1993. According to the data history, all of the primary references are stable to within $0.02 \mathrm{ppm} / \mathrm{year}$ with an average drift for the group of less than $0.005 \mathrm{ppm} /$ year. Figure 11 is a plot of the average value of the four primary reference standards in the oil bath of the ICL corrected to their respective reference temperatures.

The transfer standard is normally situated in the PSL and measured, against a bank of reference standards in the PSL, weekly to monitor the stability of the transfer standard. It is brought to the ICL to transfer its value to the primary references in the oil bath of the ICL every two to three months. Figure 12 is a block diagram illustrating the procedure used to maintain the farad obtained from the PSL and transfer it to the customer workload.

In the ICL, the primary references are used to calibrate customer's fused-silica-dielectric capacitors and to measure ICL's secondary reference standards, which are two commercial temperaturecontrolled air-bath type, fused-silica capacitance standards, one $10 \mathrm{pF}$ and one $100 \mathrm{pF}$. The exact temperature coefficients of these standards are unknown, but the temperature variations of each enclosure during measurement periods of two weeks are within $0.004^{\circ} \mathrm{C}$, with a drift rate of less than $0.002^{\circ} \mathrm{C} /$ year. Since 1988 , a data history of each secondary reference has been maintained by staff in the ICL with control charts to observe their stabilities. Figures 13 and 14 are examples of the histories of secondary reference standards \#102 and \#131 (with control limits at the 95 percent 
confidence level) and enclosure temperatures, dating from 1990. These secondary references are utilized to calibrate the check standards which are used as working standards to calibrate customer's capacitance standards with dielectrics other than fused-silica, such as nitrogen, air, and mica, also shown in Fig. 12.

\subsection{Type-2 System and Capacitance Meter}

The ICL staff also maintain control charts for each check standard given in Table 2 to assure that both the Type-2 system and the check standards are in statistical control. After the check standards have been measured against the secondary reference, the data are examined to ensure that they are within control limits. Then the check standards are used as the working standards to calibrate customer's capacitors, as indicated in Fig. 12. Figure 15 is an example illustrating the data history and control limits of one of the check standards of the Type- 2 bridge.

The C-Meter is characterized by using the check standards of the Type- 2 system to observe its stability and to determine measurement differences from the Type- 2 bridge. Results from several years of collecting data depict that the differences in measurements between using the Type- 2 bridge and the C-Meter to measure all reference and check standards are within $\pm 0.4 \mathrm{ppm}$ at the $100 \mathrm{pF}$ and $1000 \mathrm{pF}$ levels and $\pm 0.7 \mathrm{ppm}$ at the $10 \mathrm{pF}$ level. Figure 16 is an example showing the data from measurements performed by both systems on the same check standard (\#1865, shown in Fig. 15). Since 1993, the C-Meter is also used to measure customer's nitrogen-dielectric capacitors on the same date when the capacitors are being calibrated using the Type-2 bridge. Figures 17a, 17b, and $17 \mathrm{c}$ are plots of the measurement differences of customer's capacitors between using the C-Meter and the Type- 2 bridge in the $1000 \mathrm{pF}, 100 \mathrm{pF}$, and $10 \mathrm{pF}$ levels, respectively. Therefore, the C-Meter has been utilized to perform calibrations on capacitors with an uncertainty higher than $25 \mathrm{ppm}$ at a frequency of $1 \mathrm{kHz}$. Together with the Type-2 bridge, it is also used for lower uncertainty calibrations to monitor the customer's nitrogen-dielectric capacitors at $1 \mathrm{kHz}$ for a period of several days to ensure that the measured variations of the capacitors are within the assigned limits. If the difference of measurements between using the C-Meter and the Type- 2 bridge on the same day is within $\pm 0.4 \mathrm{ppm}$ for the $100 \mathrm{pF}$ and $1000 \mathrm{pF}$ levels and within $\pm 0.7 \mathrm{ppm}$ for the $10 \mathrm{pF}$ level, the average of all measurements are reported. The measurement differences are taken into account for the calibration uncertainties assigned.

\subsection{Type-12 System, Capacitance Meter, and Digital Impedance Meter}

The Type- 12 bridge uses its internal capacitors as the reference in performing measurements. Thus, the ICL staff maintain a database with control charts of two sets of check standards, which are mica capacitors of nominal values from $0.001 \mu \mathrm{F}$ to $1 \mu \mathrm{F}$, to assure that the Type- 12 system is in a state of statistical control. Table 6 is a list of NIST check standards of the Type-12 system. Figure 18 is an example illustrating the data and control limits of one of the check standards (\#27620).

Since 1993, both the C-Meter and the DIM have been characterized at $1 \mathrm{kHz}$ using the check standards of the Type- 12 bridge to observe their stabilities and measurement differences from the 
Type-12 bridge. Data obtained from these measurements show that the differences in measurements among these three systems vary in accordance to the nominal values of the capacitors. Figure 19 is an example illustrating the data from measurements using all three systems. Both the C-Meter and the DIM are utilized to perform calibrations on mica capacitors at $1 \mathrm{kHz}$ by using the "substitution method" [12], and the average of the calculated values from both meters is used in the NIST calibration reports. The range of these two measurements is used to observe the variation in measurements to check the measurement uncertainty.

\subsection{Customer's Standards}

As mentioned previously, standard capacitors received by NIST must be in good working condition, and the calibration process begins after these are in the ICL for more than 72 hours. After the calibration process is completed, the final value is compared with the data history of the customer's standard to determine if any inconsistencies occurred. In the case where the standard has not been calibrated by NIST previously, two separate calibrations are performed on the standard at an interval of several days to check for consistency. The average value of these two measurements is reported.

\section{REPORTED VALUE AND MEASUREMENT UNCERTAINTY}

The capacitance value along with its uncertainty is stated on the calibration report issued by NIST. The reported values are determined as discussed in Section 3. General information relevant to the capacitance measurement is given in the Appendix, which also contains a few Report of Calibration examples.

The uncertainty given in the Report of Calibration is the expanded uncertainty, $U$, of the assigned value, and expressed as :

$$
U=k u_{\mathrm{c}},
$$

where $u_{\mathrm{c}}$ is the combined standard uncertainty and $k$ is the coverage factor to be chosen on the basis of the approximate confidence level desired. The coverage factor used at NIST to calculate $U$ is generally $k=2$, which is consistent with current international practice $[5,15]$ and having a level of confidence of approximately 95 percent.

The combined standard uncertainty, $u_{\mathrm{c}}$, is the combination of estimated values of two types of uncertainties, the Type A and Type B standard uncertainties, and is defined as the "RSS" (rootsum-of-squares) of both types as :

$$
u_{\mathrm{c}}=\left[u_{\mathrm{a}}^{2}+u_{\mathrm{b}}^{2}\right]^{1 / 2},
$$

where $u_{\mathrm{a}}$ and $u_{\mathrm{b}}$ are Type $\mathrm{A}$ and Type $\mathrm{B}$ standard uncertainties, respectively. 
The Type A standard uncertainty contains error components that can be evaluated by statistical methods and is expressed from each known source of error as a statistical standard deviation. The Type B standard uncertainty contains those errors that are evaluated by other means [5], and is estimated from an "equivalent" standard deviation of each possible source of error, many times based solely on the experience of the metrologist.

A detailed discussion is contained in [6] for each type of uncertainty for the measurement of various standard capacitors using different measurement systems. The expanded uncertainties assigned to these capacitors are given in Tables 7 to 10, based on the following equation:

$$
U=2\left[\Sigma\left(s_{i}\right)^{2}+\Sigma\left(s_{j}\right)^{2}\right]^{1 / 2},
$$

where $s_{i}$ and $s_{j}$ are the estimated standard deviations of the components of Type A and Type B standard uncertainties, respectively.

\section{CONCLUSION}

The NIST capacitance calibration service is described in this publication, which contains material from internal documents dated back to 1960 . Over the past decade, the quality of the measurements performed in the impedance calibration laboratory (ICL) has been improved tremendously. Highquality commercial instruments, such as detectors and function generators, are now used in the Type2 system to improve its resolution. The use of oil-bath type fused-silica capacitors with known temperature corrections as reference standards in the ICL has increased the stability and consistency of the local unit of capacitance. The development of automatic measurement procedures using characterized commercial meters reduces measurement time and the possibility for human errors. References [3] and [6] constitute additional, more detailed documentation for selected aspects of the NIST capacitance calibration service.

\section{REFERENCES}

1. J. Q. Shields, R. F. Dziuba, and H. P. Layer, "New Realization of the Ohm and Farad Using the NBS Calculable Capacitor," IEEE Trans. Instrum. Meas. Vol. 38, No. 2, pp. 249-251, April 1989.

2. R. D. Cutkosky, "Capacitance Bridge -- NBS Type 2, "National Bureau of Standards Report 7103, March 1961.

3. Y. M. Chang, "NIST Measurement Assurance Program for Capacitance Standards at $1 \mathrm{kHz}$," NIST Technical Note 1417, March 1996. 
4. "NIST Calibration Services Users Guide," Natl. Inst. Stand. Tech. Special Publication 250, 1991 edition, U. S. Government Printing Office, Washington, DC 20402.

5. B. N. Taylor and C. E. Kuyatt, "Guidelines for Evaluating and Expressing the Uncertainty of NIST Measurement Results," NIST Technical Note 1297, 1994 Ed., September 1994.

6. Y. M. Chang, "Error Analysis and Calibration Uncertainty of Capacitance Standards at NIST," NIST Technical Note (to be published)

7. C. R. Levy, "Testing to Quantify the Effects of Handling of Gas Dielectric Standard Capacitors," NBS Technical Note 1161, October 1982.

8. M. C McGregor, J. F. Hersh, R. D. Cutkosky, F. K. Harris, and F. R. Kotter, "New Apparatus at the National Bureau of Standards for Absolute Capacitance Measurement," IRE Trans. Instrum. vol I-7, nos. 3 \& 4, pp. 253-261, December 1958.

9. W. D. Voelker, "An Improved Capacitance Bridge for Precision Measurements," Bell Labs Record, vol. 20, pp. 133-137, January 1942.

10. H. T. Wilhelm, "The Type-12 Capacitance Bridge," Bell Labs Memorandum, MM 70-4735-9, Case 70052-213, File 37954-15, May 1970.

11. Y. M. Chang, "NIST Capacitance Measurement Assurance Program (MAP)," Measurement Science Conference, Anaheim, CA, January 1993.

12. Y. M. Chang and S. B. Tillett, "Calibration Procedures for Inductance Standards Using a Commercial Impedance Meter as a Comparator," NISTIR 4466, November 1990.

13. J. M. Cameron, "The Use of the Method of Least Squares in Calibration," NBSIR 74-587, September 1974.

14. W. G. Eicke and J. M. Cameron, "Designs for Surveillance of the Volt Maintained by a Small Group of Saturated Standard Cells," NBS Technical Note 430, October 1967.

15. International Bureau of Weights and Measures (BIPM) Working Group on the Statement of Uncertainties, Metrologia, vol. 17, pp. 73-74, 1981. 
Table 1. Summary of Standard Capacitors Acceptable for Calibrations

\begin{tabular}{|c|c|c|c|}
\hline Manufacturer & Norminal Values & Terminal Configuration & Frequency $(\mathrm{Hz})$ \\
\hline \multicolumn{4}{|l|}{ General Radio Co.* } \\
\hline GR1403 & $0.001 \mathrm{pF}$ to $1000 \mathrm{pF}$ & 3-T Coaxial & $100 \quad 400 \& 1000$ \\
\hline GR1404 & $10 \mathrm{pF}$ to $1000 \mathrm{pF}$ & 3-T Coaxial & $100 \quad 400 \& 1000$ \\
\hline GR1405 & $1 \mathrm{pF}$ to $20 \mathrm{pF}$ & 2-T Coaxial & 1000 \\
\hline GR1406 & $50 \mathrm{pF}$ to $1000 \mathrm{pF}$ & 2-T Coaxial & 1000 \\
\hline GR1407 & $0.001 \mu \mathrm{F} \quad$ to $\quad 0.1 \mu \mathrm{F}$ & 2-T Coaxial & 1000 \\
\hline GR1408 & $10 \mathrm{pF}$ and $100 \mathrm{pF}$ & 3-T Coaxial & $100 \quad 400 \& 1000$ \\
\hline GR1409 & $0.001 \mu \mathrm{F} \quad$ to $\quad 1 \mu \mathrm{F}$ & 2-T \& 3-T Binding Post & $66 \quad 100400 \quad 1000 \& 10000$ \\
\hline GR509 & $0.001 \mu \mathrm{F} \quad$ to $\quad 1 \mu \mathrm{F}$ & 2-T Binding Post & $66 \quad 100400 \quad 1000 \& 10000$ \\
\hline GR1615-P1 & $10000 \mathrm{pF}$ & 3-T Coaxial & 1000 \\
\hline GR900-WO & $\begin{array}{c}0.172 \mathrm{pF} \\
\text { (open-circuit termination) }\end{array}$ & 2-T HF Coaxial & 1000 \\
\hline GR900-WO4 & $\begin{array}{c}2.67 \mathrm{pF} \\
\text { (open-circuit termination) }\end{array}$ & 2-T HF Coaxial & 1000 \\
\hline \multicolumn{4}{|l|}{$\begin{array}{l}\text { Electro-Scientific } \\
\text { Industries Inc. }\end{array}$} \\
\hline ESI SCIO00 & $1000 \mathrm{pF}$ & 3-T Coaxial & $100400 \& 1000$ \\
\hline \multicolumn{4}{|l|}{ Andeen-Hagerling Inc. } \\
\hline AH11 A & $1 \mathrm{pF}$ to $100 \mathrm{pF}$ & 3-T BNC & $100 \quad 400 \& 1000$ \\
\hline
\end{tabular}

* or one of its successor companies. 
Table 2. Summary of Reference and Check Standards of the Type-2 Bridge

\begin{tabular}{|c|c|c|c|c|c|}
\hline & Serial No. & Values (pF) & Dielectric & Control & Temperature $\left({ }^{\circ} \mathrm{C}\right)$ \\
\hline $\begin{array}{l}\text { Primary } \\
\text { Reference }\end{array}$ & $\begin{array}{l}\# 121 \\
\# 181 \\
\# 183 \\
\# 184\end{array}$ & $\begin{array}{l}10 \\
10 \\
10 \\
10\end{array}$ & Fused-Silica & Oil-Bath & 25 \\
\hline $\begin{array}{l}\text { Secondary } \\
\text { Reference }\end{array}$ & $\begin{array}{l}\# 102 \\
\# 131 \\
\# 254 \\
\# 230\end{array}$ & $\begin{array}{r}10 \\
100 \\
10 \\
100\end{array}$ & Fused-Silica & Air-Bath & 30 \\
\hline $\begin{array}{c}\text { Check } \\
\text { Standards }\end{array}$ & $\begin{array}{c}\# 89790 \\
\# 871 \\
\# 493 \\
\# 517 \\
\# 1717 \\
\# 1865 \\
\# 202201 \\
\text { \#NBS1615 }\end{array}$ & $\begin{array}{r}1 \\
10 \\
100 \\
100 \\
1000 \\
1000 \\
10000 \\
10000\end{array}$ & Nitrogen & $\begin{array}{c}\text { Stable } \\
\text { Laboratory } \\
\text { Environment }\end{array}$ & 23 \\
\hline
\end{tabular}


Table 3. NIST Calibration Design for Fused-Silica-Dielectric Standard Capacitors

\begin{tabular}{|c|c|c|c|c|c|c|}
\hline \multirow{2}{*}{$\begin{array}{c}\begin{array}{c}\text { Standards } \\
\text { Used }\end{array} \\
\text { Serial No. }\end{array}$} & \multirow{2}{*}{$\begin{array}{c}\begin{array}{c}\text { Primary } \\
\text { Reference }\end{array} \\
\# 121\end{array}$} & \multicolumn{2}{|c|}{ Secondary Reference } & \multicolumn{3}{|c|}{$\begin{array}{l}\text { Customer's Capacitors } \\
\text { (GR-1408 and AH11A) }\end{array}$} \\
\hline & & $\# 102$ & $\# 131$ & $\mathrm{C}_{\mathrm{X} 01}$ & $\mathrm{C}_{\mathrm{X} 11}$ & $\mathrm{C}_{\mathrm{X} 21}$ \\
\hline $\begin{array}{l}\text { Nominal } \\
\text { Value }\end{array}$ & $10 \mathrm{pF}$ & $10 \mathrm{pF}$ & $100 \mathrm{pF}$ & $1 \mathrm{pF}$ & $10 \mathrm{pF}$ & $100 \mathrm{pF}$ \\
\hline \multirow[t]{6}{*}{ Group A } & +0.1 & -0.1 & & & & \\
\hline & +0.1 & & & -1 & & \\
\hline & & +0.1 & & -1 & & \\
\hline & -0.1 & +0.1 & & & & \\
\hline & -0.1 & & & +1 & & \\
\hline & & -0.1 & & +1 & & \\
\hline \multirow[t]{6}{*}{ Group B } & +1 & -1 & & & & \\
\hline & +1 & & & & -1 & \\
\hline & & +1 & & & -1 & \\
\hline & -1 & +1 & & & & \\
\hline & -1 & & & & +1 & \\
\hline & & -1 & & & +1 & \\
\hline \multirow[t]{6}{*}{ Group C } & +1 & & -0.1 & & & \\
\hline & +1 & & & & & -0.1 \\
\hline & & & +0.1 & & & -0.1 \\
\hline & -1 & & +0.1 & & & \\
\hline & -1 . & & & & & +0.1 \\
\hline & & & -0.1 & & & +0.1 \\
\hline
\end{tabular}


Table 4a. NIST Calibration Design for 10 pF Nitrogen-Dielectric Standard Capacitors

\begin{tabular}{|c|c|c|c|}
\hline $\begin{array}{c}\text { Standards } \\
\text { Used }\end{array}$ & $\begin{array}{c}\text { Secondary } \\
\text { Reference }\end{array}$ & $\begin{array}{c}\text { Check Standard } \\
\text { (GR-1404 without trimmers) }\end{array}$ & $\begin{array}{c}\text { Customer's Capacitor } \\
\text { ( GR-1404) }\end{array}$ \\
\hline Serial No. & $\# 102$ & $\# 871$ & $\mathrm{C}_{\mathrm{X} 12}$ \\
\hline $\begin{array}{c}\text { Nominal } \\
\text { Value }\end{array}$ & $10 \mathrm{pF}$ & $10 \mathrm{pF}$ & $10 \mathrm{pF}$ \\
\hline Group D & +1 & -1 & -1 \\
\cline { 2 - 4 } & +1 & +1 & -1 \\
\cline { 2 - 4 } & -1 & +1 & +1 \\
\cline { 2 - 4 } & -1 & -1 & +1 \\
\hline
\end{tabular}

Table 4b. NIST Calibration Design for $100 \mathrm{pF}$ Nitrogen-Dielectric Check Standards

\begin{tabular}{|c|c|c|c|}
\hline $\begin{array}{c}\text { Standards } \\
\text { Used }\end{array}$ & $\begin{array}{c}\text { Secondary } \\
\text { Reference }\end{array}$ & $\begin{array}{c}\text { Check Standard } \\
\text { (GR-1404 without trimmers) }\end{array}$ & $\begin{array}{c}\text { Check Standard } \\
\text { (GR-1404 without trimmers) }\end{array}$ \\
\hline Serial No. & $\# 131$ & $\# 493$ & $\# 517$ \\
\hline $\begin{array}{c}\text { Nominal } \\
\text { Value }\end{array}$ & $100 \mathrm{pF}$ & $100 \mathrm{pF}$ & $100 \mathrm{pF}$ \\
\hline Group E & +1 & -1 & -1 \\
\cline { 2 - 4 } & +1 & +1 & -1 \\
\cline { 2 - 4 } & -1 & +1 & +1 \\
\cline { 2 - 4 } & -1 & -1 & +1 \\
\hline
\end{tabular}

Table 4c. NIST Calibration Design for 1000 pF Nitrogen-Dielectric Check Standards

\begin{tabular}{|c|c|c|c|}
\hline $\begin{array}{c}\text { Standards } \\
\text { Used }\end{array}$ & $\begin{array}{c}\text { Secondary } \\
\text { Reference }\end{array}$ & $\begin{array}{c}\text { Check Standard } \\
\text { (GR-1404 without trimmers) }\end{array}$ & $\begin{array}{c}\text { Check Standard } \\
\text { (GR-1404 without trimmers) }\end{array}$ \\
\hline Serial No. & $\# 131$ & $\# 1717$ & $\# 1865$ \\
\hline $\begin{array}{c}\text { Nominal } \\
\text { Value }\end{array}$ & $100 \mathrm{pF}$ & $1000 \mathrm{pF}$ & $1000 \mathrm{pF}$ \\
\hline Group F & +1 & -0.1 & -0.1 \\
\cline { 2 - 4 } & +1 & +0.1 & -0.1 \\
& -1 & +0.1 & +0.1 \\
\cline { 2 - 4 } & -1 & & +0.1 \\
\hline
\end{tabular}


Table 4d. NIST Calibration Design for One $100 \mathrm{pF}$ (or $1000 \mathrm{pF)} \mathrm{Nitrogen-Dielectric} \mathrm{Standard} \mathrm{Capacitor}$

\begin{tabular}{|c|c|c|c|}
\hline $\begin{array}{c}\text { Standards } \\
\text { Used }\end{array}$ & \multicolumn{2}{|c|}{$\begin{array}{c}\text { Working Standards } \\
\text { (GR-1404 without trimmers ) }\end{array}$} & $\begin{array}{c}\text { One Customer's Capacitor } \\
\text { (GR-1404 \& ESI SC-1000) }\end{array}$ \\
\hline Serial No. & $\# 493$ (or \#1717) & $\# 517$ (or \#1865) & C $222_{\text {(or } C_{\mathrm{X} 31} \text { ) }}$ \\
\hline $\begin{array}{c}\text { Nominal } \\
\text { Value }\end{array}$ & 100 (or 1000) pF & 100 (or 1000) pF & 100 (or 1000) pF \\
\hline $\begin{array}{c}\text { Group of } \\
3 \text { Standards }\end{array}$ & -1 & +1 & -1 \\
\cline { 2 - 4 } & -1 & +1 & +1 \\
\cline { 2 - 4 } & & -1 & +1 \\
\cline { 2 - 4 } & +1 & -1 & -1 \\
\hline
\end{tabular}

Table 4e. NIST Calibration Design for Two $100 \mathrm{pF}$ (or $1000 \mathrm{pF)} \mathrm{Nitrogen-Dielectric} \mathrm{Standard} \mathrm{Capacitors}$

\begin{tabular}{|c|c|c|c|c|}
\hline $\begin{array}{c}\text { Standards } \\
\text { Used }\end{array}$ & \multicolumn{2}{|c|}{$\begin{array}{c}\text { Working Standards } \\
\text { (GR-1404 without trimmers ) }\end{array}$} & \multicolumn{2}{c|}{$\begin{array}{c}\text { Two Customer's Capacitors } \\
\text { (GR-1404 \& ESI SC-1000 ) }\end{array}$} \\
\hline Serial No. & $\# 493$ (or \#1717) & $\# 517$ (or \#1865) & $\mathrm{C}_{\mathrm{X} 22}\left(\right.$ or $\mathrm{C}_{\mathrm{X} 31}$ ) & $\mathrm{C}_{\mathrm{X} 23}\left(\right.$ or $\mathrm{C}_{\mathrm{X} 32}$ ) \\
\hline $\begin{array}{c}\text { Nominal } \\
\text { Value }\end{array}$ & 100 (or 1000) $\mathrm{pF}$ & 100 (or 1000) $\mathrm{pF}$ & 100 (or 1000) pF & 100 (or 1000) pF \\
\hline $\begin{array}{c}\text { Group of } \\
4 \text { Standards }\end{array}$ & +1 & -1 & -1 & \\
\cline { 2 - 6 } & +1 & -1 & +1 & \\
\cline { 2 - 6 } & & & +1 & -1 \\
\cline { 2 - 6 } & & +1 & & -1 \\
& -1 & +1 & & +1 \\
\hline
\end{tabular}

Table 4f. NIST Calibration Design for Three 100 pF (or 1000 pF) Nitrogen-Dielectric Standard Capacitor

\begin{tabular}{|c|c|c|c|c|c|}
\hline $\begin{array}{l}\text { Standards } \\
\text { Used }\end{array}$ & \multicolumn{2}{|c|}{$\begin{array}{c}\text { Working Standards } \\
\text { ( GR-1404 without trimmers ) }\end{array}$} & \multicolumn{3}{|c|}{$\begin{array}{l}\text { Three Customer's Capacitors } \\
\text { ( GR-1404 \& ESI SC-1000) }\end{array}$} \\
\hline Serial No. & $\# 493$ (or \#1717) & $\# 517$ (or \#1865) & $\mathrm{C}_{\mathrm{X} 22}\left(\right.$ or $\left.\mathrm{C}_{\mathrm{X} 31}\right)$ & $\mathrm{C}_{\mathrm{X} 23}\left(\right.$ or $\left.\mathrm{C}_{\mathrm{X} 32}\right)$ & $\mathrm{C}_{\mathrm{X} 24}\left(\right.$ or $\left.\mathrm{C}_{\mathrm{X} 33}\right)$ \\
\hline $\begin{array}{c}\text { Nominal } \\
\text { Value }\end{array}$ & 100 (or 1000$) \mathrm{pF}$ & $100($ or 1000$) \mathrm{pF}$ & $100($ or 1000$) \mathrm{pF}$ & 100 (or 1000$) \mathrm{pF}$ & $100($ or 1000$) \mathrm{pF}$ \\
\hline \multirow{10}{*}{$\begin{array}{c}\text { Group of } \\
5 \text { Standards }\end{array}$} & +1 & & -1 & & \\
\hline & +1 & & & & -1 \\
\hline & & & & +1 & -1 \\
\hline & -1 & & & +1 & \\
\hline & -1 & +1 & & & \\
\hline & & +1 & & -1 & \\
\hline & & & +1 & -1 & \\
\hline & & -1 & +1 & & \\
\hline & & -1 & & & +1 \\
\hline & & & -1 & & +1 \\
\hline
\end{tabular}


Table 5. NIST Large Uncertainty Calibration Design for Nitrogen- and Air-Dielectric Standard Capacitors

\begin{tabular}{|c|c|c|c|c|}
\hline $\begin{array}{c}\text { Standards } \\
\text { Used }\end{array}$ & $\begin{array}{c}\text { Working } \\
\text { Standards }\end{array}$ & $\begin{array}{c}\text { Customer's } \\
\text { Capacitors }\end{array}$ & $\begin{array}{c}\text { Working } \\
\text { Standard }\end{array}$ & $\begin{array}{c}\text { Customer's } \\
\text { Capacitor }\end{array}$ \\
\hline Nominal Value & $1 \mathrm{pF}$ to $10000 \mathrm{pF}$ & $1 \mathrm{pF}$ to $10000 \mathrm{pF}$ & $1 \mathrm{pF}$ & $0.1 \mathrm{pF}$ \\
\hline Ratio & \multicolumn{2}{|c|}{$1: 1$} & \multicolumn{2}{|c|}{$1: 10$} \\
\hline & +1 & -1 & +0.1 & -1 \\
& -1 & +1 & -0.1 & +1 \\
\hline
\end{tabular}


Table 6. Summary of Check Standards of the Type-12 Bridge

\begin{tabular}{|c|c|c|c|}
\hline \multicolumn{2}{|c|}{ Serial No. } & \multirow{2}{*}{$\begin{array}{c}\text { Nominal } \\
\text { Value } \\
(\mu \mathrm{F})\end{array}$} & \multirow{2}{*}{$\begin{array}{r}\text { Model } \\
\text { GR1409 } \\
\text { Type }\end{array}$} \\
\hline $\begin{array}{c}\text { Primary } \\
\text { Set }\end{array}$ & $\begin{array}{c}\text { Secondary } \\
\text { Set }\end{array}$ & & \\
\hline \#3068 & \#1812 & 0.001 & $\mathrm{~F}$ \\
\hline \#547 & \#11741 & 0.002 & G \\
\hline \#496 & $\# 11758$ & 0.005 & K \\
\hline \#27620 & \#10541 & 0.01 & $\mathrm{~L}$ \\
\hline \#1509 & \#11180 & 0.02 & $\mathrm{M}$ \\
\hline \#3687 & \#11525 & 0.05 & $\mathrm{R}$ \\
\hline \#5149 & $\# 12223$ & 0.1 & $\mathrm{~T}$ \\
\hline$\# 7632$ & $\# 5248$ & 0.2 & $\mathrm{U}$ \\
\hline \#3938 & $\# 3858$ & 0.5 & $\mathrm{X}$ \\
\hline$\# 4214$ & \#3390 & 1 & Y \\
\hline
\end{tabular}


Table 7. Calibration Uncertainties of Fused-Silica- and Nitrogen-Dielectric Standard Capacitors

\begin{tabular}{|c|c|c|c|c|c|c|c|}
\hline \multicolumn{9}{|c|}{ Expanded Uncertainties (ppm) } \\
\hline Dielectric Type & \multicolumn{3}{|c|}{ Fused-Silica } & \multicolumn{4}{c|}{ Nitrogen } \\
\hline Test Type & \multicolumn{2}{|c|}{ Small Uncertainty } & Large Uncertainty \\
\hline Frequency (Hz) & 100 & 400 & 1000 & 100 & 400 & 1000 & $100,400, \& 1000$ \\
\hline Nominal Value (pF) & & & & & & & \\
\hline 1 & 8.5 & 4.5 & 3.8 & & & & \\
10 & 4 & 2.5 & 1.7 & 6 & 5 & 4 & 25 \\
100 & 4 & 2.5 & 1.7 & 6 & 5 & 4 & 25 \\
\hline
\end{tabular}


Table 8. Calibration Uncertainties of Air-Dielectric and Two-Terminal HF Coaxial Connector Standard Capacitors

\begin{tabular}{|c|c|c|c|c|}
\hline \multicolumn{5}{|c|}{ Expanded Uncertainties (ppm) } \\
\hline Configuration & \multicolumn{2}{|c|}{ Three-Terminal Coaxial } & \multicolumn{2}{|c|}{ Two-Terminal HF Coaxial } \\
\hline Dielectric Type & \multicolumn{2}{|c|}{ Air } & \multicolumn{2}{|c|}{ Air and Mica } \\
\hline Frequency $(\mathrm{Hz})$ & 100 & $400 \& 1000$ & Frequency $(\mathrm{Hz})$ & 1000 \\
\hline Nominal Value $(\mathrm{pF})$ & & & Nominal Value $(\mathrm{pF})$ & \\
\hline 0.001 & & 2000 & 1 & 840 \\
\hline 0.01 & 1500 & 200 & 2 & 420 \\
\hline 0.1 & 230 & 100 & 5 & 200 \\
\hline 1 to 1000 & 100 & 100 & 10 & 100 \\
\hline \multirow[t]{6}{*}{10000} & & 150 & 20 & 75 \\
\hline & & & 50 to 1000 & 60 \\
\hline & & & 5000 to 10000 & 65 \\
\hline & & & (Open-Circuit Terminations) & \\
\hline & & & 0.172 & 1000 \\
\hline & & & 2.67 & 450 \\
\hline
\end{tabular}


Table 9. Calibration Uncertainties of Capacitance Values of Two- and Three-Terminal Mica-Dielectric Standard Capacitors

\begin{tabular}{|c|c|c|c|c|}
\hline \multicolumn{5}{|c|}{ Expanded Uncertainties of Capacitance (ppm) } \\
\hline Configuration & \multicolumn{2}{|c|}{ Two-Terminal } & \multicolumn{2}{|c|}{ Three-Terminal } \\
\hline Frequency (Hz) & $66,100,400$, and 1000 & 10000 & $66,100,400$, and 1000 & 10000 \\
\hline Nominal Value $(\mu \mathrm{F})$ & & & & \\
\hline 0.001 & 180 & 180 & 120 & 120 \\
\hline 0.002 & 120 & 120 & 100 & 100 \\
\hline 0.005 & 120 & 120 & 100 & 100 \\
\hline 0.01 & 120 & 120 & 100 & 100 \\
\hline 0.02 & 120 & 120 & 100 & 100 \\
\hline 0.05 & 120 & 120 & 100 & 120 \\
\hline 0.1 & 120 & 150 & 100 & 150 \\
\hline 0.2 & 120 & 250 & 100 & 250 \\
\hline 0.5 & 120 & 500 & 100 & 500 \\
\hline 1 & 120 & 1000 & 120 & NA \\
\hline
\end{tabular}


Table 10. Calibration Uncertainties of Conductance Values of Two- and Three-Terminal Mica-Dielectric Standard Capacitors

\begin{tabular}{|c|c|c|c|}
\hline \multicolumn{4}{|c|}{ Expanded Uncertainties of Conductance $(\mu S)$} \\
\hline Frequency $(\mathrm{Hz})$ & $66 \& 100$ & $400 \& 1000$ & 10000 \\
\hline Nominal Value $(\mu \mathrm{F})$ & & & \\
\hline 0.001 & 0.0003 & 0.0005 & 0.001 \\
\hline 0.002 & 0.0003 & 0.0007 & 0.002 \\
\hline 0.005 & 0.0003 & 0.0007 & 0.005 \\
\hline 0.01 & 0.0004 & 0.0009 & 0.01 \\
\hline 0.02 & 0.0005 & 0.003 & 0.02 \\
\hline 0.05 & 0.0009 & 0.005 & 0.1 \\
\hline 0.1 & 0.002 & 0.015 & 0.2 \\
\hline 0.2 & 0.005 & 0.04 & 0.7 \\
\hline 0.5 & 0.008 & 0.13 & 5 \\
\hline 1 & 0.02 & 0.3 & $\begin{array}{c}15 \\
\text { (two-terminal only) }\end{array}$ \\
\hline
\end{tabular}




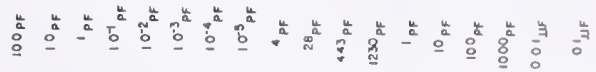

$$
\begin{aligned}
& \text { u }
\end{aligned}
$$

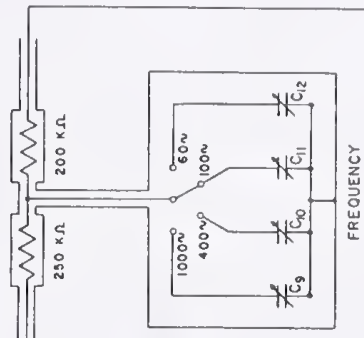

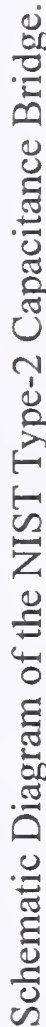

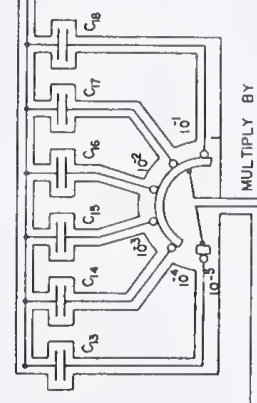

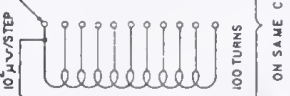

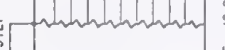
* Celleves a 9909090900 รั้ 育 Cevedebe

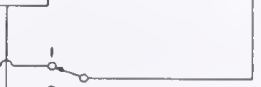

$$
\left(\begin{array}{c}
n \\
\frac{2}{2} \\
\frac{2}{2} \\
8 \\
0
\end{array}\right.
$$

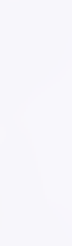




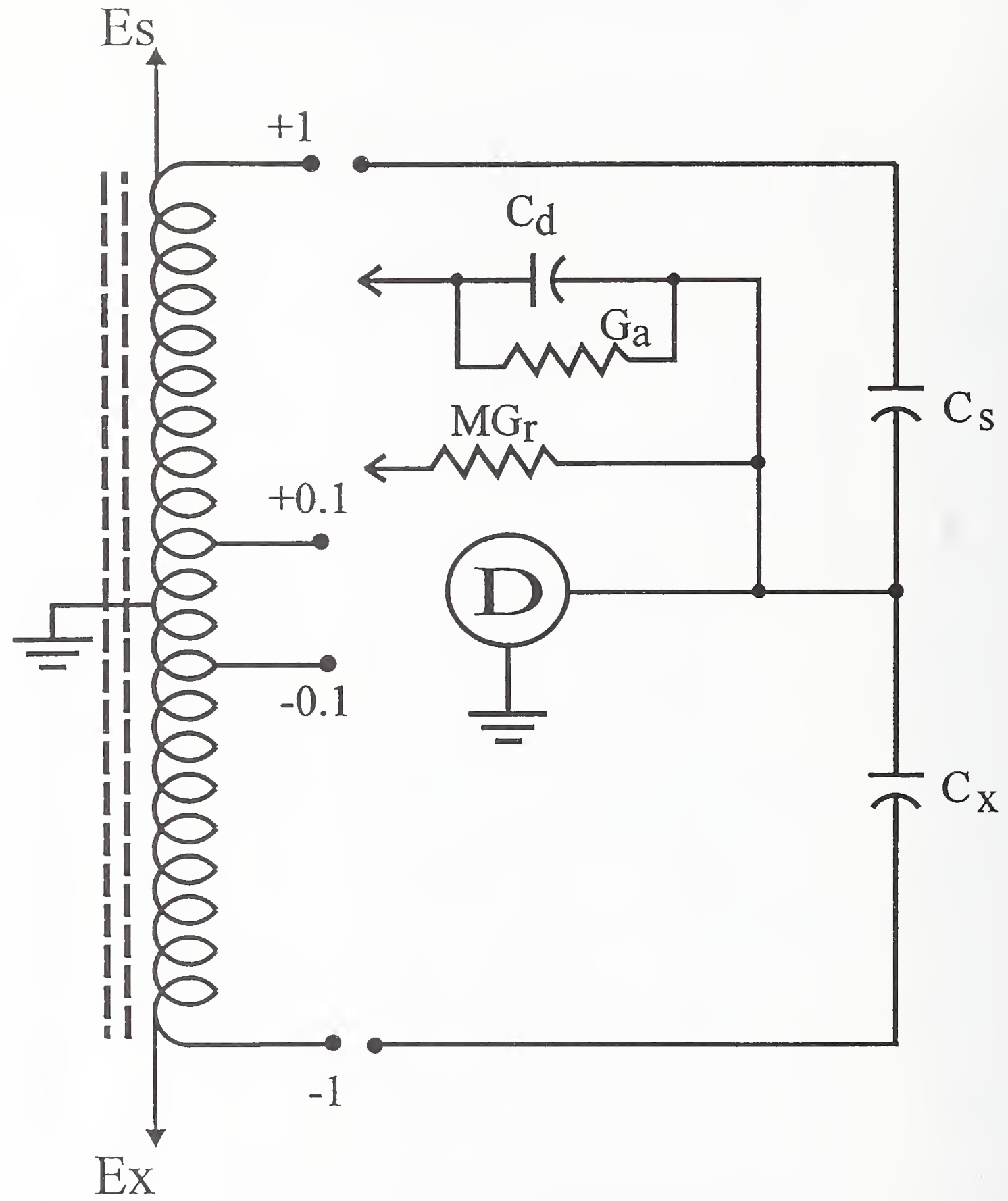

Figure 1b. Simplified Circuit Diagram of the NIST Type-2 Capacitance Bridge. 


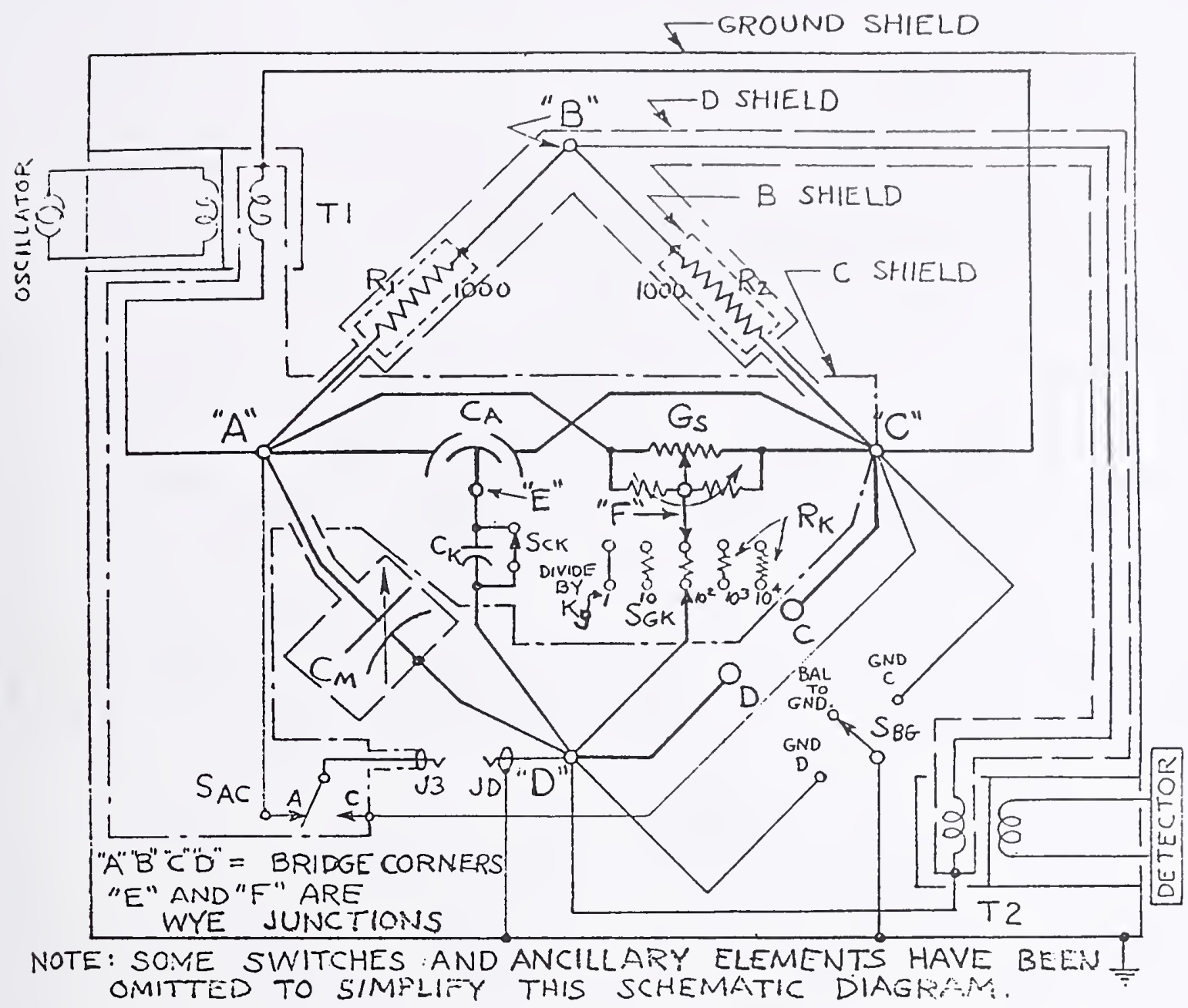

$C_{A}$ : AIR CAPACITOR $10 \times(1000,100,10)$ PF + 10 PF DIFFERENTIAL CONTINUOUS.

$C_{K}$ : DIVIDE-BY-TEN CAPACITOR: 600PF OR 10OPF (SER. NOS. ADOVE 1100,000$)$

CM: MICA CAPACITANCE STD $10 \times(0.1,0.01)$ UF

GS: CONDUCTANCE STAINAARD: $10 \times(100,10)$ UMHO + $1-11$ UNIHO

RK: CONDUCTANCE DIVIDER RESISTOÓS: $0,1800,19800 \Omega ; 0.1978 \varepsilon 2$ MEGS.

RI,R2 : 1000-DHM RATIO ARMIS

(DIVIOE GS BY, $1,10,10^{2}, 10^{3}, 10^{4}$ )

$S_{A C}$ : DIRECT CAPACITANCE A-OR-C SWITCH

SGK: GONDUGTAIUEE. DIVIDER SWITCH SCK CAPACITANGE DIVIDER SWITCH

$S_{B G}$ : BALANCE OR GPDLND SWITH'

T1, T2: D- $17963220 \mathrm{~Hz}-200 \mathrm{kHZ}$ DOUHLE-SHIELOED TKANGFORMERS (D-15:-7.90 200 Hz-200 kHz IN BRIDGES BEFORE W-10iis-ij)

$C, D:$ TEST TERMINALS.

J3,JD: DIRECT CAPAEITANCE TEST JAC:YS.

\begin{tabular}{|c|c|c|}
\hline ISSUE $/ 9 / 15 / 67 \mathrm{fi}$ & ENGR & TITLE NO. 12- \\
\hline 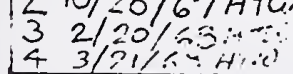 & 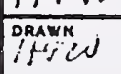 & SIMPLIFIED SCHEMATIC \\
\hline
\end{tabular}

Figure 2a. Schematic Diagram of the NIST Type-12 Capacitance Bridge. 


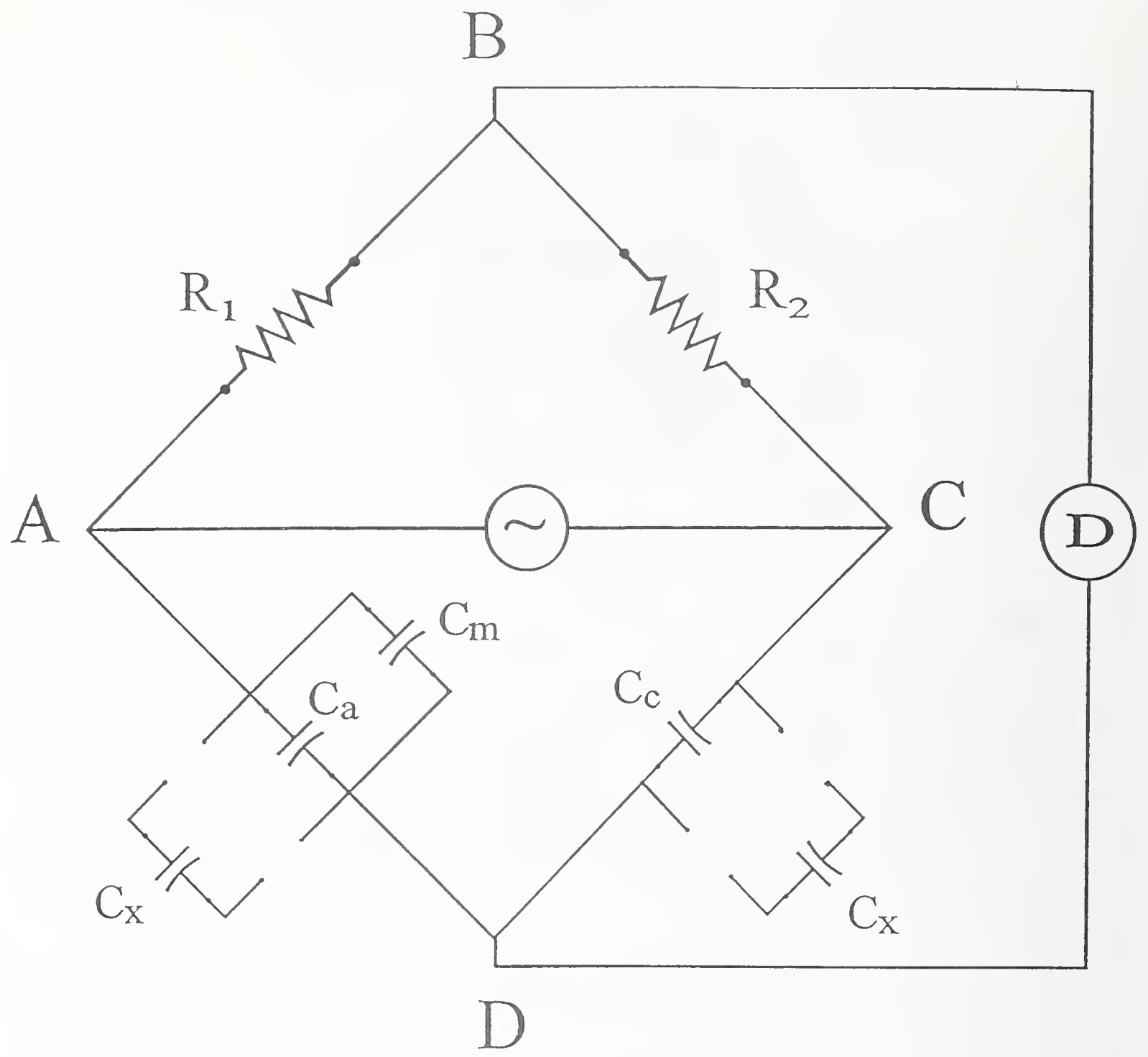

Figure 2b. Simplified Circuit Diagram of the NIST Type-12 Capacitance Bridge. (Generally Showing only the Capacitance Components) 


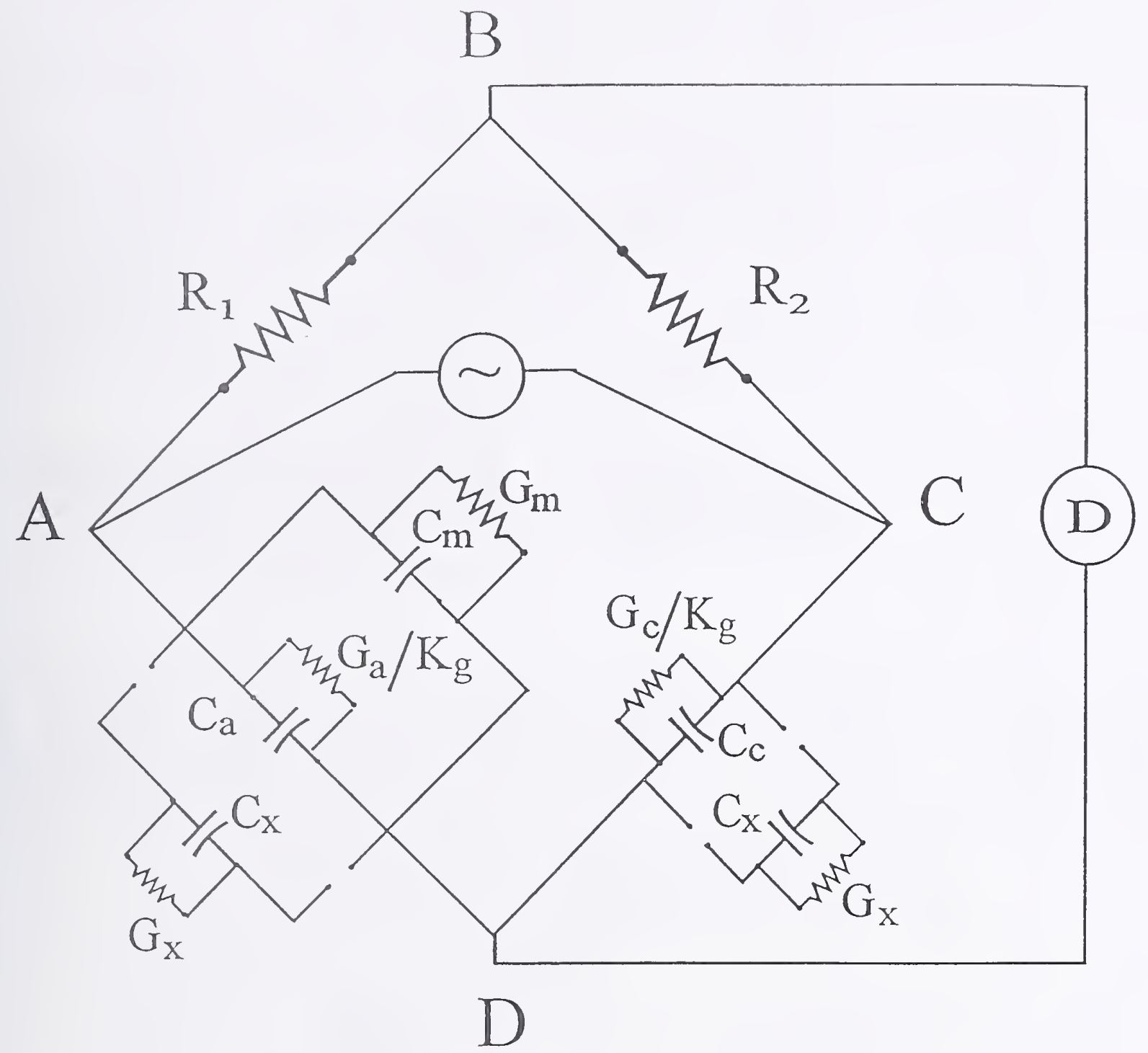

Figure 3. The NIST Type-12 Capacitance Bridge with Conductance Components. 


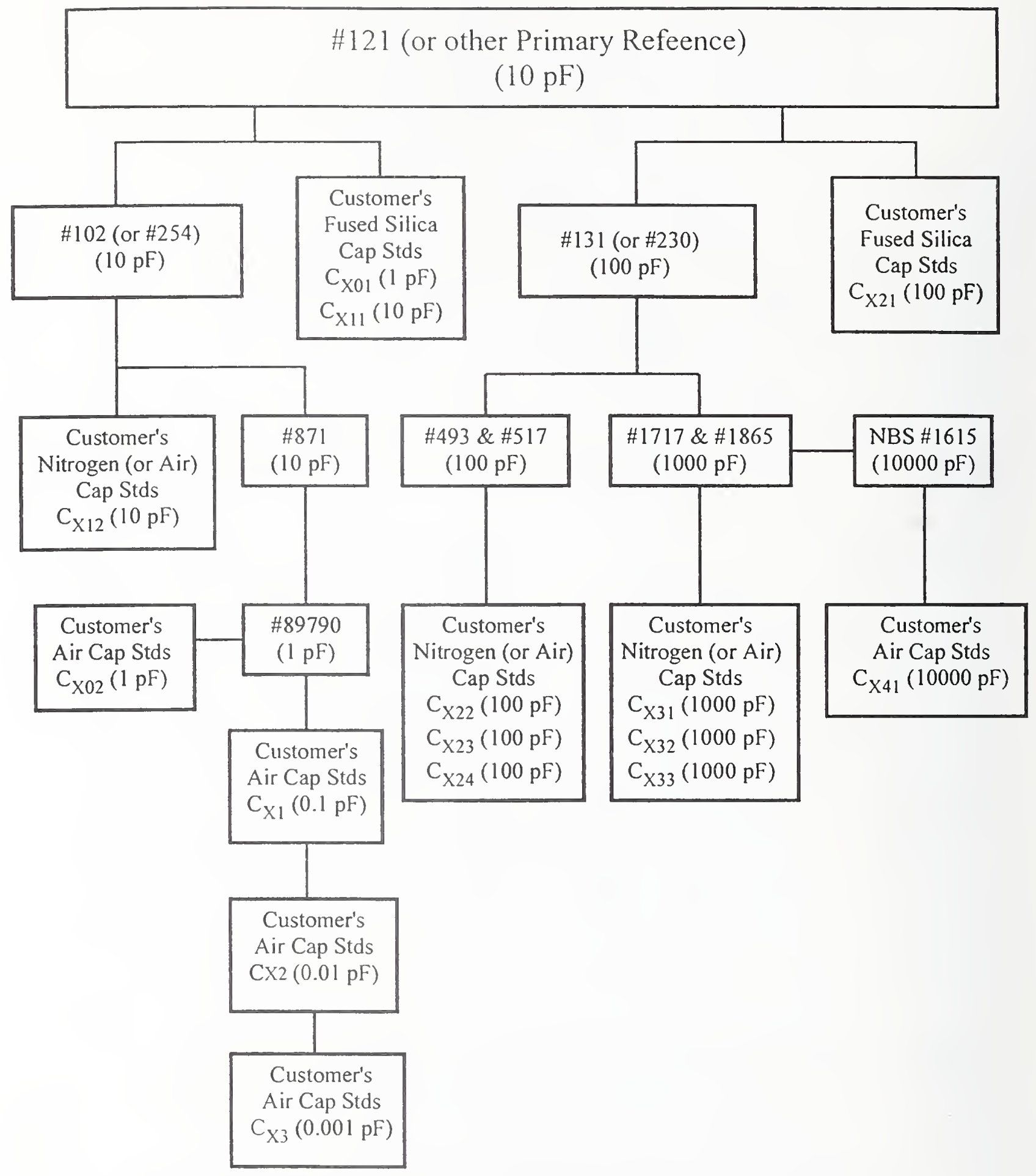

Figure 4. Block Diagram of Measurement Process and Standards being Used In the Impedance Calibration Laboratory. 


\section{NIST REFERENCE ADAPTER}

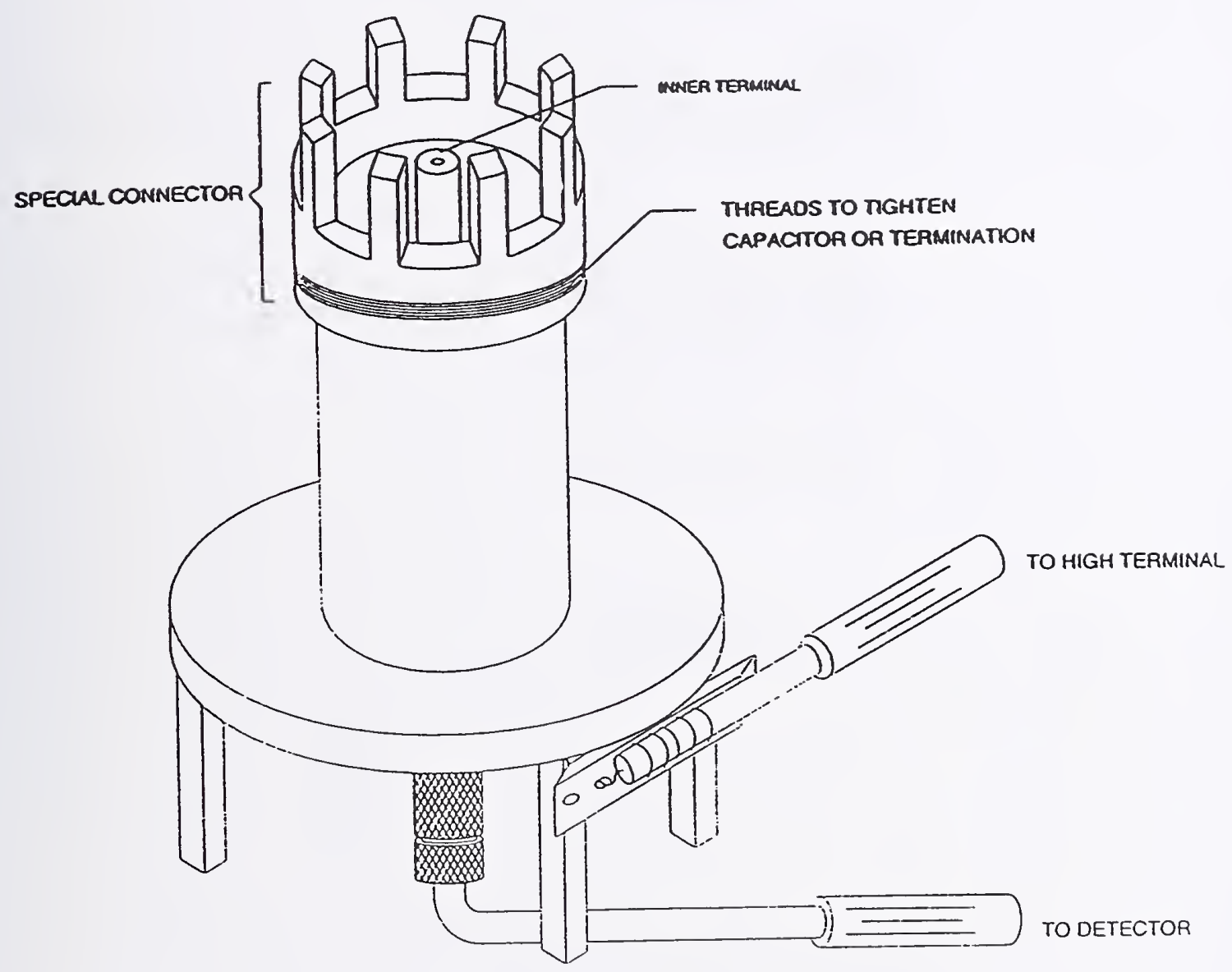

Figure 5. NIST Reference Adapter for Two-Terminal HF Coaxial Connector Capacitors. 


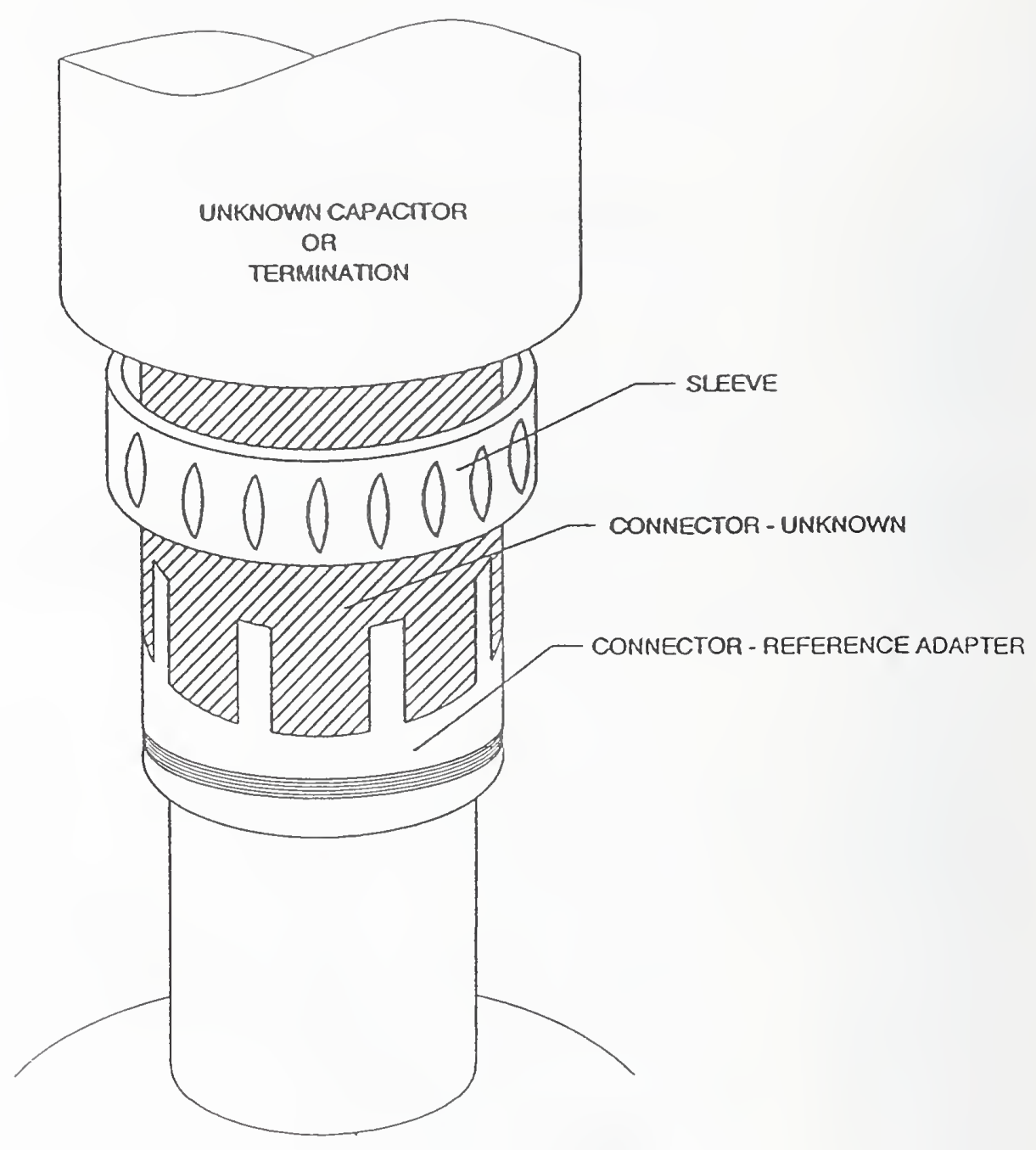

Figure 6. Connection of Reference Adapter and HF Coaxial Connector Capacitors 


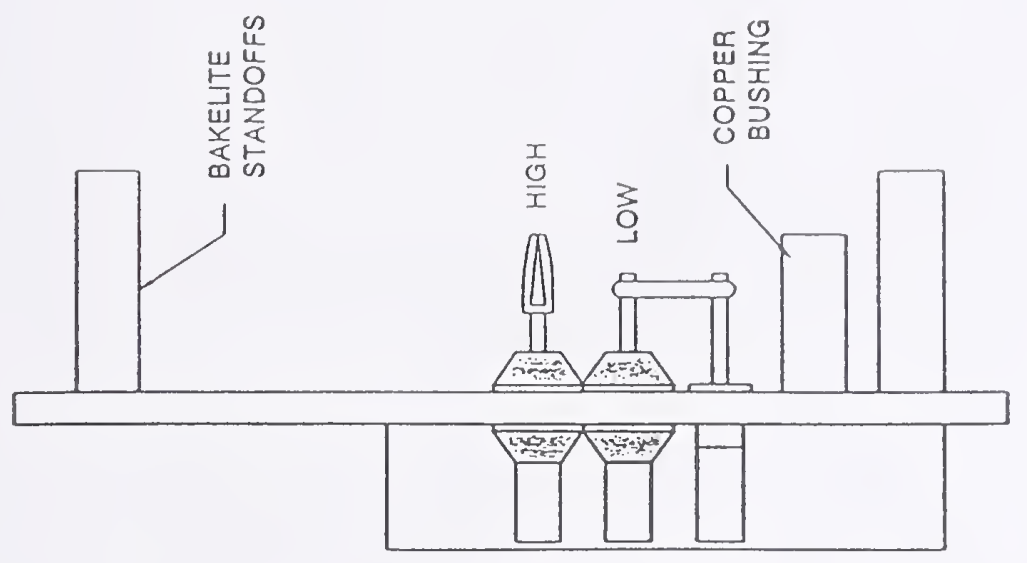

站
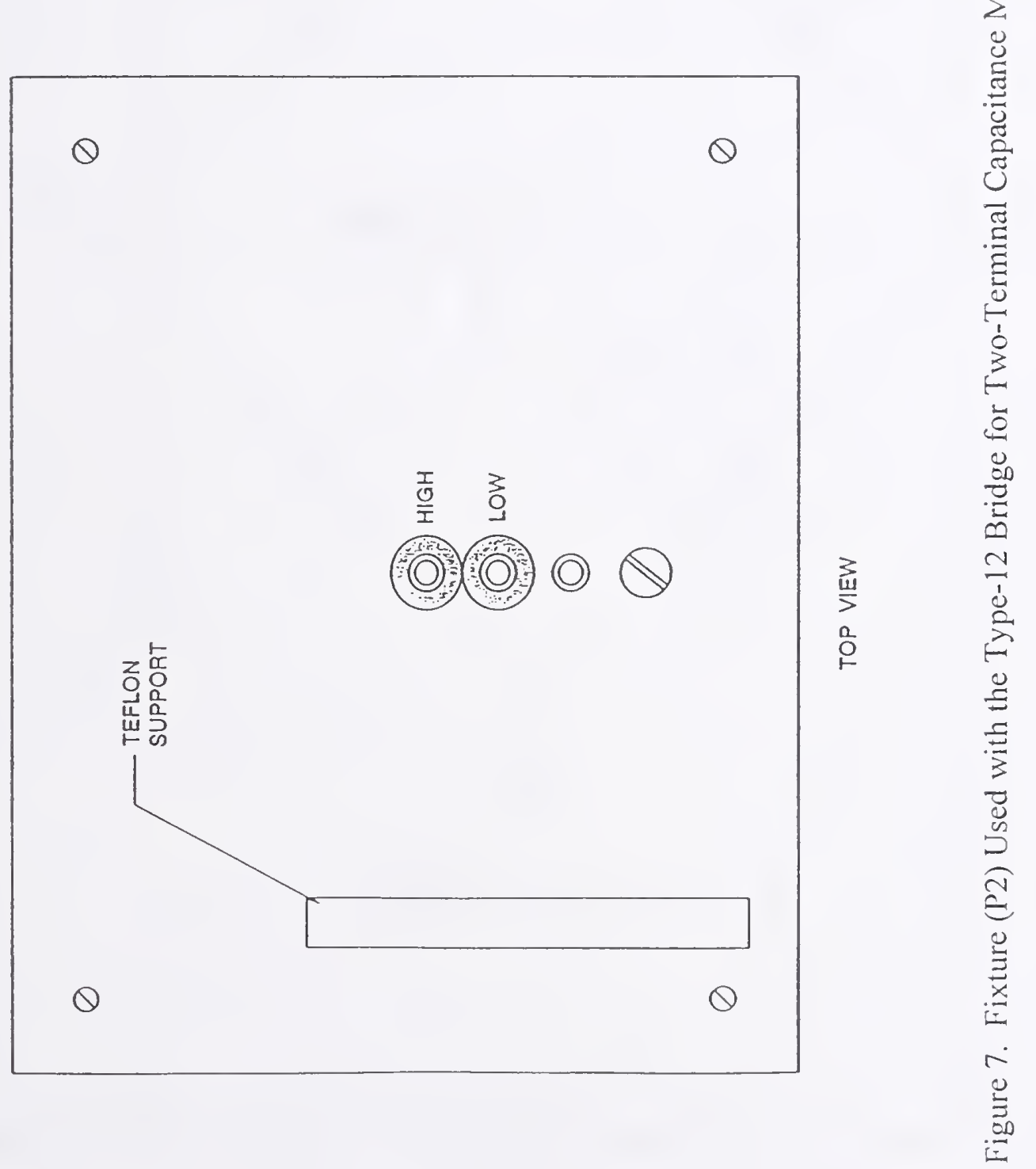


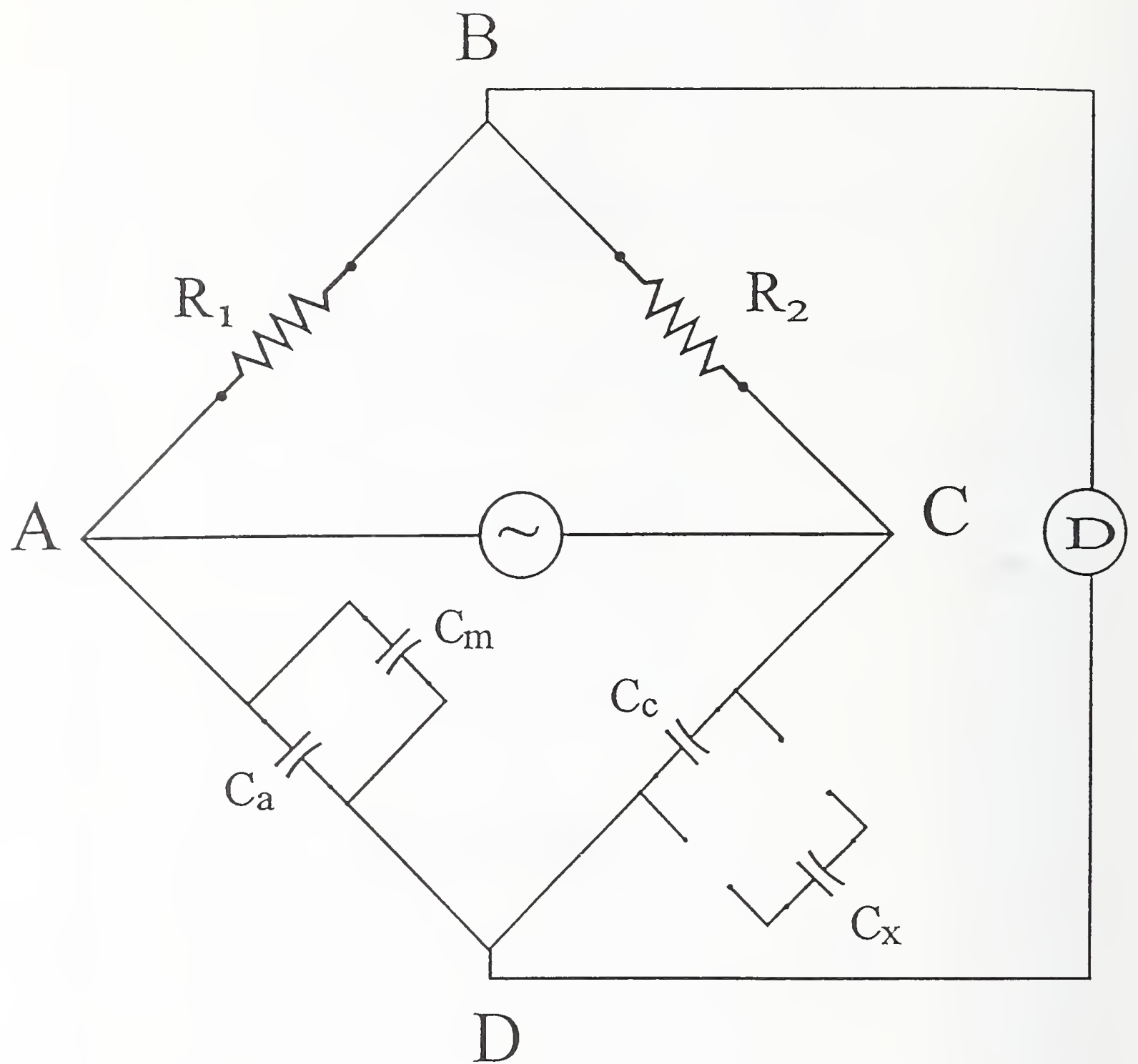

Figure 8. Components of the Type-12 Bridge for Two-Terminal Capacitance Measurements. 

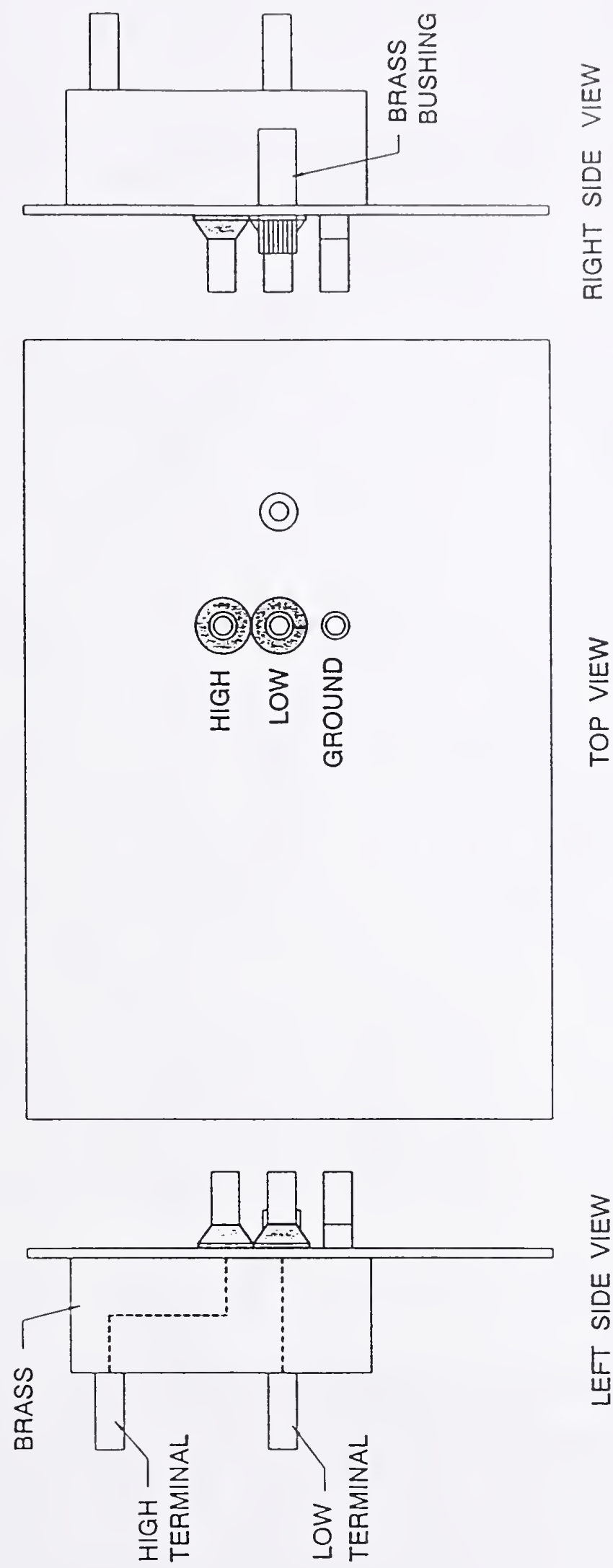

$\stackrel{3}{3}$

荡 


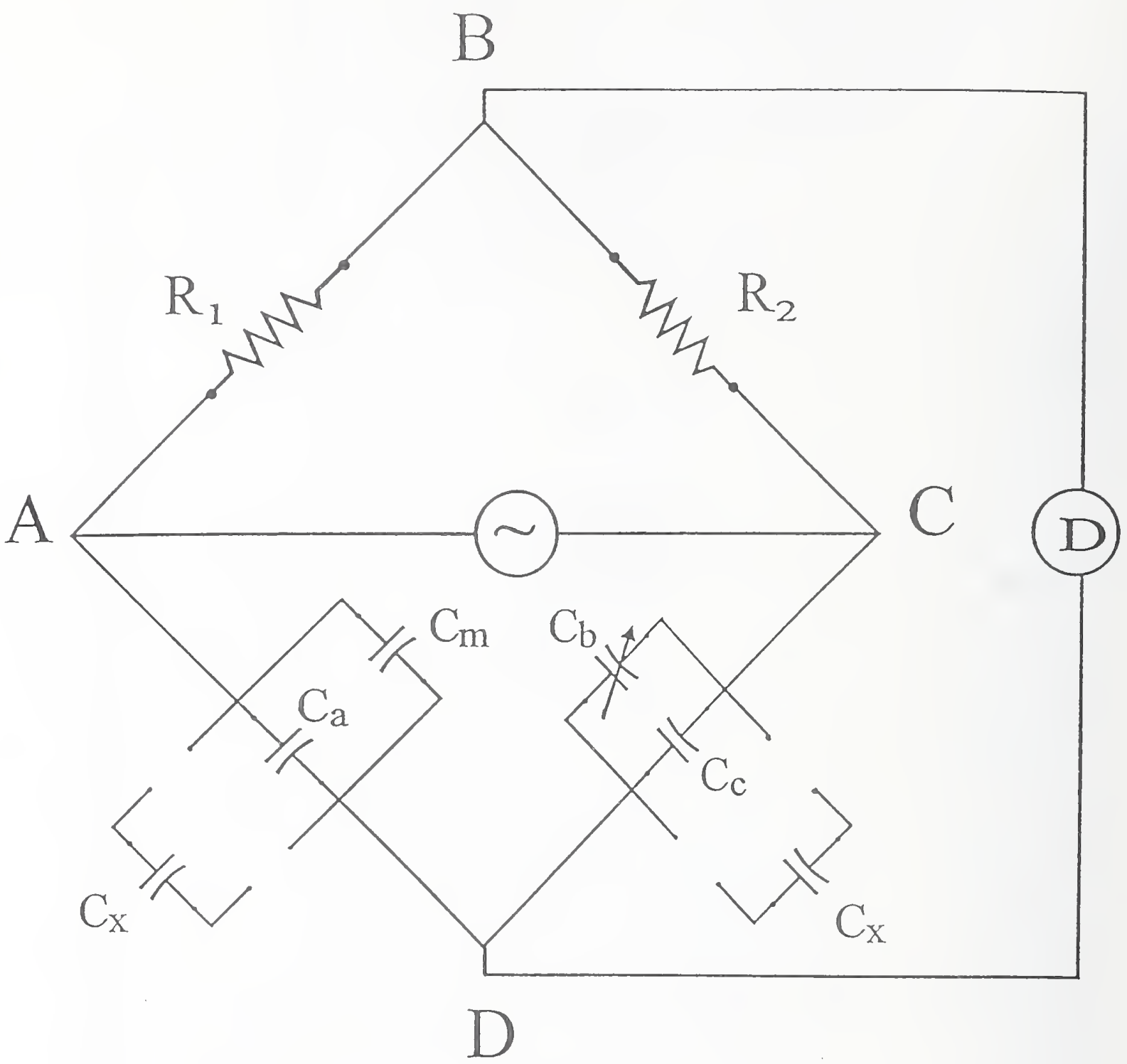

Figure 10. Components of the Type-12 Bridge for Three-Terminal Capacitance Measurements. 


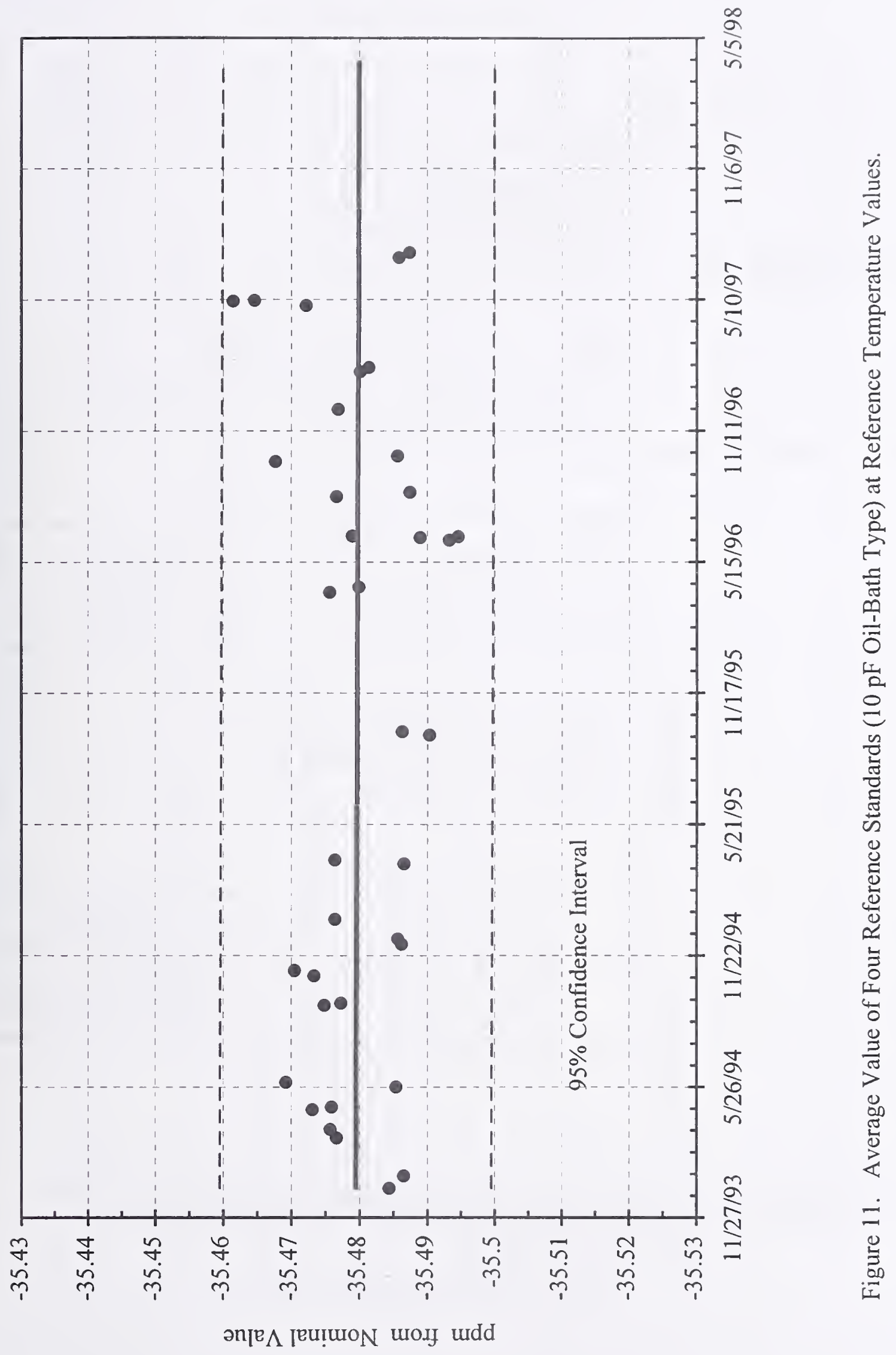




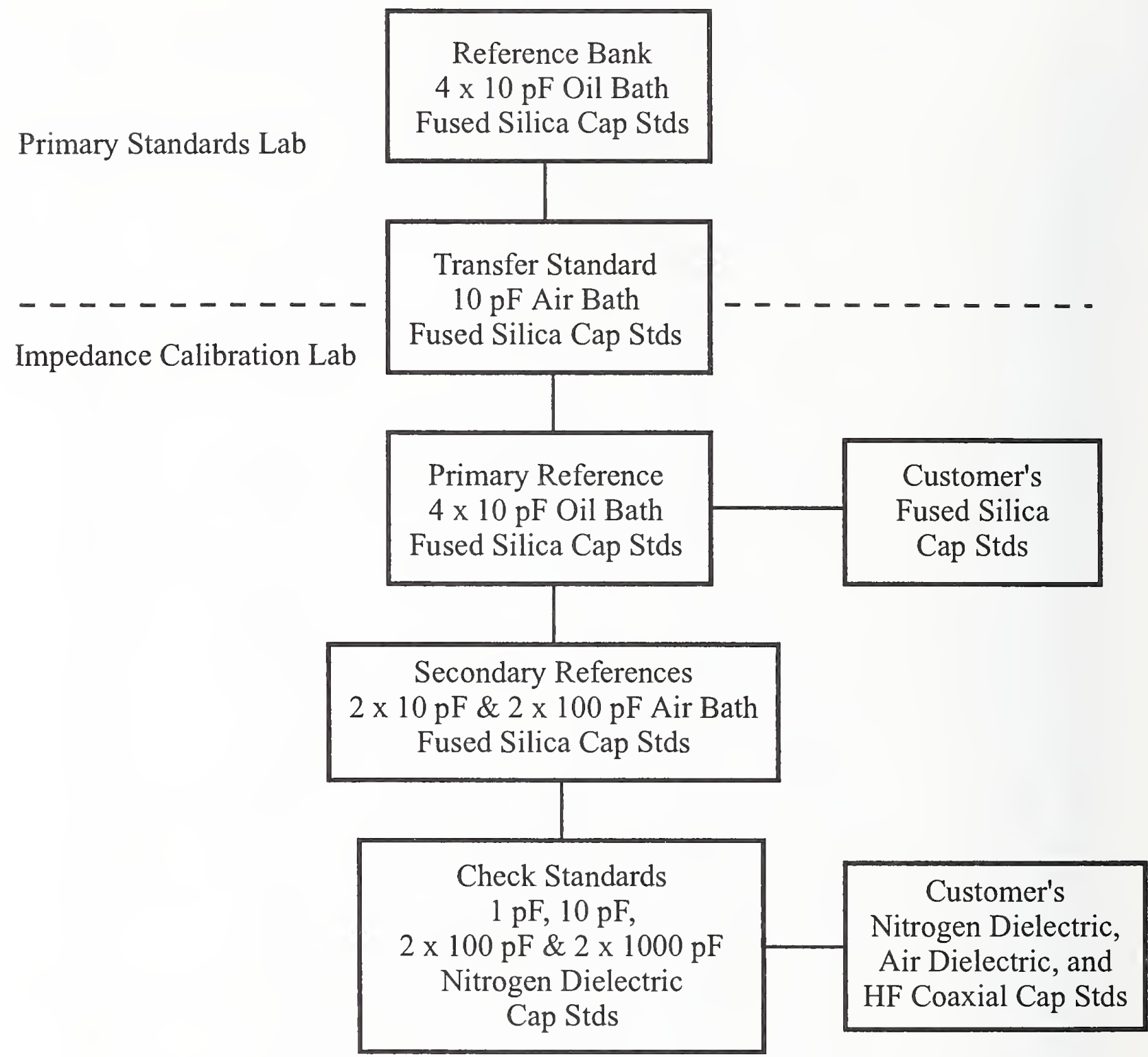

Figure 12. Block Diagram of the Farad Transfer and Calibration Process Using the Type-2 Bridge. 


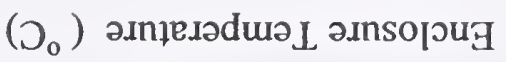

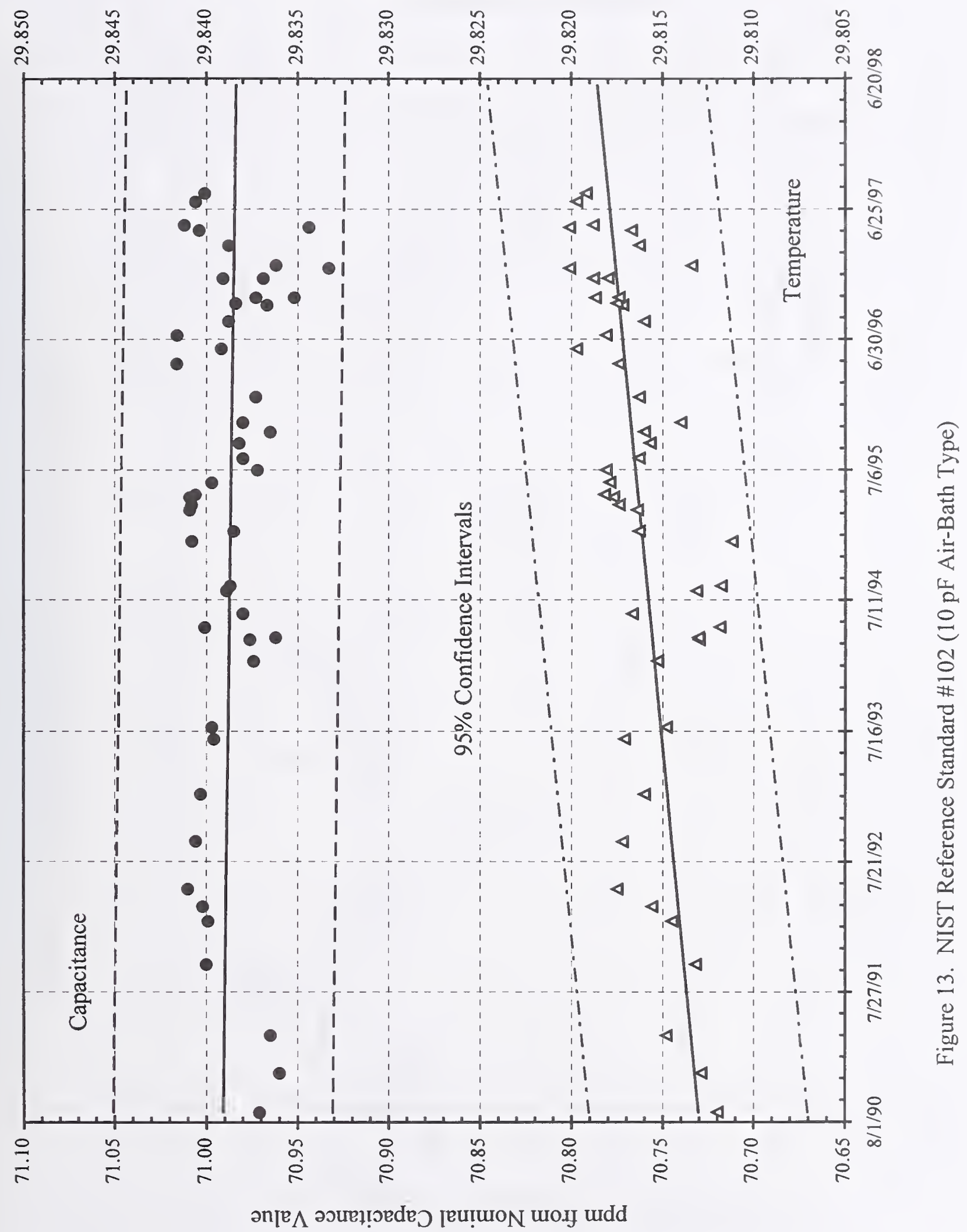




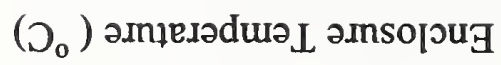

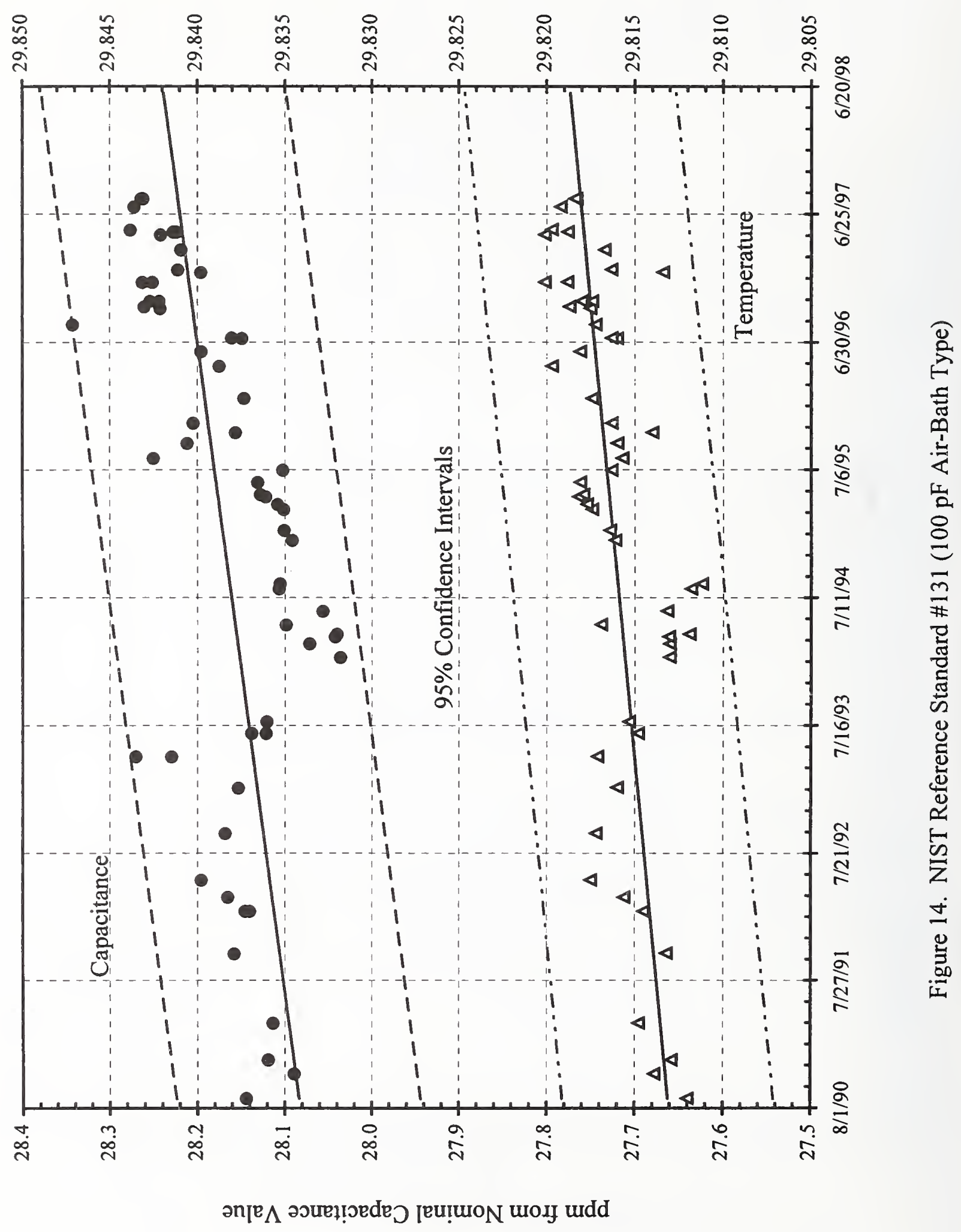




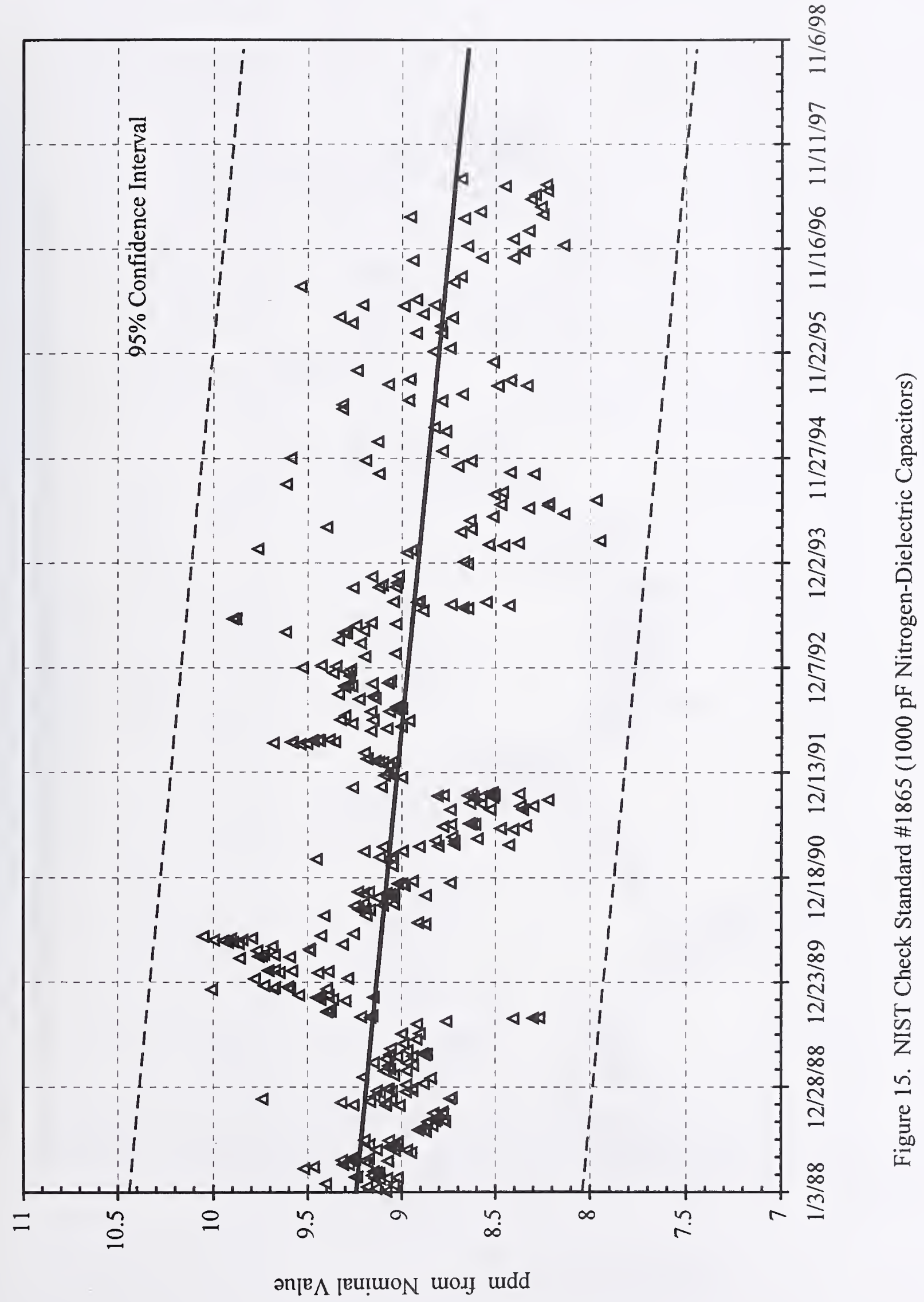




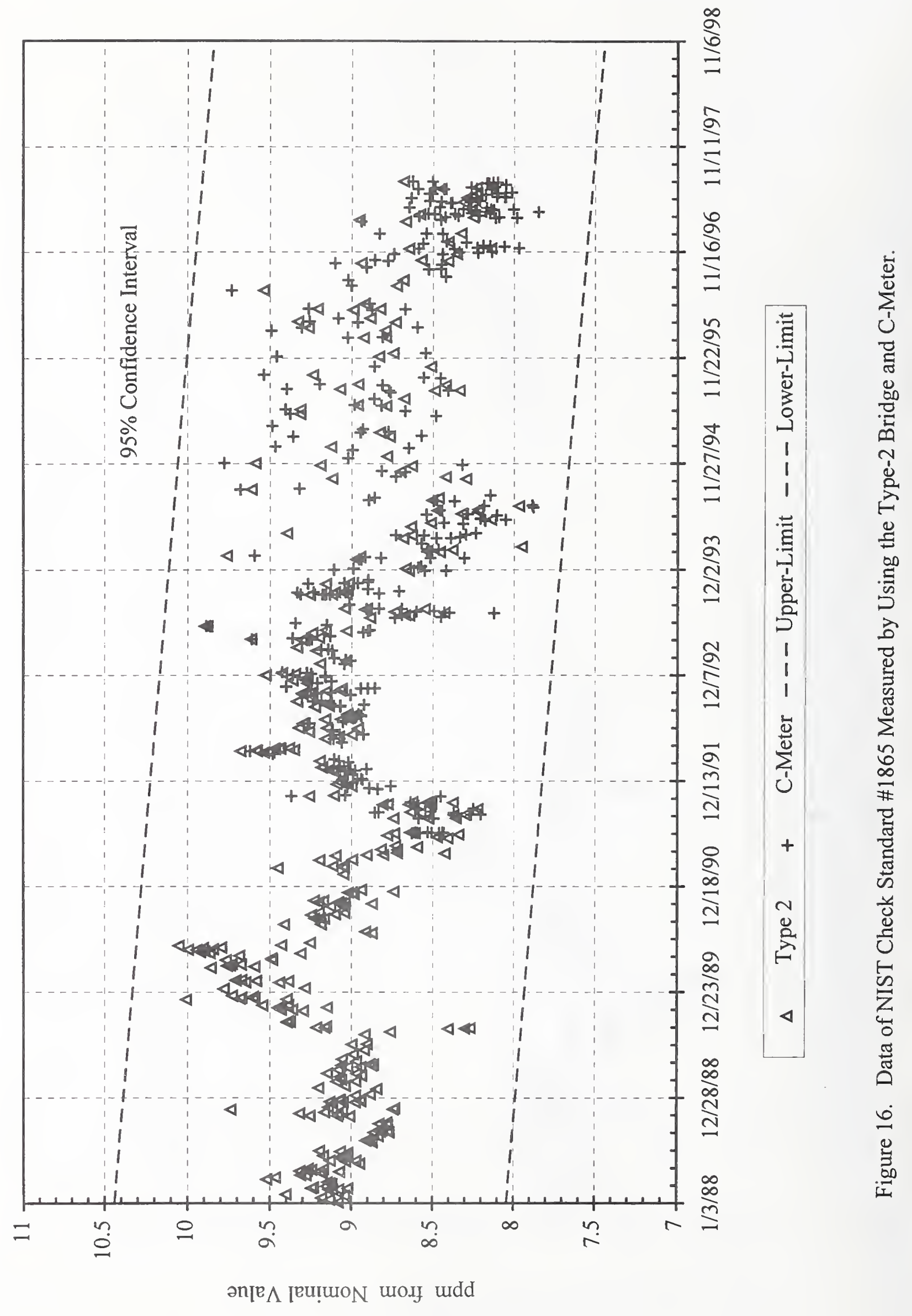




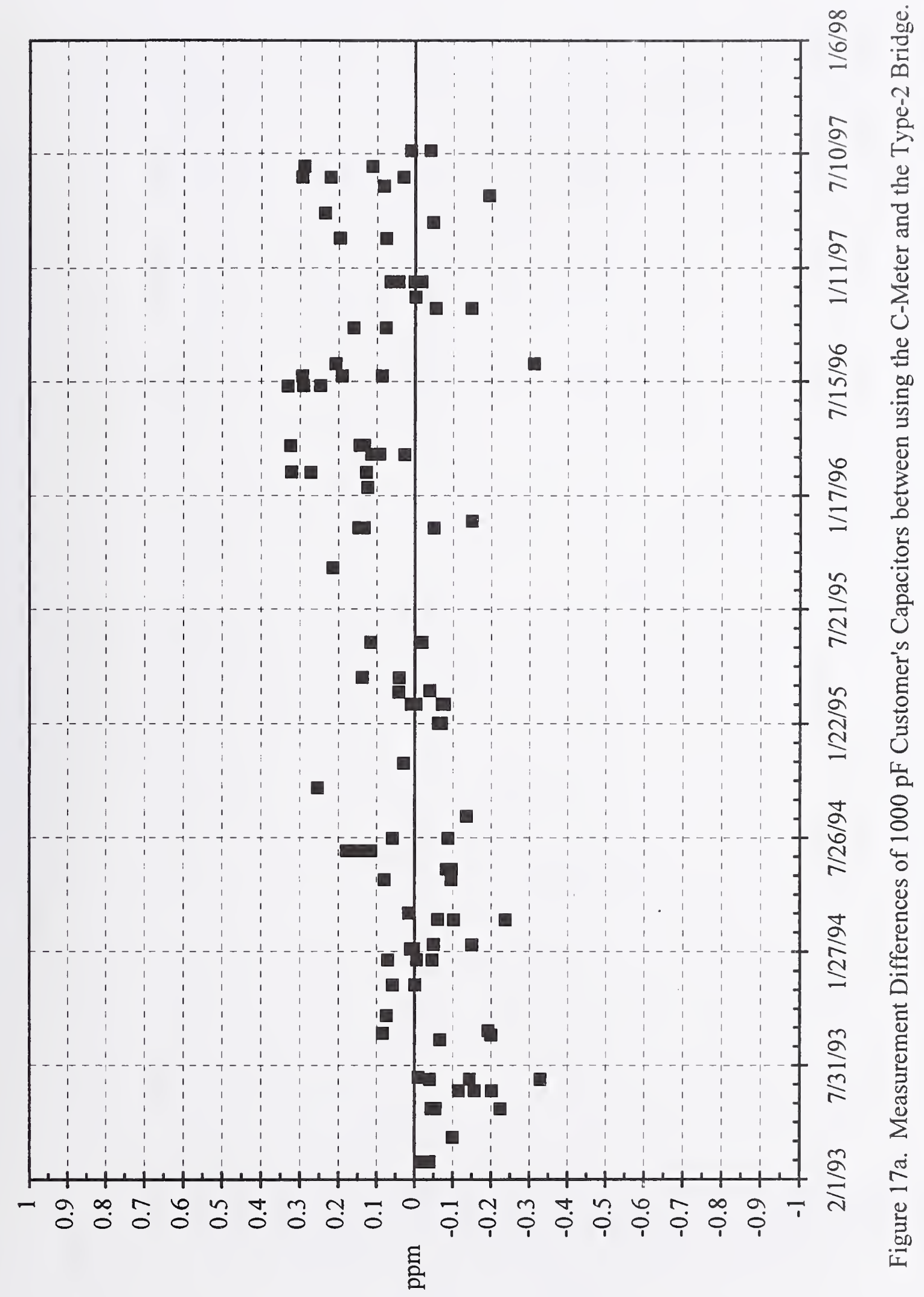




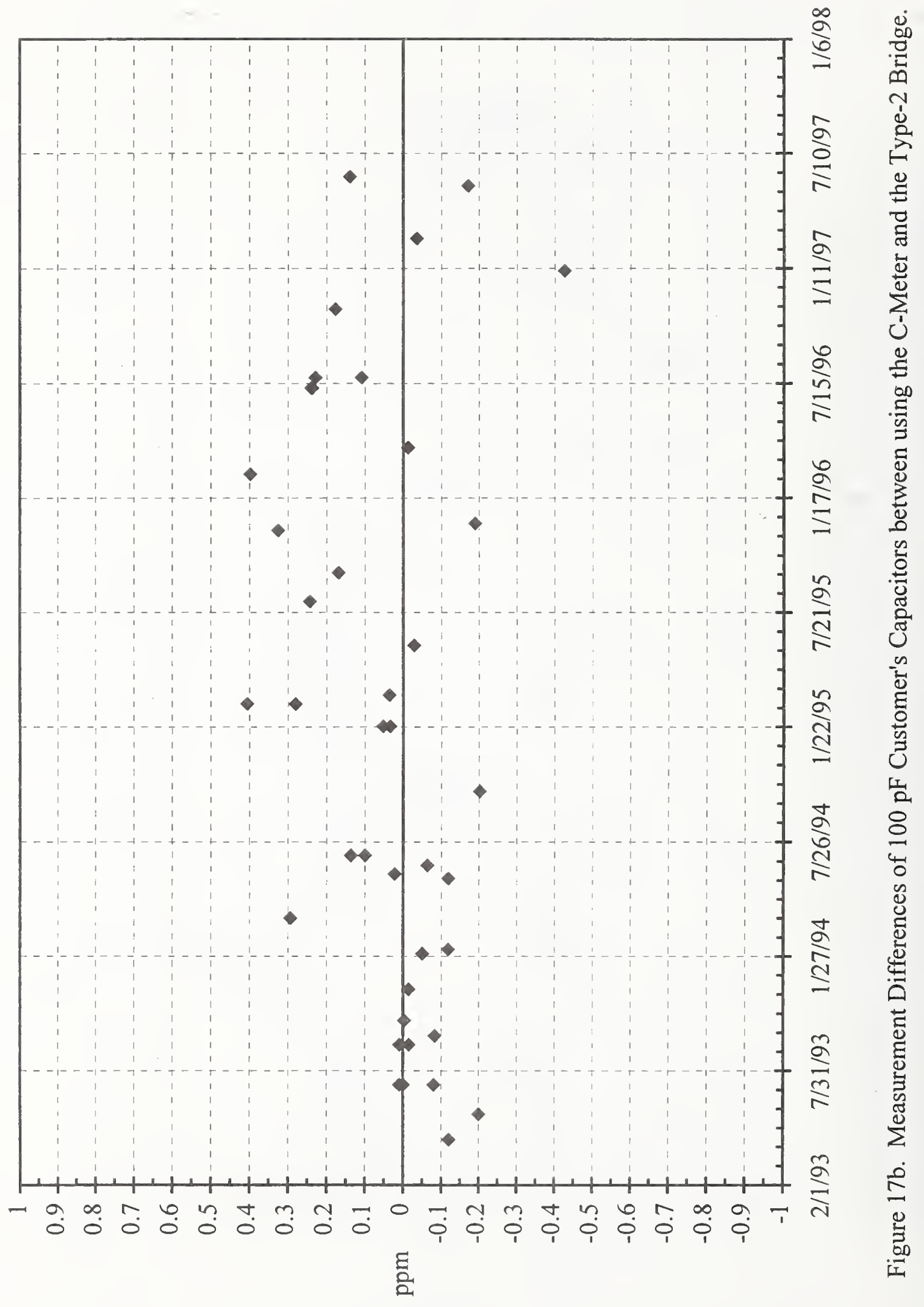




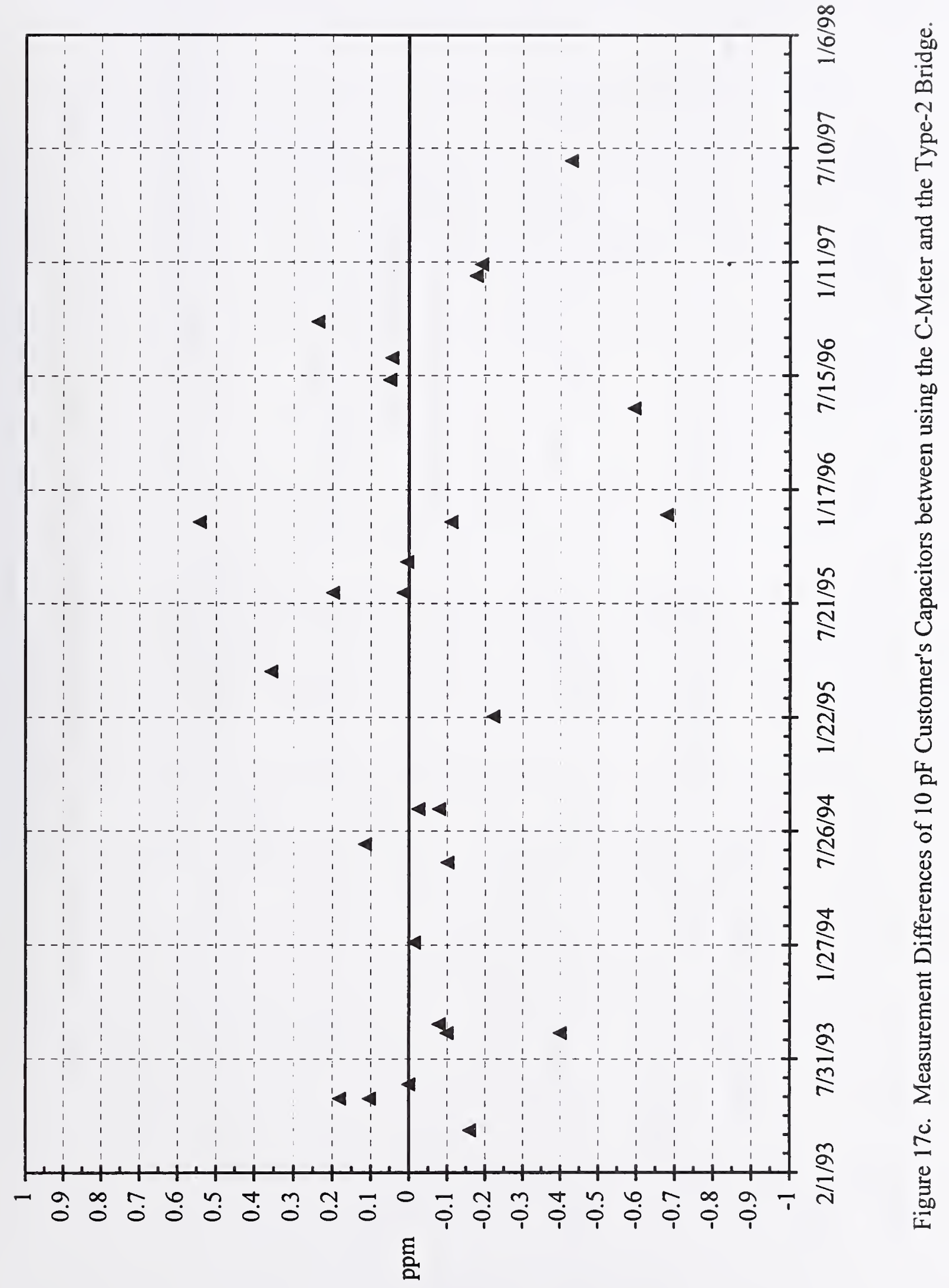




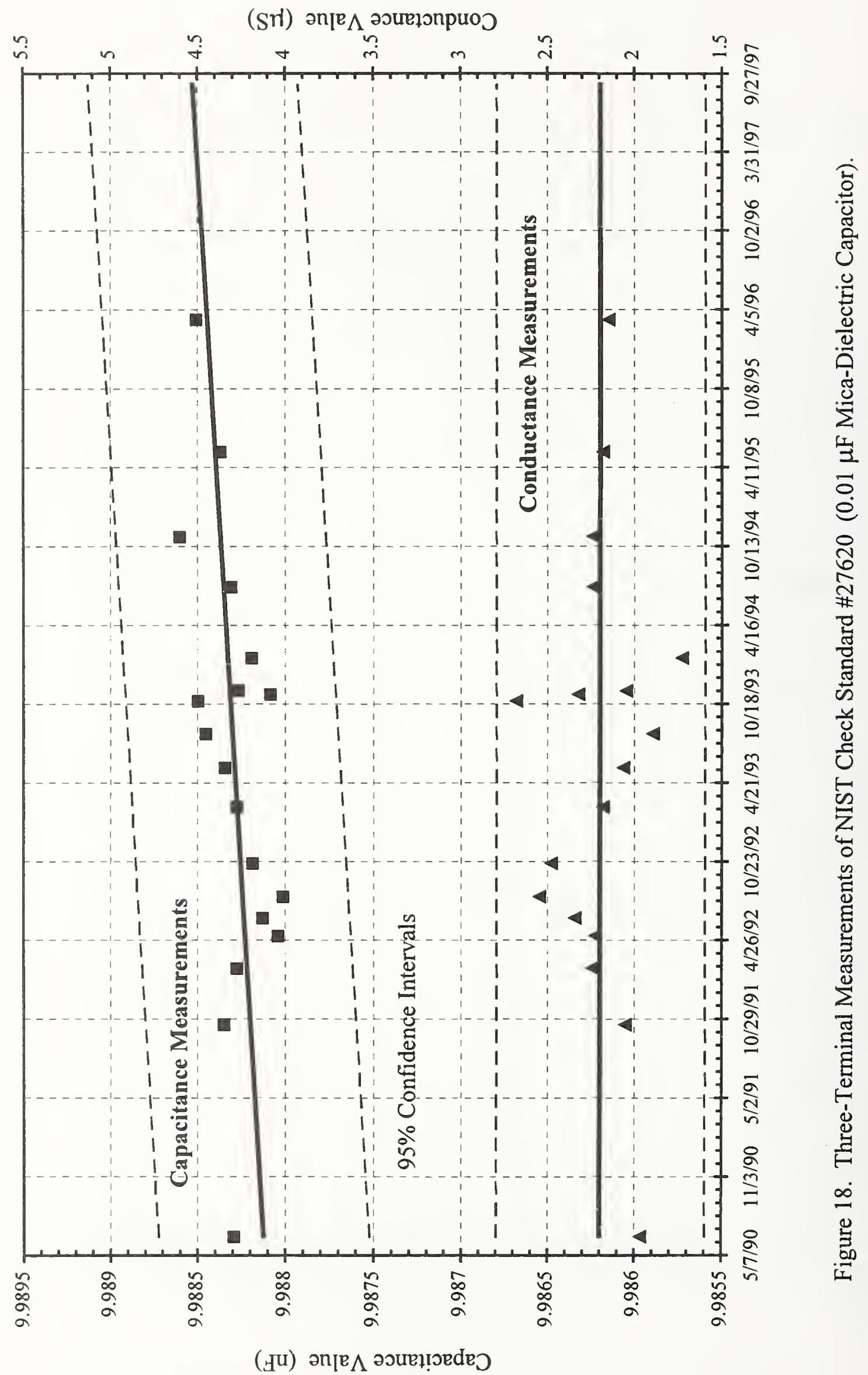




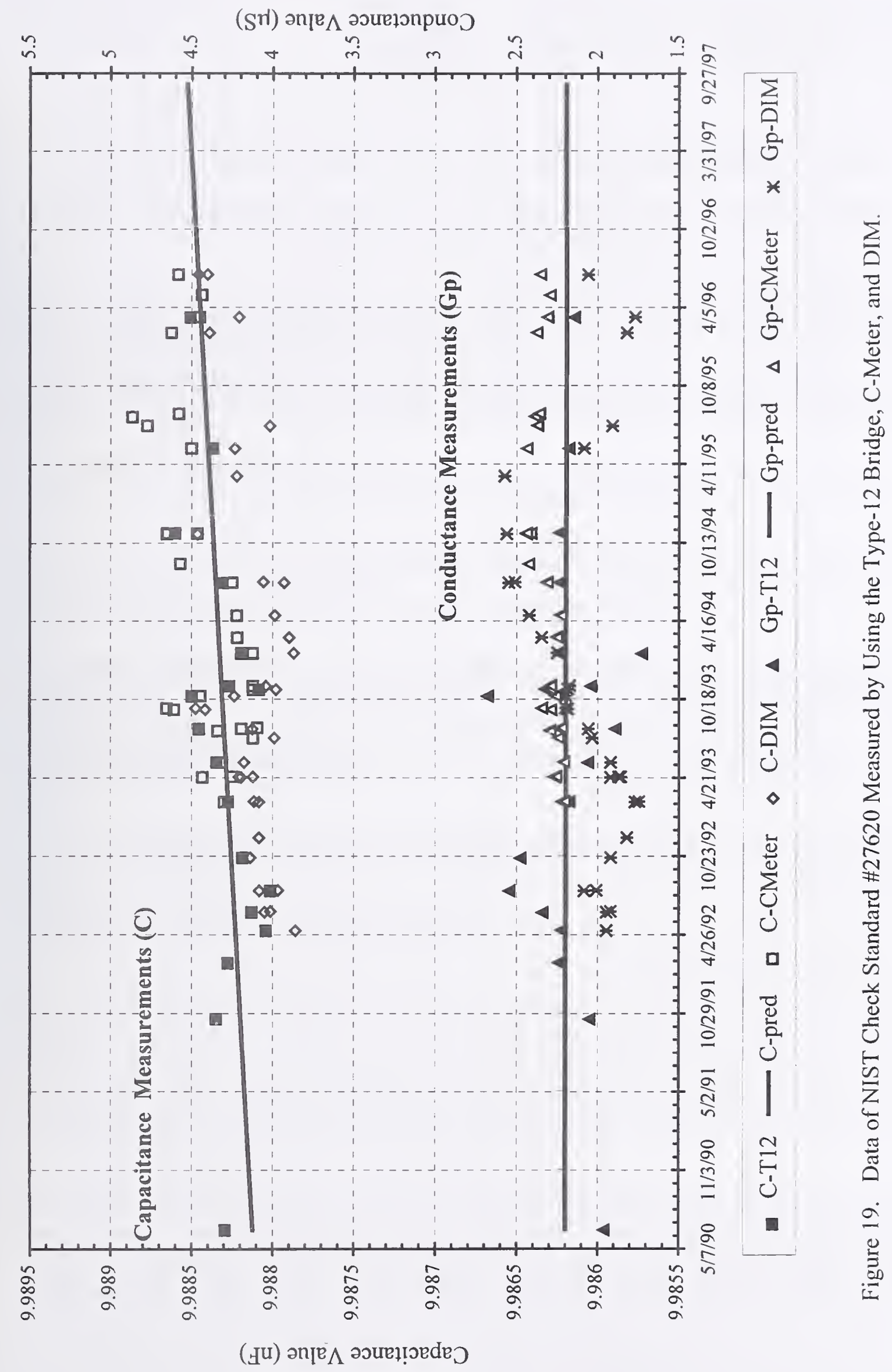




\section{APPENDIX}

A1. General Information on Fused-Silica-Dielectric Standard Capacitors.

A2. Typical REPORT OF CALIBRATION for Fused-Silica-Dielectric Standard Capacitors.

A3. General Information on Nitrogen-Dielectric Standard Capacitors.

A4. Typical REPORT OF CALIBRATION for Nitrogen-Dielectric Standard Capacitors.

A5. Description of Tests used to Determine the Effect of Small Mechanical Stress on High Stability, Nitrogen-Dielectric Standard capacitors.

A6. Typical REPORT OF CALIBRATION for Test Results of the Effect of Small Mechanical Stress on Nitrogen-Dielectric Standard Capacitors.

A7. General Information on Three-Terminal Standard Capacitors.

A8. Typical REPORT OF CALIBRATION for Three-Terminal Standard Capacitors.

A9. General Information on Two-Terminal Standard Capacitors with Precision Coaxial Connectors.

A10. Typical REPORT OF CALIBRATION for Two-Terminal Standard Capacitors with Precision Coaxial Connectors.

A11. General Information on Mica-Dielectric Standard Capacitors with Binding Post Connectors.

A12. Typical REPORT OF CALIBRATION for Mica-Dielectric Standard Capacitors with Binding Post Connectors. 


\section{Representation of the Unit of Capacitance}

As a result of new absolute measurements of the farad in terms of the units of length and time, the legal unit of capacitance was established at NIST/NBS in 1975 [1], and re-established in 1989 [2]. The reported values of capacitance since that time reflect the values assigned to NIST standards used for the maintenance of the legal unit. Since 1989, the difference between the NIST unit, which includes an allowance for possible drift, and the farad is believed to be no greater than $\pm 0.1 \mathrm{ppm}$.

\section{Fused-Silica Dielectric Standard Capacitors}

Three-terminal standard capacitors of fused-silica dielectric are calibrated with a NIST transformer bridge [3] using NIST fused-silica 10-pF capacitors [4] as reference standards. Capacitance is measured by intercomparison with the reference standards in a least squares design.

The measured capacitances are the mean of the results of several measurements of direct capacitance with the capacitor connected to the NIST transformer bridge as a two-terminal-pair admittance [5]. If the terminals of the capacitor are not two-terminal-pair, connections with negligible impedance are made to make them so. All capacitors must be in the calibration laboratory for 72 hours or more before measurements are performed.

The temperature of an air-bath type fused-silica capacitor is obtained by means of a platinum resistance thermometer placed in the well of the bath. The Type B uncertainty of the measured temperatures is estimated to be $0.002{ }^{\circ} \mathrm{C}$. The bridge used in measuring the resistance of the thermometer has a limiting resolution of $0.0001^{\circ} \mathrm{C}$.

The average ambient temperature of the laboratory is $23^{\circ} \mathrm{C} \pm 1{ }^{\circ} \mathrm{C}$ with hourly variations of about $0.1^{\circ} \mathrm{C}$. The variation of the ambient temperature may affect the temperature of the air-bath, which determines the value of a capacitor. Therefore, for best accuracy in the use of this type of capacitors, corrections for the capacitance value are required if the temperature of the air-bath is changed significantly. If it is not possible to apply corrections for the temperature differences, the magnitude of the errors usually can be estimated from information supplied by the manufacturer, and the uncertainty in the measurement increased accordingly.

The limiting resolution at $1000 \mathrm{~Hz}$ of the NIST transformer bridge and detector is $0.02 \mathrm{ppm}$. This is larger than the change of capacitance corresponding to the limiting resolution of the temperature measurement, which is equivalent in capacitance to $0.0012 \mathrm{ppm}$. Therefore, if the standard deviation of the average temperature is expressed as a change in capacitance, then it may be smaller than the 
standard deviation of the measured capacitance by an order of magnitude or more.

The reported value of capacitance is in terms of the NIST unit of capacitance maintained with a group of stable standards [4]. The expanded uncertainties include allowance for both Type A and Type B uncertainties in the chain of calibration measurements, and are assigned to the capacitance values using the coverage factor $k=2$ [6]. These do not include any uncertainties that may be associated with long term instability, temperature hysteresis, changes due to stresses incurred during shipment, and long term drift of the temperature of the enclosure of the air-bath type, fused-silica capacitors.

Measurements of three-terminal coaxial standard capacitors are not made at frequencies exceeding $1 \mathrm{kHz}$ because of limitations in the present NIST measurement apparatus. Depending upon the construction and presence of films, the frequency dependence of the capacitors considered here ranges from $1 \mathrm{ppm}$ to about $10 \mathrm{ppm}$ for a frequency change from $100 \mathrm{~Hz}$ to $1 \mathrm{kHz}$. The principal factor causing such changes is usually the variation in dielectric constant with frequency of insulating material located so that it changes the electrostatic field associated with the direct capacitance. Frequency dependence due to series inductance and resistance can be estimated from manufacturer's data or by resonance methods [7].

\section{References}

[1] R.D. Cutkosky, "New NBS Measurements of the Absolute Farad and Ohm," IEEE Trans. on Instrumentation and Measurements, Vol. IM 23, No. 4, Dec. 1974.

[2] J. Q. Shields, R. F. Dziuba, and H. P. Layer, "New Realization of the Ohm and Farad Using the NBS Calculable Capacitor," IEEE Trans. Instrum. Meas. Vol. 38, No. 2, pp. 249-251, April 1989.

[3] M. C. McGregor, J. F. Hersh, R. D. Cutkosky, F. K. Harris, and F. R. Kotter, "New Apparatus at the National Bureau of Standards for Absolute Capacitance Measurement," IRE Trans. on Instr., Vol. I-7, No. 3 \& 4, pp. 253-261, Dec. 1958.

[4] R. D. Cutkosky and L. H. Lee, "Improved Ten-picofarad Fused Silica Dielectric Capacitor," Jour. of Res. NBS, Vol. 69C, No. 3, July \& Sept. 1965.

[5] A. M. Thompson, "The Precise Measurement of Small Capacitances," IRE Trans. on Instr., Vol. I-7, No. 3 \& 4, pp. 245-255, Dec. 1958.

[6] B. N. Taylor and C. E. Kuyatt, "Guidelines for Evaluating and Expressing the Uncertainty of NIST Measurement Results," NIST Tech. Note No. 1297, Jan. 1993.

[7] R.N. Jones, "A Technique for Extrapolating the $1 \mathrm{kC}$ Values of Secondary Capacitance Standards to Higher Frequencies," NBS Tech. Note No. 201, Nov. 1963. 


\title{
REPORT OF CALIBRATION
}

\author{
Standard Capacitor \\ General Radio Company \\ Type 1408-A, Serial No. \#\#\# \\ Enclosure Serial No. \#\#\# \\ Submitted by:
}

$\begin{array}{cccccc}\begin{array}{c}\text { Frequency } \\ (\mathrm{Hz})\end{array} & \begin{array}{c}\text { Average } \\ \text { Temperature } \\ \left({ }^{\circ} \mathrm{C}\right)\end{array} & \begin{array}{c}\text { Range of } \\ \text { Temperature }\end{array} & \begin{array}{c}\text { Capacitance } \\ \left({ }^{\circ} \mathrm{C}\right)\end{array} & \begin{array}{c}\text { Type-A } \\ \text { Uncertainty } \\ (\mathrm{ppm})\end{array} & \begin{array}{c}\text { Expanded } \\ \text { Uncertainty } \\ (\mathrm{ppm})\end{array} \\ 1000 & 23.1234 & 0.1234 & 10.0012346 & 0.02 & 2.5\end{array}$

The reported temperatures are based upon ten or more measurements. The capacitance is based upon five or more intercomparisons with similar capacitors. The Type-A uncertainty given above is calculated from measured values, indicating the capacitor's behavior. The expanded uncertainty given above is the combined standard uncertainty expanded by a coverage factor of $k=2$.

For additional information regarding the calibration of capacitors of this type at NIST, the user should consult the information sheet(s) enclosed with this report.

Period of Calibration: December 1, 1997 to December 15, 1997

Measurements performed by:

For the Director,

Summerfield B. Tillett

Engineering Technician
Barry A. Bell, Group Leader

Electricity Division

Test Report No.: $811 /$

Reference:

Date: January 6, 1998

Telephone Contact: 301-975-4221" 

UNITED STATES DEPARTMENT OF COMMERCE

National Institute of Standards and Technology

Gaithersburg. Maryland 20899-0001

\section{GENERAL INFORMATION ON NITROGEN-DIELECTRIC STANDARD CAPACITORS}

\section{Representation of the Unit of Capacitance}

As a result of new absolute measurements of the farad in terms of the units of length and time, the legal unit of capacitance was established at NIST/NBS in 1975 [1], and re-established in 1989 [2]. The reported values of capacitance since that time reflect the values assigned to NIST standards used for the maintenance of the legal unit. Since 1989, the difference between the NIST unit, which includes an allowance for possible drift, and the farad is believed to be no greater than $\pm 0.1 \mathrm{ppm}$.

\section{Nitrogen Dielectric Standard Capacitors}

Three-terminal standard capacitors of nitrogen dielectric are calibrated with a NIST transformer bridge [3] using NIST fused-silica 10-pF capacitors [4] as reference standards. Capacitance is measured by direct comparison with stable working standards, which are calibrated in terms of the reference standards with the NIST transformer bridge. This is done each time they are used.

The measured capacitances are the mean of the results of two or more measurements of direct capacitance with the capacitor connected to the NIST transformer bridge as a two-terminal-pair admittance [5]. If the terminals of the capacitor are not two-terminal-pair, connections with negligible impedance are made to make them so. All capacitors must be in the calibration laboratory for 72 hours or more before measurements are performed. The average ambient temperature of the laboratory is $23^{\circ} \mathrm{C} \pm 1{ }^{\circ} \mathrm{C}$ with hourly variations of about $0.1{ }^{\circ} \mathrm{C}$. The relative humidity in the laboratory varies but does not exceed $50 \%$.

During the measurements in small uncertainty calibrations, the capacitor to be calibrated is placed in a partially insulated box and the platinum resistance probe of a digital thermometer is placed near the capacitor. The temperature of the capacitor is obtained by direct readouts of the thermometer, which has a resolution of $0.001{ }^{\circ} \mathrm{C}$ and limits of errors of $\pm 0.01{ }^{\circ} \mathrm{C}$. The capacitance and temperature values given in the Report of Calibration are the average values of the respective measurement results. The standard deviation of the capacitance measurements is also calculated to assure it is within limits based on the estimated population standard deviation.

If it is requested, six physical tests are performed on the capacitor to detect the effects of mechanical stress on it. If these tests are performed on a capacitor, a description of the tests and the results of the tests for the capacitor will be given in a separate Report of Calibration.

The reported value of capacitance is in terms of the NIST unit of capacitance maintained with a group of stable standards [4]. The expanded uncertainties include allowance for both Type A and 
Type B uncertainties in the chain of measurements, and are assigned to the capacitance values using the coverage factor $k=2[6]$. These do not include any uncertainties that may be associated with long term instability, temperature hysteresis, and changes due to stresses incurred during shipment.

Measurements of three-terminal coaxial standard capacitors are not made at frequencies exceeding $1 \mathrm{kHz}$ because of limitations in the present NIST measurement apparatus. Depending upon the construction and presence of films, the frequency dependence of the capacitors considered here ranges from $1 \mathrm{ppm}$ to about $10 \mathrm{ppm}$ for a frequency change from $100 \mathrm{~Hz}$ to $1 \mathrm{kHz}$. The principal factor causing such changes is usually the variation in dielectric constant with frequency of insulating material located so that it changes the electrostatic field associated with the direct capacitance. Frequency dependence due to series inductance and resistance can be estimated from manufacturer's data or by resonance methods [7].

For best accuracy in the use of this type of capacitors, corrections for the capacitance values may be required if the temperature is changed significantly. If it is not possible to apply corrections for the temperature differences, the magnitude of the errors usually can be estimated from information supplied by the manufacturer, and the uncertainty in the measurement increased accordingly.

\subsection{References}

[1] R.D. Cutkosky, "New NBS Measurements of the Absolute Farad and Ohm," IEEE Trans. on Instrumentation and Measurements, Vol. IM 23, No. 4, Dec. 1974.

[2] J. Q. Shields, R. F. Dziuba, and H. P. Layer, "New Realization of the Ohm and Farad Using the NBS Calculable Capacitor," IEEE Trans. Instrum. Meas. Vol. 38, No. 2, pp. 249-251, April 1989.

[3] M. C. McGregor, J. F. Hersh, R. D. Cutkosky, F. K. Harris, and F. R. Kotter, "New Apparatus at the National Bureau of Standards for Absolute Capacitance Measurement," IRE Trans. on Instr., Vol. I-7, No. 3 \& 4, pp. 253-261, Dec. 1958.

[4] R. D. Cutkosky and L. H. Lee, "Improved Ten-picofarad Fused Silica Dielectric Capacitor," Jour. of Res. NBS, Vol. 69C, No. 3, July \& Sept. 1965.

[5] A. M. Thompson, "The Precise Measurement of Small Capacitances," IRE Trans. on Instr., Vol. I-7, No. 3 \& 4, pp. 245-255, Dec. 1958.

[6] B. N. Taylor and C. E. Kuyatt, "Guidelines for Evaluating and Expressing the Uncertainty of NIST Measurement Results," NIST Tech. Note No. 1297, Jan. 1993.

[7] R.N. Jones, "A Technique for Extrapolating the $1 \mathrm{kC}$ Values of Secondary Capacitance Standards to Higher Frequencies," NBS Tech. Note No. 201, Nov. 1963. 


\title{
REPORT OF CALIBRATION
}

\author{
Standard Capacitor \\ General Radio Company \\ Type 1404-A, Serial No. \#\#\#
}

Submitted by:

\section{Frequency}

(Hz)

1000
Temperature

$\left({ }^{\circ} \mathrm{C}\right)$

22.34

\author{
Capacitance \\ (pF)
}

999.9998
Expanded

Uncertainty

(ppm)

4

The expanded uncertainty stated above is valid only if the results of the tests used to determine the effects of small mechanical stresses are of the order of a few tenths of a ppm. These test results are given in the accompanying report.

For additional information regarding the calibration of capacitors of this type at NIST, the user should consult the information sheet(s) enclosed with this report.

Date of Calibration: April 3, 1997

Measurements performed by:

For the Director,

Sumerfield B. Tillett

Electricity Division
Barry A. Bell, Group Leader

Electricity Division

Test No. $811 /$

Reference:

Date: January 6, 1998

Telephone Contact: 301-975-4221 


\section{DESCRIPTION OF TESTS USED TO DETERMINE THE EFFECT OF SMALL MECHANICAL STRESSES ON HIGH STABILITY, NITROGEN-DIELECTRIC STANDARD CAPACITORS}

The high stability, nitrogen-dielectric standard capacitors with coaxial connectors and having nominal values of $(10,100$ and 1000$) \mathrm{pF}$ are not susceptible to changes due to the stresses of normal handling and proper shipping. However, experience has shown that there are a significant number that exhibit unusual changes in value when mechanical stresses are applied. These changes are not usually detected during calibration measurements because most operators will handle the capacitors very carefully. Careful handling during measurement, while appropriate for the actual determination of capacitance value, will not result in the detection of changes in capacitance which may occur when the capacitor is handled roughly or during shipment. Six tests have been devised to determine a capacitor's response to some small stresses which any capacitor may be subjected to.

These tests are named the Orientation Test, Small Angle Test, Tilt Test, Knock Soft Test, Knock Hard Test, and Drop Test. These names are nomenclatures rather than accurate descriptors of the tests. They are performed in the order given since some of the stresses in the first tests do affect the later tests.

The following is a brief description of each test's procedure and data reduction. Except for the orientation and small angle tests, data reduction is the same for all tests.

ORIENTATION TEST - The capacitance is measured with the capacitor in its usual upright position, lying on each of its four sides, and back to the original upright position. The five differences between the capacitances of the six orientations are calculated. Then the maximum difference is given as the result for this test. The original purpose of this test was to determine whether it could be used to predict the results of the other tests or not. It has been shown that it is not correlated with the other tests except for the Small Angle Test.

SMALL ANGLE TEST - The capacitor is placed on a horizontal surface and its capacitance measured. Then a side is elevated three degrees above horizontal and the capacitance measured. This is repeated for the remaining three sides. The changes in capacitance resulting from the elevation of each side from the horizontal are calculated. The range of these changes is given as the result of this test.

TILT TEST - The capacitor is placed in the usual upright position and its capacitance measured. Then one side of the capacitor is rotated to the horizontal position and returned to the upright position and its capacitance re-measured. This is repeated for the remaining sides and for the top. The five successive differences between the six measured capacitances are calculated. The range 
of these differences is given as the result of this test.

KNOCK SOFT TEST - In this test the capacitor is struck by a rubber tipped pendulum. The force generated by the pendulum is roughly equivalent to that generated by a mild wrist motion blow of the human hand. The capacitor is placed in the usual upright position and its capacitance measured. Then the pendulum is rotated 45 degrees and allowed to strike the capacitor's top edge once, after which its capacitance is measured. This is repeated for the remaining sides and the four corners. The successive differences between the measured capacitances are calculated. The range of these differences is given as the result of this test.

KNOCK HARD TEST - This test is identical to the Knock Soft Test except that a plastic tipped pendulum rotated 15 degrees is used.

DROP TEST - The capacitor is placed in the upright position and its capacitance measured. Then the bottom of a side is raised 3.8 centimeters and allowed to drop freely. The capacitance is remeasured after this drop. This is repeated for the remaining sides. The successive differences are calculated and the range of these differences is given as the result of this test. 


\title{
REPORT OF CALIBRATION
}

\author{
Standard Capacitor \\ General Radio Company \\ Type 1404-A \\ Serial No. \#\#\# \\ Submitted by:
}

$\begin{array}{cccccc}\begin{array}{c}\text { Orientation } \\ \text { (Maximum) }\end{array} & \begin{array}{c}\text { Small } \\ \text { Angle } \\ \text { (Range) }\end{array} & \begin{array}{c}\text { Tilt } \\ \text { (Range) }\end{array} & \begin{array}{c}\text { Knock } \\ \text { Soft } \\ \text { (Range) }\end{array} & \begin{array}{c}\text { Knock } \\ \text { Hand } \\ \text { (Range) }\end{array} & \begin{array}{c}\text { Drop } \\ \text { (Range) }\end{array} \\ 0.74 & 0.13 & 0.11 & 0.13 & 0.21 & 0.06\end{array}$

The results of the six tests are used to determine the effects of small mechanical stresses on high-stability, nitrogen dielectric standard capacitors are given above, in units of parts per million (ppm). They are not included in the expanded uncertainty given in the accompanying report of calibration (NIST SP250 Service ID No. 52140C). Therefore, except for the results of the orientation test, the above values should be included in the expanded uncertainty of the calibration as the Type B uncertainty, especially if any of them are larger than $0.5 \mathrm{ppm}$. Unless the standard is carefully hand-carried back to the user's laboratory and then left in the upright position at all times, the expanded uncertainty in the other report should be increased by one half of the sum of all the ranges.

For additional information regarding the calibration of capacitors of this type at NIST, the user should consult the information sheet(s) enclosed with this report.

Date of Calibration: April 3, 1997

Measurements performed by:

For the Director,

Summerfield B. Tillett

Engineering Technician
Barry A. Bell, Group Leader

Electricity Division

Test Report No.: 811/

Reference:

Date: January 5, 1998

Telephone Contact: 301-975-4221 


\section{GENERAL INFORMATION ON THREE-TERMINAL STANDARD CAPACITORS}

\section{Representation of the Unit of Capacitance}

As a result of new absolute measurements of the farad in terms of the units of length and time, the legal unit of capacitance was established at NIST/NBS in 1975 [1], and re-established in 1989 [2]. The reported values of capacitance since that time reflect the values assigned to NIST standards used for the maintenance of the legal unit. Since 1989, the difference between the NIST unit, which includes an allowance for possible drift, and the farad is believed to be no greater than $\pm 0.1 \mathrm{ppm}$.

\section{Three-Terminal Standard Capacitors}

Three-terminal standard capacitors of nitrogen and air dielectric are calibrated with a NIST transformer bridge [3] using NIST fused-silica 10-pF capacitors [4] as reference standards. Capacitance is measured by direct comparison with stable working standards, which are calibrated in terms of the reference standards. This is done each time they are used.

The measured capacitances are the results of two or more measurements of direct capacitance with the capacitor connected to the NIST transformer bridge as a two-terminal-pair admittance [5]. If the terminals of the capacitor are not two-terminal-pair, connections with negligible impedance are made to make them so. All capacitors must be in the calibration laboratory for 72 hours or more before measurements are performed.

The average ambient temperature of the laboratory is $23^{\circ} \mathrm{C} \pm 1{ }^{\circ} \mathrm{C}$, with hourly variations of about $0.1^{\circ} \mathrm{C}$, which is the temperature values given in the Report of Calibration. Measurements are not made if the ambient laboratory temperature differed from the set-point by more than $1^{\circ} \mathrm{C}$ during the last 24 hours. The standard deviation of the capacitance measurements is also calculated to assure it is within limits of the estimated population standard deviation. The relative humidity in the laboratory varies but does not exceed $50 \%$.

The reported value of capacitance is in terms of the NIST unit of capacitance maintained with a group of stable standards [4]. The expanded uncertainties include allowance for both Type A and Type B uncertainties in the chain of calibration measurements, and are assigned to the capacitance values using the coverage factor $k=2$ [6]. These do not include any uncertainties that may be associated with long term instability, temperature hysteresis, changes due to stresses incurred during shipment. In addition, no allowance is made for the variations in the capacitance of unsealed air dielectric capacitors due to changes in humidity since the magnitude of these variations is dependent upon the surface conditions of the plates. 
Measurements of three-terminal coaxial standard capacitors are not made at frequencies exceeding $1 \mathrm{kHz}$ due to limitations in the present NIST measurement apparatus. Depending upon the construction and presence of films, the frequency dependence of the capacitors considered here ranges from $1 \mathrm{ppm}$ to about $10 \mathrm{ppm}$ for a frequency change from $100 \mathrm{~Hz}$ to $1 \mathrm{kHz}$. The principal factor causing such changes is usually the variation in dielectric constant with frequency of insulating material located so that it changes the electrostatic field associated with the direct capacitance. Frequency dependence due to series inductance and resistance can be estimated from manufacturer's data or by resonance methods [7].

For best accuracy in the use of this type of capacitors, corrections for the capacitance values may be required if the temperature is changed significantly. If it is not possible to apply corrections for the temperature differences, the magnitude of the errors usually can be estimated from information supplied by the manufacturer, and the uncertainty in the measurement increased accordingly.

\subsection{References}

[1] R.D. Cutkosky, "New NBS Measurements of the Absolute Farad and Ohm," IEEE Trans. on Instrumentation and Measurements, Vol. IM 23, No. 4, Dec. 1974.

[2] J. Q. Shields, R. F. Dziuba, and H. P. Layer, "New Realization of the Ohm and Farad Using the NBS Calculable Capacitor," IEEE Trans. Instrum. Meas. Vol. 38, No. 2, pp. 249-251, April 1989.

[3] M. C. McGregor, J. F. Hersh, R. D. Cutkosky, F. K. Harris, and F. R. Kotter, "New Apparatus at the National Bureau of Standards for Absolute Capacitance Measurement," IRE Trans. on Instr., Vol. I-7, No. 3 \& 4, pp. 253-261, Dec. 1958.

[4] R. D. Cutkosky and L. H. Lee, "Improved Ten-picofarad Fused Silica Dielectric Capacitor," Jour. of Res. NBS, Vol. 69C, No. 3, July \& Sept. 1965.

[5] A. M. Thompson, "The Precise Measurement of Small Capacitances," IRE Trans. on Instr., Vol. I-7, No. 3 \& 4, pp. 245-255, Dec. 1958.

[6] B. N. Taylor and C. E. Kuyatt, "Guidelines for Evaluating and Expressing the Uncertainty of NIST Measurement Results," NIST Tech. Note No. 1297, Jan. 1993.

[7] R.N. Jones, "A Technique for Extrapolating the $1 \mathrm{kC}$ Values of Secondary Capacitance Standards to Higher Frequencies," NBS Tech. Note No. 201, Nov. 1963. 


\title{
REPORT OF CALIBRATION
}

\author{
Standard Capacitor \\ General Radio Company \\ Type 1403-D, Serial No. \#\#\#
}

Submitted by:

Frequency

(Hz)

1000
Capacitance

(pF)

100.013
Expanded

Uncertainty

(\%)

100

For additional information regarding the calibration of capacitors of this type at NIST, the user should consult the information sheet(s) enclosed with this report.

Temperature: $23^{\circ} \mathrm{C} \pm 1^{\circ} \mathrm{C}$

Date of Calibration: December 1, 1997

Measurements performed by:

For the Director,

Summerfield B. Tillett

Electricity Division
Barry A. Bell, Group Leader Electricity Division

Test No. $811 /$

Reference:

Date: January 6, 1998

Telephone Contact: 301-975-4221 



\section{GENERAL INFORMATION ON TWO-TERMINAL STANDARD CAPACITORS WITH PRECISION COAXIAL CONNECTORS}

\section{Representation of the Unit of Capacitance}

As a result of new absolute measurements of the farad in terms of the units of length and time, the legal unit of capacitance was established at NIST/NBS in 1975 [1], and re-established in 1989 [2]. The reported values of capacitance since that time reflect the values assigned to NIST standards used for the maintenance of the legal unit. Since 1989, the difference between the NIST unit, which includes an allowance for possible drift, and the farad is believed to be no greater than $\pm 0.1 \mathrm{ppm}$.

\section{Two-Terminal Standard Capacitors with HF Coaxial Connectors}

Standard capacitors with precision coaxial connectors [3] are calibrated at frequencies up to $1000 \mathrm{~Hz}$ with a NIST transformer bridge [4] using working standards, which are calibrated in terms of NIST fused silica $10 \mathrm{pF}$ [5] reference standards. The general calibration procedure is described in [6].

The measured parallel capacitance is the mean of the results of four or more measurements of the "capacitance added" $[3,6,7]$. Between each measurement, the capacitor is disconnected, rotated 90 degrees around the vertical axis of the connector, and reconnected. The measurements are made with a special three-terminal to two-terminal adapter whose "zero" value to the reference plane is known to within $0.004 \mathrm{pF}$. The "capacitance added" with this adapter is the capacitance to the reference plane of the connector. If an open-ended termination (with an inner conductor preferably) is supplied and if it is specially requested that the change in capacitance be referenced to the termination, then the change in capacitance is that due to disconnecting the termination and connecting the capacitor [8]. This type of change is probably the most useful to the user since effects due to small dissimilarities between the NIST adapter and the user's adapter will tend to cancel out.

In order to realize the stated uncertainties, the user's adapter and capacitor connectors must be kept in good condition. These must be clean so that proper mating occurs and a uniform radial field is maintained within the connectors. Changes in concentricity, depth of the end of the inner conductors or damage to the leaf contacts can easily change the capacitance values by $0.01 \mathrm{pF}$ or more. The use of any non-precision or different connector with these capacitors virtually will destroy any usefulness of the capacitance value and its uncertainty.

All capacitors must be in the calibration laboratory for 72 hours or more before measurements are performed. The average ambient temperature of the laboratory is $23^{\circ} \mathrm{C} \pm 1{ }^{\circ} \mathrm{C}$ with hourly variations of about $0.1{ }^{\circ} \mathrm{C}$. Measurements are not made if the ambient laboratory temperature differed from the set-point by more than $1^{\circ} \mathrm{C}$ during the last 24 hours. 
The reported value of capacitance is in terms of the NIST representation of the farad. The expanded uncertainties include allowance for both Type A and Type B uncertainties in the chain of calibration measurements, and are assigned to the capacitance values using the coverage factor $k=2$ [9]. They do not include any components of uncertainty that may be associated with long term instability, temperature hysteresis or changes due to stresses incurred during shipment. In addition, no allowance is made for the variations in the capacitance of unsealed capacitors due to changes in humidity since the magnitude of these variations is dependent upon the surface conditions of the plates. The relative humidity in the laboratory varies but does not exceed $50 \%$.

\section{References}

[1] R.D. Cutkosky, "New NBS Measurements of the Absolute Farad and Ohm," IEEE Trans. on Instrumentation and Measurements, Vol. IM 23, No. 4, Dec. 1974.

[2] J. Q. Shields, R. F. Dziuba, and H. P. Layer, "New Realization of the Ohm and Farad Using the NBS Calculable Capacitor," IEEE Trans. Instrum. Meas. Vol. 38, No. 2, pp. 249-251, April 1989.

[3] "IEEE Standard for Precision Coaxial Connectors," IEEE Trans. on Instr. Meas., Vol. IM-17, No. 3, pp. 204-218, Sept. 1968.

[4] M. C. McGregor, J. F. Hersh, R. D. Cutkosky, F. K. Harris, and F. R. Kotter, "New Apparatus at the National Bureau of Standards for Absolute Capacitance Measurement," IRE Trans. on Instr., Vol. I-7, No. 3 \& 4, pp. 253-261, Dec. 1958.

[5] R. D. Cutkosky and L. H. Lee, "Improved Ten-picofarad Fused Silica Dielectric Capacitor," Jour. of Res. NBS, Vol. 69C, No. 3, July \& Sept. 1965.

[6] R. D. Cutkosky, "Capacitance Bridge -- NBS Type 2," National Bureau of Standards Report 7103, March 1961.

[7] J. F. Hersh, "A Close Look at Connection Errors in Capacitance Measurements," General Radio Experimenter, Vol. 33, No. 7, July 1959.

[8] R. W. Orr, "Capacitance Standards with Precision Connectors," General Radio Experimenter, Vol. 41, No. 9, Sept. 1967.

[9] B. N. Taylor and C. E. Kuyatt, "Guidelines for Evaluating and Expressing the Uncertainty of NIST Measurement Results," NIST Tech. Note No. 1297, Jan. 1993. 


\section{REPORT OF CALIBRATION}

$\begin{array}{lc}\text { Standard Capacitor } & \\ \text { General Radio Company } \\ \text { Type 1406-A, Serial No. \#\#\# } \\ \text { Submitted by: }\end{array}$

For additional information regarding the calibration of capacitors of this type at NIST, the user should consult the information sheet(s) enclosed with this report.

Temperature: $23^{\circ} \mathrm{C} \pm 1^{\circ} \mathrm{C}$

Date of Calibration: October 2, 1997

Measurements performed by:

For the Director,

Summerfield B. Tillett

Electricity Division
Barry A. Bell, Group Leader

Electricity Division

Test No. 811/

Reference:

Date: January 6, 1998

Telephone Contact: 301-975-4221 



\section{GENERAL INFORMATION ON MICA-DIELECTRIC STANDARD CAPACITORS WITH BINDING POST CONNECTORS}

\section{Representation of the Unit of Capacitance}

As a result of new absolute measurements of the farad in terms of the units of length and time, the legal unit of capacitance was established at NIST/NBS in 1975 [1], and re-established in 1989 [2]. The reported values of capacitance since that time reflect the values assigned to NIST standards used for the maintenance of the legal unit. Since 1989, the difference between the NIST unit, which includes an allowance for possible drift, and the farad is believed to be no greater than $\pm 0.1 \mathrm{ppm}$.

\section{Mica-Dielectric Capacitors with Binding Post Connectors}

Two- and three-terminal standard capacitors with plug and binding post connectors are calibrated with a resistance ratio-arm bridge, as described in [3]. This bridge is calibrated with working standards that are calibrated in terms of NIST fused silica $10 \mathrm{pF} \mathrm{[4]} \mathrm{reference} \mathrm{standards.}$

The measured parallel capacitance and conductance are the means of two or more measurements obtained by connecting the capacitor into the bridge via the binding posts of the terminal plate with the plugs supplied by the customers. If no plugs are supplied, measurements are performed by using standard connectors model GR274. The binding posts of the capacitor are never used for this measurement.

The uncertainty for the measured capacitance contains a $0.01 \mathrm{pF}$ systematic component for binding posts and plate geometry [5]. The measured capacitance of any capacitor with exposed connectors is dependent upon the mechanical and electrical geometry of the connections to the capacitor, the stability of this geometry and of the surroundings [6]. For example, changes in plug type and heights, hole depths, center to center distance of the binding posts can cause changes of $1 \mathrm{pF}$ or more. In some cases, connectors other than binding posts and a plate can cause changes of $0.1 \mathrm{pF}$ or more. In order to realize the stated uncertainty, the user must compare his/her geometry with that used in the calibration of the capacitor and make appropriate calculations and/or measurements for the differences. If this cannot be done, it is reasonable to assume that the addition of $1 \mathrm{pF}$ to the stated uncertainty would be adequate for most geometries.

All capacitors must be in the calibration laboratory for 72 hours or more before measurements are performed. All measurements are made in a laboratory where the temperature control set-point is $23^{\circ} \mathrm{C}$. Measurements are not made if the ambient laboratory temperature differed from the set-point by more than $1^{\circ} \mathrm{C}$ during the last 24 hours. 
The reported values of capacitance are in terms of the NIST representation of the farad. The capacitance calibration uncertainties are expanded uncertainties and include allowances for both Type A and Type B uncertainties in the chain of calibration measurements, and are assigned to the capacitance values using the coverage factor $k=2$ [7]. The standard deviation is estimated to be less than $40 \mathrm{ppm}$ for all nominal values and frequencies except for $1000 \mathrm{pF}$ at $66 \mathrm{~Hz}$ where it is estimated to be $55 \mathrm{ppm}$.

The uncertainties of the measured conductances also include both Type A and Type B uncertainties and these are usually of secondary importance. However, it should be mentioned that series resistance in the connections, leads, etc., to the larger nominal capacitance values at the higher frequencies can cause large increases in the measured conductance. Such increases are proportional to the square of the frequency and to the square of the capacitance.

The uncertainties do not include any allowance for long-term instability, temperature hysteresis or changes due to stresses incurred during shipment.

\section{References}

[1] R.D. Cutkosky, "New NBS Measurements of the Absolute Farad and Ohm," IEEE Trans. on Instrumentation and Measurements, Vol. IM 23, No. 4, Dec. 1974.

[2] J. Q. Shields, R. F. Dziuba, and H. P. Layer, "New Realization of the Ohm and Farad Using the NBS Calculable Capacitor, ${ }^{n}$ IEEE Trans. Instrum. Meas. Vol. 38, No. 2, pp. 249-251, April 1989.

[3] W. D. Voelker, "An Improved Capacitance Bridge for Precision Measurements," Bell System Record, Jan. 1942.

[4] R. D. Cutkosky and L. H. Lee, "Improved Ten-picofarad Fused Silica Dielectric Capacitor," Jour. of Res. NBS, Vol. 69C, No. 3, July \& Sept. 1965.

[5] J. F. Hersh, "A Close Look at Connection Errors in Capacitance Measurements," General Radio Experimenter, Vol. 33, No. 7, July 1959.

[6] R. D. Cutkosky, "Capacitance Bridge -- NBS Type 2," National Bureau of Standards Report 7103, March 1961.

[7] B. N. Taylor and C. E. Kuyatt, "Guidelines for Evaluating and Expressing the Uncertainty of NIST Measurement Results," NIST Tech. Note No. 1297, Jan. 1993. 


\title{
REPORT OF CALIBRATION
}

\author{
Standard Capacitor \\ General Radio Company \\ Type 1409-Y, Serial No. \#\#\#\#
}

Submitted by:

$\begin{array}{cccccc}\begin{array}{c}\text { Type of } \\ \text { Measurement }\end{array} & \begin{array}{c}\text { Frequency } \\ (\mathbf{H z})\end{array} & \begin{array}{c}\text { Capacitance } \\ (\mu \mathrm{F})\end{array} & \begin{array}{c}\text { Capacitance } \\ \text { Uncertainty } \\ (\%)\end{array} & \begin{array}{c}\text { Conductance } \\ (\mu \mathrm{S})\end{array} & \begin{array}{c}\text { Conductance } \\ \text { Uncertainty } \\ (\mu \mathrm{S})\end{array} \\ \text { 2-Terminal } & 1000 & 0.99878 & 0.018 & 0.5 & 0.4\end{array}$

For additional information regarding the calibration of capacitors of this type at NIST, the user should consult the information sheet(s) enclosed with this report.

Temperature: $23^{\circ} \mathrm{C} \pm 1^{\circ} \mathrm{C}$

Date of Calibration: December 1, 1997

Measurements performed by:

For the Director,

Summerfield B. Tillett

Electricity Division
Barry A. Bell, Group Leader Electricity Division

Test No. 811/

Reference:

Date: January 5, 1998

Telephone Contact: 301-975-4221 



\section{SP 250-1 Spectral Radiance Calibrations PB87179883}

SP 250-2 Far Ultraviolet Detector Standards PB87227609

SP 250-3 Radiometric Standards in the Vacuum Ultraviolet PB87227625

SP 250-4 Fricke Dosimetry in High-Energy Electron Beams PB88110374

SP 250-5 Alpha-Particle Calibrations PB88168620

SP 250-6 Regular Spectral Transmittance PB88108550

SP 250-7 Radiance Temperature Calibrations PB88123674

SP 250-8 Spectral Reflectance PB88109905

SP 250-9 Calibration of Beta-Particle-Emitting Ophthalmic Applicators

PB88108535

SP 250-10 Radioactivity Calibrations with the " $4 \pi$ " Gamma lonization Chamber and Other Radioactivity Calibration Capabilities PB88123708

SP 250-11 Dosimetry for High Dose Applications PB88201587

SP 250-12 Neutron Personnel Dosimetry PB87227617

SP 250-13 Activation Foil Irradiation with Californium Fission Sources PB88217443

SP 250-14 Activation Foil Irradiation by Reactor Cavity Fission Sources PB88217435

SP 250-15 Photometric Calibrations PB88153747

SP 250-16 Calibration of X-Ray and Gamma-Ray Measuring Instruments PB88211826

SP 250-17 The NBS Photodetector Spectral Response Calibration Transfer Program PB88201595

SP 250-18 Neutron Source Strength Calibrations PB88211818

SP 250-19 Calibration of Gamma-Ray-Emitting Brachytherapy Sources PB89193858
SP 250-20 Spectral Irradiance Calibrations PB88123781

SP 250-21 Calibration of Beta-Particle Radiation Instrumentation PB88201579

SP 250-22 Platinum Resistance Thermometer Calibrations PB88138367

SP 250-23 Liquid-in-Glass Thermometer Calibration Service PB89128888

SP 250-24 Standard Cell Calibrations PB88123690

SP 250-25 Calibration Service for Inductive Voltage Dividers

SP 250-26 NBS Phase Angle Calibration Services PB88225636

SP 250-27 AC-DC Difference Calibrations PB892222616

SP 250-28 Solid-State DC Voltage Standard Calibrations PB88168703

SP 250-29 Traceable Frequency Calibrations PB88168364

SP 250-30 GOES Satellite Time Code Dissemination: Description and Operation PB88168760

SP 250-31 Mass Calibrations PB89153894

SP 250-32 A Calibration Service for $30 \mathrm{MHz}$ Attenuation and Phase Shift PB88238324

SP 250-33 A Calibration Service for Voltage Transformers and High-Voltage Capacitors PB882252903

SP 250-34 High Vacuum Standard and Its Use PB89193841

SP 250-35 The Calibration of Thermocouples and Thermocouple Materials PB89209340

SP 250-36 A Calibration Service for Current Transformers

SP 250-38 NIST Leak Calibration Service

SP 250-40 Absorbed-Dose Calibration of lonization Chambers in a ${ }^{60} \mathrm{Co}$ Gamma-Ray Beam SN003-003-03034-1 \$2.00

* Entries Entries containing a stock number (SN003-003-) and price can be purchased from the Superintendent of Documents, U.S. Government Printing Office, Washington, DC 20402. GPO will accept checks, money orders, VISA, and MasterCard. For more infomation, or to place an order, call (202) 783-3238. Be sure to cite the stock number on all orders.

Entries containing PB numbers can be purchased from the National Technical Information Service, Springfield, VA 22161. NTIS will accept American Express in addition to the payment methods listed for GPO. For more information call (703) 487-4650; to place an order call (800) 336-4700. Be sure to cite the PB number on all orders.

Entries without stock or PB numbers are in preparation. 


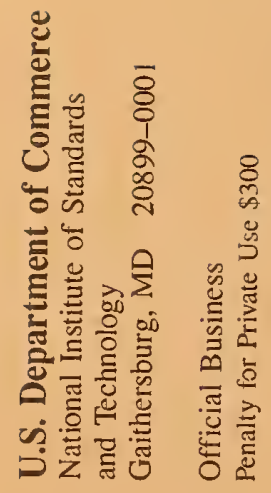

